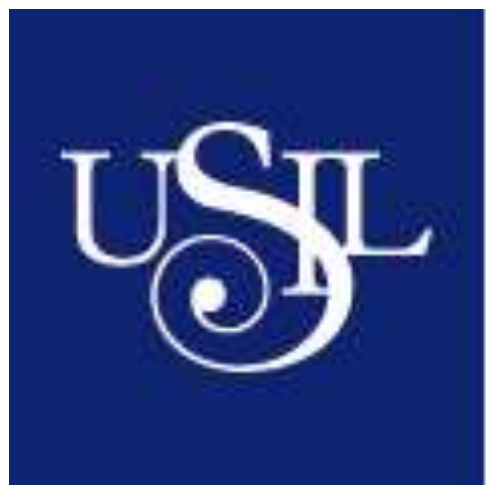

ESCUELA DE

POSTGRADO

UNIVERSIDAD

SAN IGNACIO DE LOYOLA

\title{
PROYECTO DE INVESTIGACION APLICADO
}

Plan de Negocios "Presta Mas"

\author{
Abarca Lino, Nadia Jazmina \\ Mallma Mauricio, Milton Guillermo \\ Pérez Valencia, José Luis \\ Vidal Mostacero, Frank
}

Asesor: Dr. Lorenzo Edmundo González Zavaleta

Lima - Perú

Mayo 2017 
Plan de Negocios "Presta Mas" 


\section{AGRADECIMIENTO}

A nuestras familias quienes nos han apoyado en todo momento, brindándonos su compresión y tiempo que dedicamos a cumplir a nuestros objetivos. 


\section{RESUMEN EJECUTIVO}

La propuesta de creación de una ONG para satisfacer la demanda de créditos de micro empresarios del distrito de San Juan de Lurigancho, con actividades económicas formales e informales con gran potencial productivo, creativo e innovador y de comercialización, que enfrentan limitaciones de expansión por barreras financieras de la banca tradicional y especializada en microfinanzas que dificulta el acceso al financiamiento. La ONG PrestaMas pretende ser una agente de bancarización formal no supervisado, acorde a las normativas que rigen actividad económica y de actividad financiera. La propuesta es financiar y apoyar el desarrollo de las actividades económicas del distrito, busca atender el segmento abandonado y/o descuidado por la oferta de las empresas micro financieras. A través del financiamiento se perfila apoyar el crecimiento y desarrollo de la actividad micro económico y encaminar su formalización. El distrito de San Juan de Lurigancho, sui generis por sus características de tamaño de población y cercanía al centro de Lima, brinda una oportunidad de desarrollo de la actividad micro financiera, la ONG PrestaMas sustenta todos sus ingresos financieros por los créditos directamente otorgados sobre los cuales se cobra intereses compensatorios y en menor medida por los intereses moratorios, no contempla generación por provisión de nuevos servicios financieros.

PrestaMas inicia actividades con fondos aportados por los socios iniciales por un importe de S/ 332910 y un préstamo que cubra la diferencia, en su desarrollo el Capital se incrementará con las ganancias de cada periodo, así como de aportes adicionales externos en calidad de aportes y/o créditos directos a la ONG.

Se estima empezar a tener indicadores de rentabilidad económica a partir del tercer año y una rentabilidad financiera a partir del segundo año.

La oferta principal es el Micro crédito con un monto promedio de S/. 500 cuyo elemento diferenciador se caracteriza por la atención personalizada y asesoramiento por parte del 
asesor de créditos, fácil acceso dado que el trámite para adquirir el producto no es muy engorroso, distintas modalidades de desembolso así como una variedad de alternativas para los pagos, el contacto directo con el asesor de créditos se constituyen en la principal herramienta de fidelización, quien tendrá una cantidad máxima de clientes por cartera así como una zona específica de acción que permita el cumplimiento de sus labores, se estima contar con 20 funcionarios de negocios con capacidad para administrar 300 clientes cada uno, se tiene previsto el apoyo de un área de marketing que estará a cargo del Administrador de la Agencia dado que no requiere de mucho presupuesto adicional al gasto previsto, uso de volantes y material de promoción que son básicamente pequeños suvenires de bajo costo pero de gran impacto es éste segmento de clientes.

La industria micro financiera ha forjado especialistas con dominio de la tecnología de micro finanzas, ha mostrado oportunidad de usos de herramientas tecnológicas y mayor cobertura a través de cajeros automáticos, cajeros corresponsales, banca electrónica, banca telefónica, que refuerza la oportunidad de brindar un servicio de mayor impacto financiamiento integral con menor requerimiento de inversión en paralelo a la industria financiera supervisada y regulada.

La propuesta de emprendimiento surge de la participación de involucrados en actividades micro financieras Ing. José Luis Pérez Valencia actualmente funcionario de la CMAC Cusco en San Juan de Lurigancho y Eco. Guillermo Mallma actualmente encargado de la parte comercial en la Financiera TFC a nivel nacional y de dos involucrados en actividades comerciales de vehículos y metalmecánica Frank Vidal y Nadia Abarca.

Consideramos que esta investigación es de gran importancia tanto para el distrito, la comunidad e individuos con deseos de lograr mayor beneficio dado su capacidad de ahorro.

San Juan de Lurigancho, por su potencial de habitantes, cercanía a los distritos más dinámicos del país garantiza su crecimiento económico sostenido, ello se traduce en 
necesidad de financiamiento que de consumo y crédito; junto a ello, la desatención en los créditos base por la oferta formal supervisada existente como por otras alternativas empresariales costosas sin adecuada tecnología, ni prácticas de autorregulación de microcrédito y nula información de resultados financieros a la comunidad, brindan la oportunidad de incursionar en el segmento de las micro finanzas, con la convicción de brindar un servicio de calidad, transparente, diferenciado con pilares de excelencia, que brinden satisfacción de clientes, empleados y asociados. 


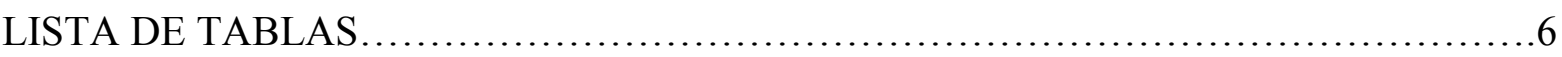

LISTA DE FIGURAS......................................................... 10

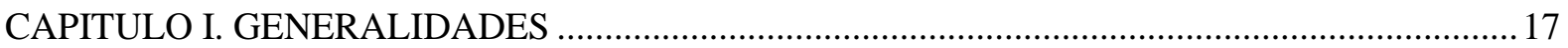

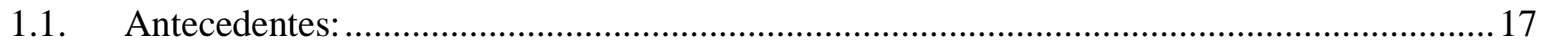

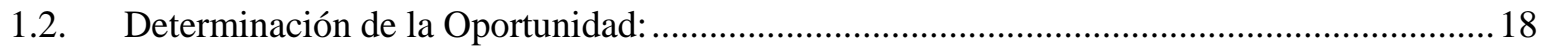

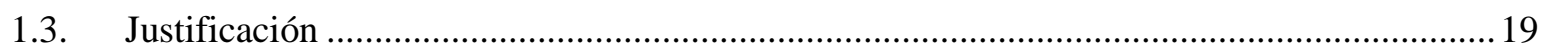

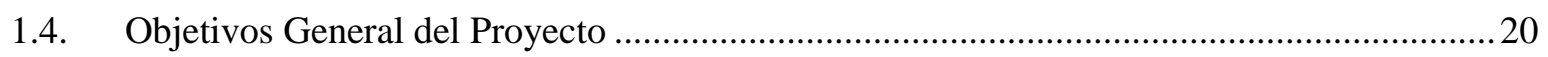

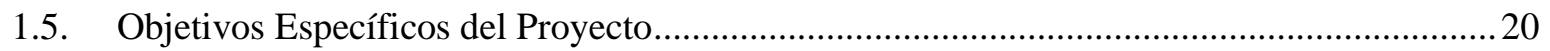

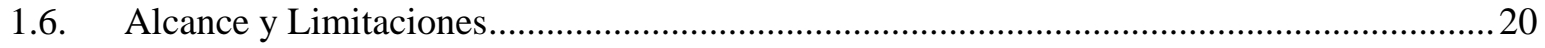

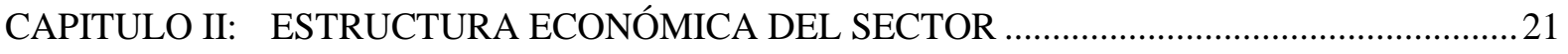

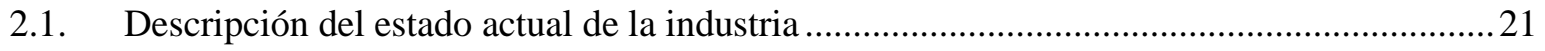

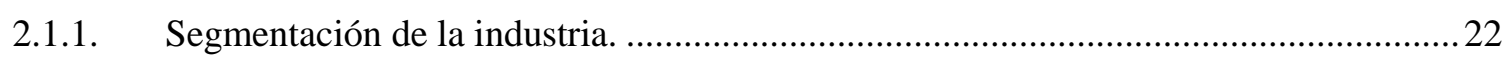

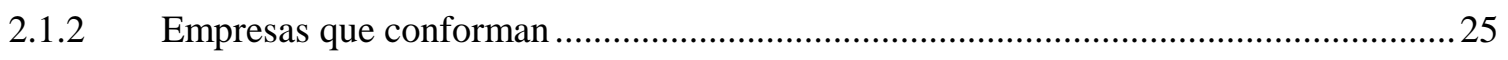

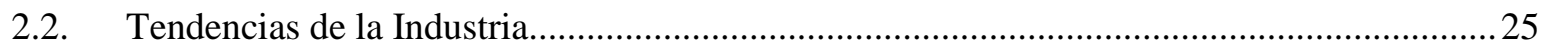

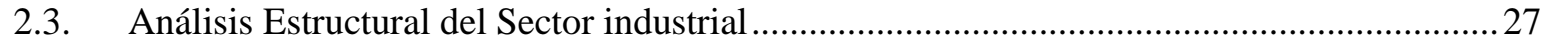

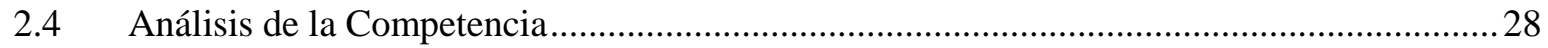

2.4.1. Empresas que la conforman y su participación de mercado ….......................................... 36

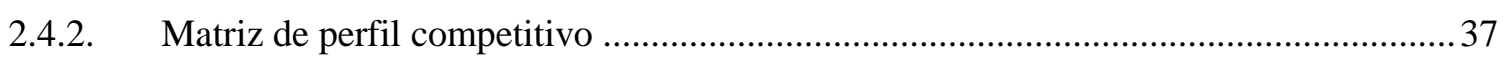

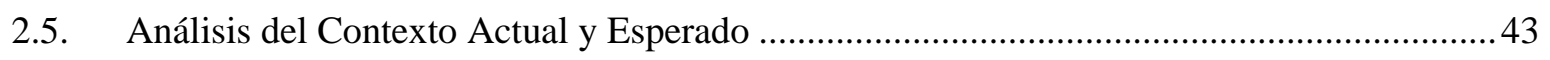

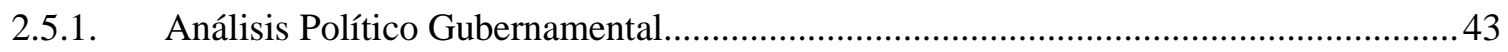

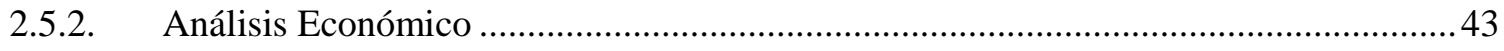

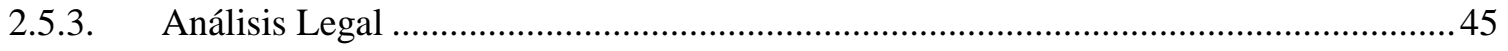

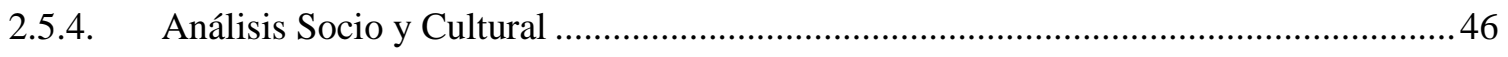

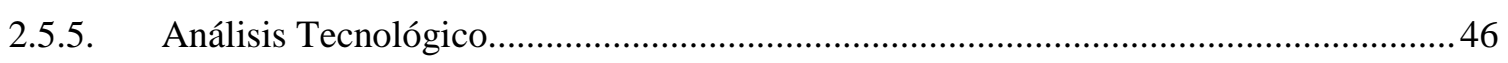

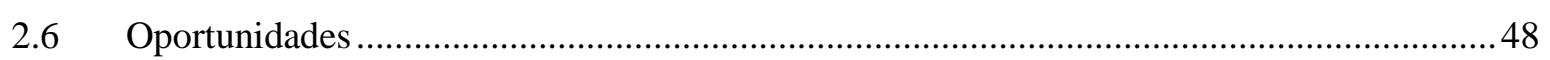

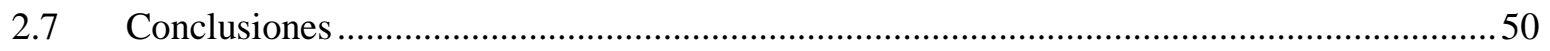

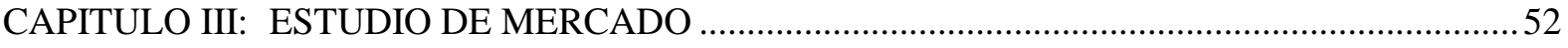

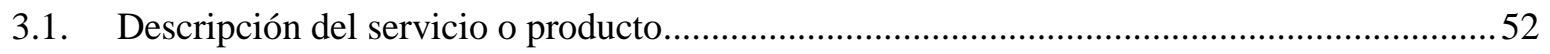

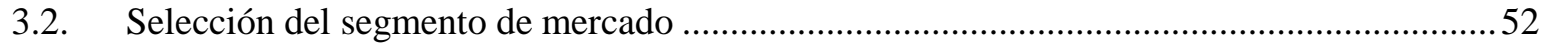

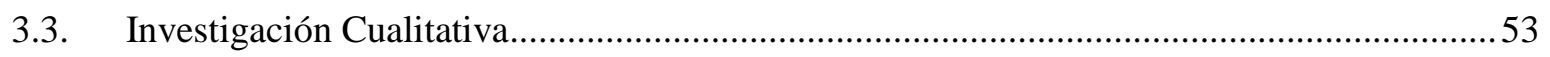

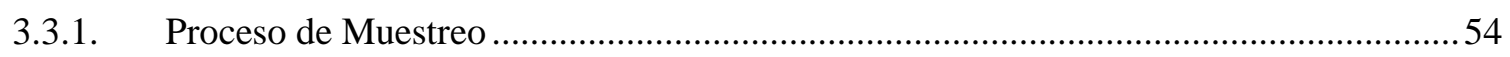

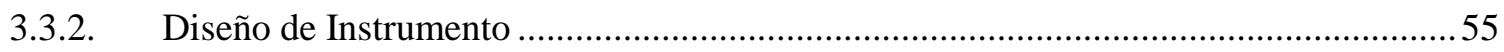

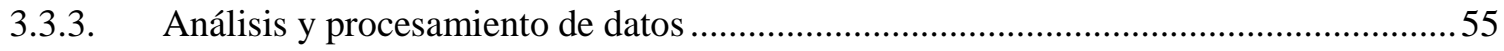

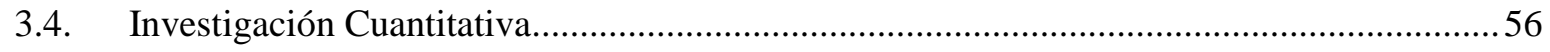




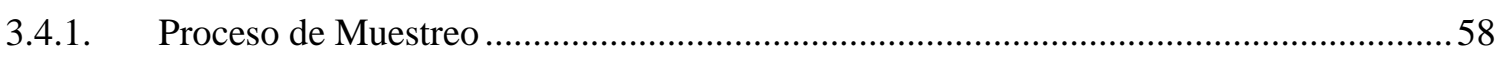

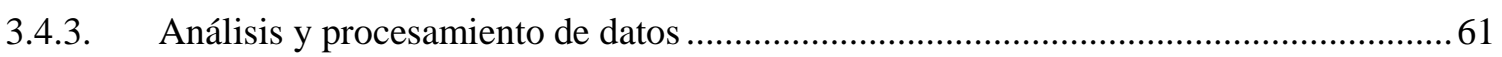

3.5. Conclusiones y recomendaciones del Estudio Cualitativo y Cuantitativo ...............................68

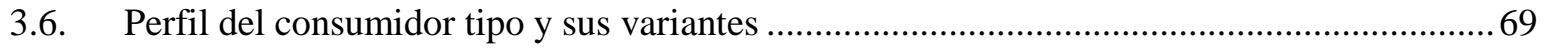

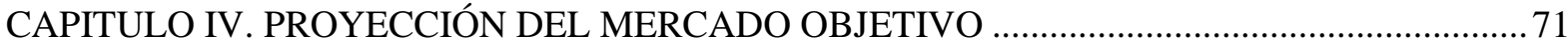

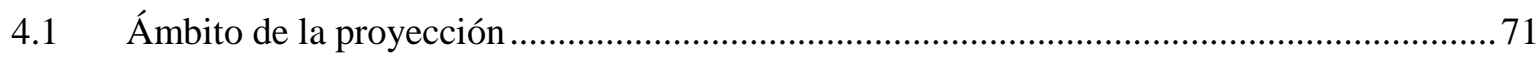

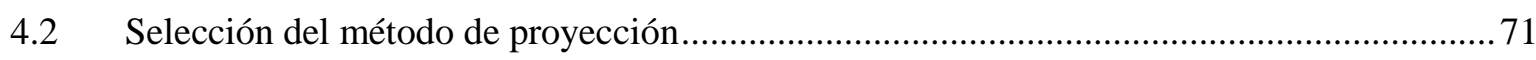

74

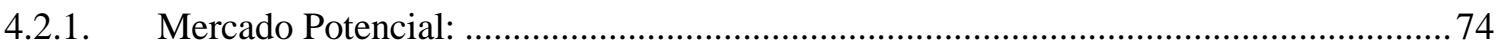

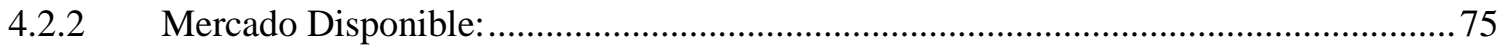

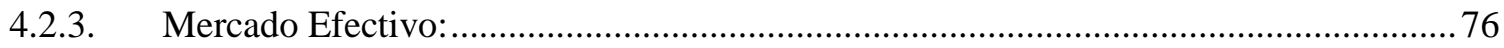

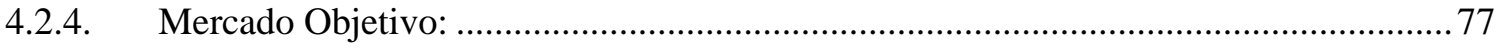

4.3. Pronóstico de Ventas-Colocaciones, Crecimiento de Cartera, Ingresos ............................... 79

4.4. Aspectos críticos que impactan el pronóstico de ventas ............................................................ 79

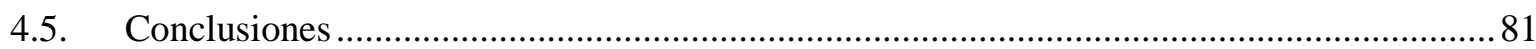

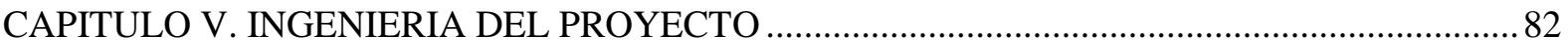

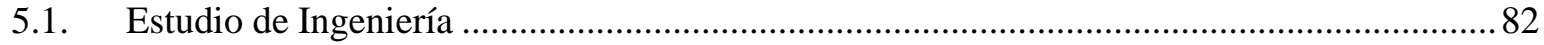

5.1.1. Modelamiento y selección de procesos productivos ....................................................... 82

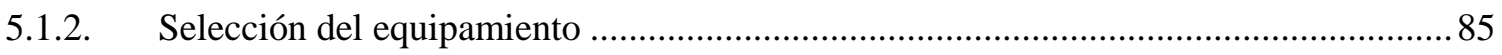

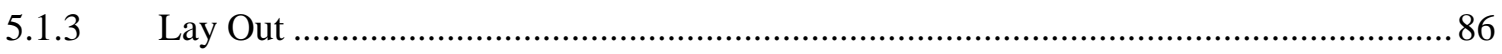

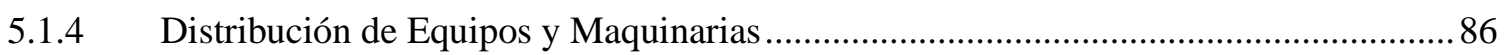

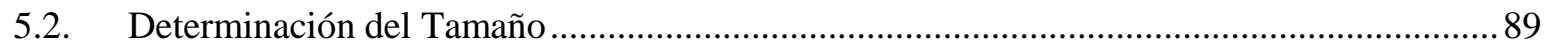

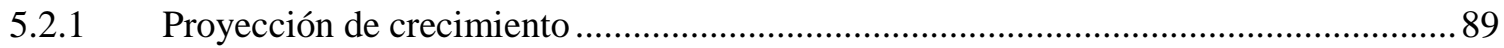

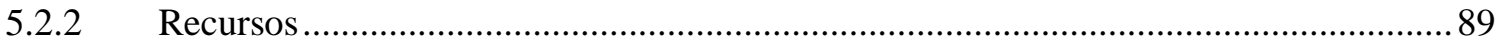

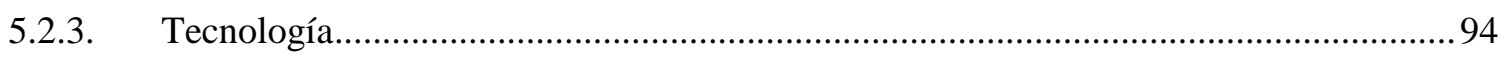

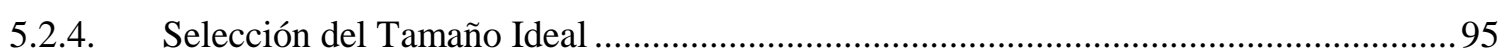

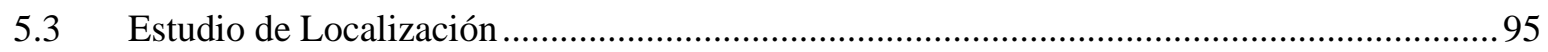

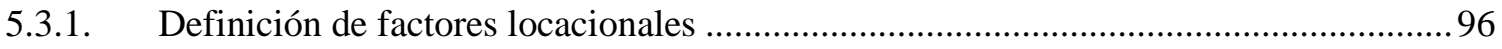

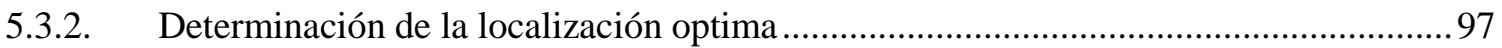

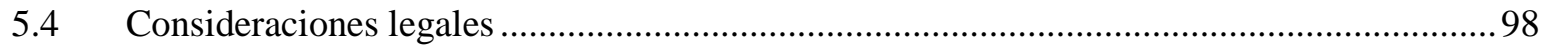

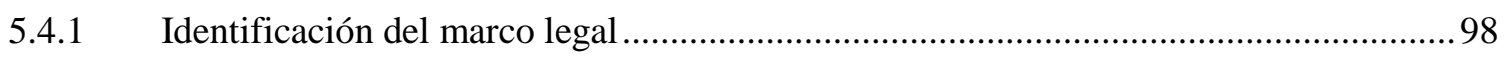

5.4.2 Ordenamiento Jurídico Tributario de empresa................................................................ 101

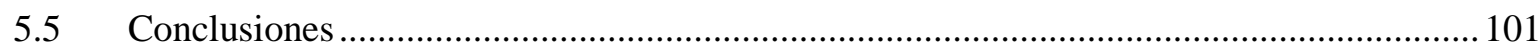

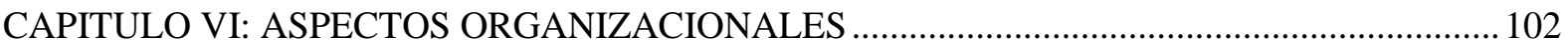

6.1. Caracterización de la Cultura Organizacional Deseada ..................................................... 102

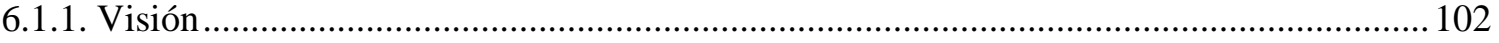

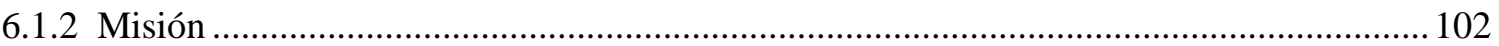

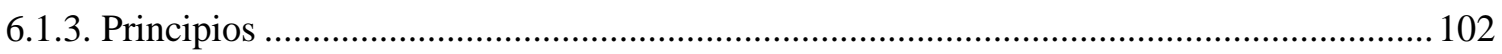




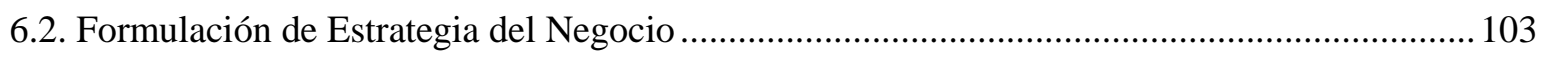

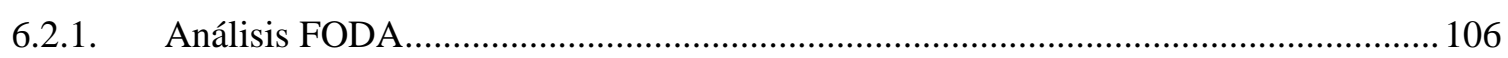

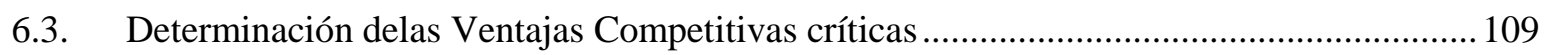

6.4. Diseño de la estructura organizacional deseada ............................................................... 110

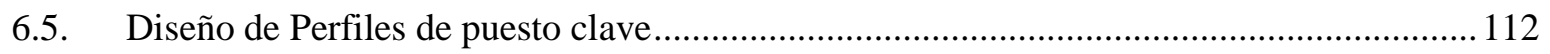

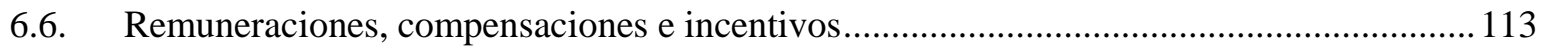

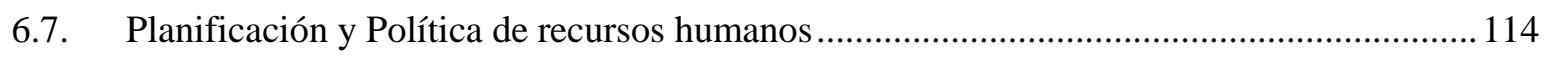

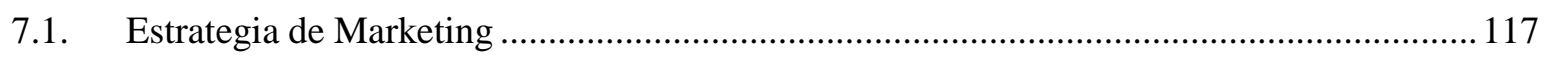

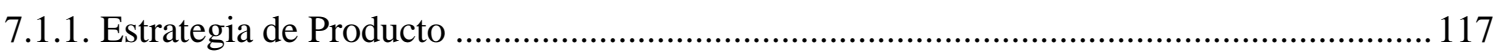

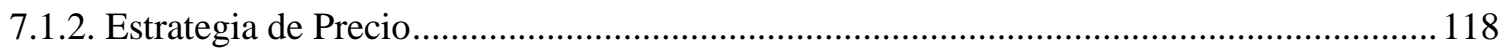

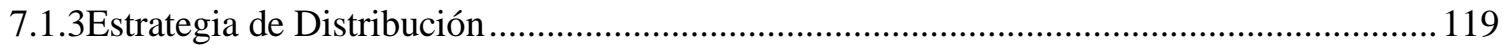

7.1.4. Estrategia de Promoción y Publicidad ................................................................................. 120

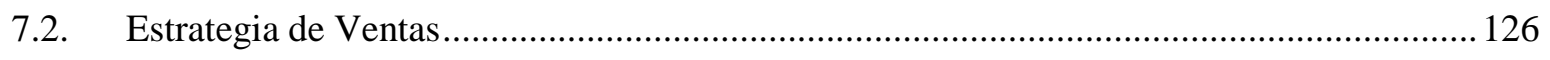

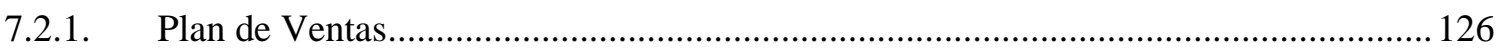

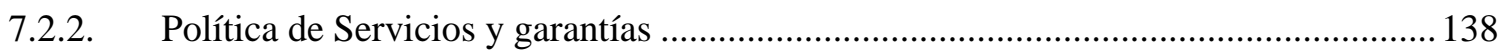

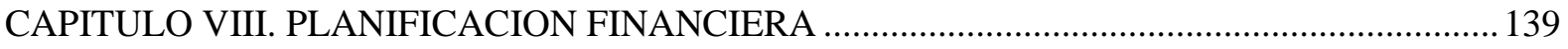

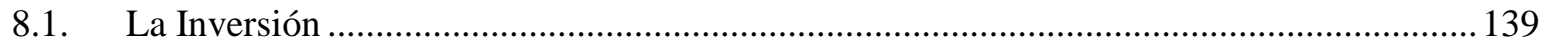

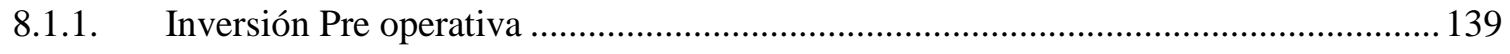

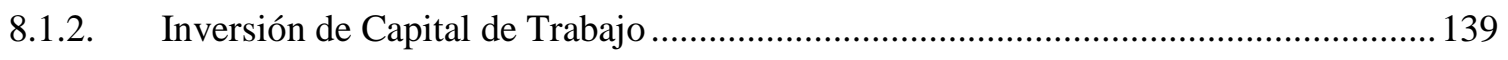

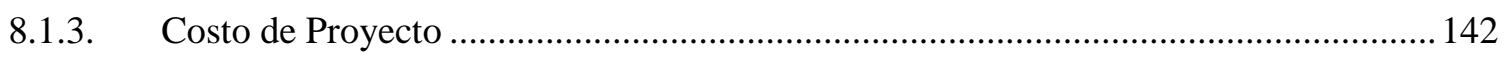

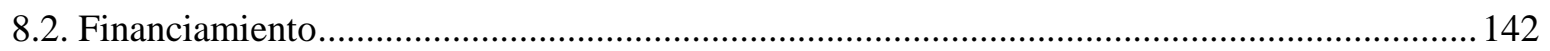

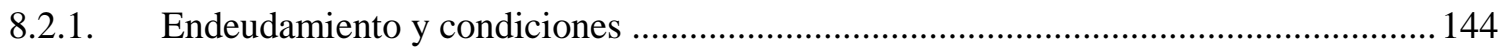

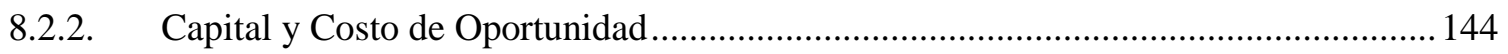

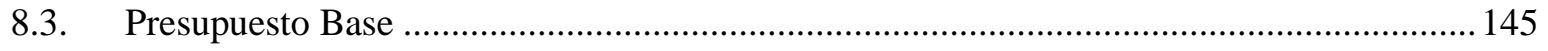

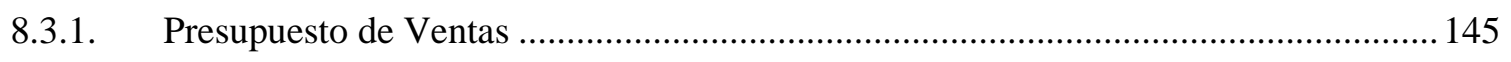

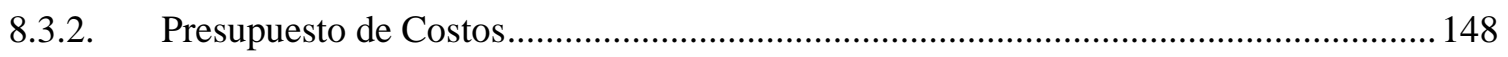

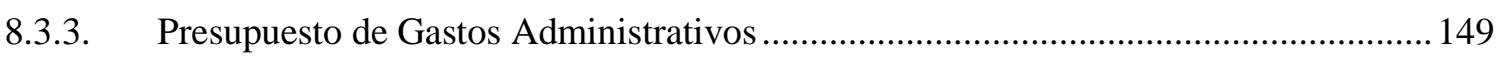

8.3.4. Presupuesto de Marketing y Ventas ........................................................................... 151

8.4.1. Estado de Ganancias y Pérdidas proyectado ................................................................. 154

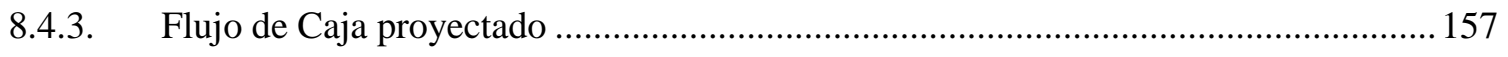

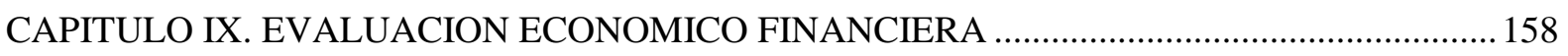

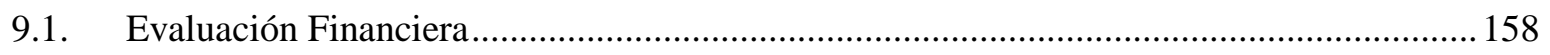

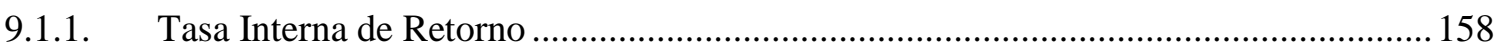

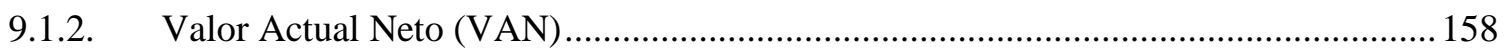

9.1.3. ROE

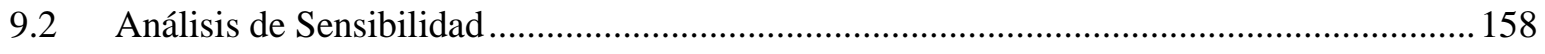

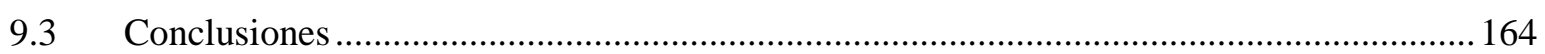




\section{LISTA DE TABLAS}

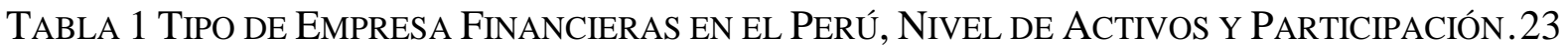
TABla 2 Tipo de EMPRESA Financieras en el PERÚ y Productos Crediticios .................24

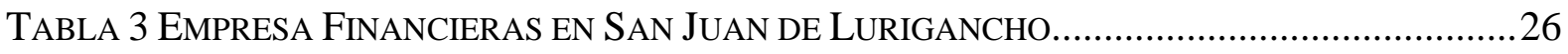

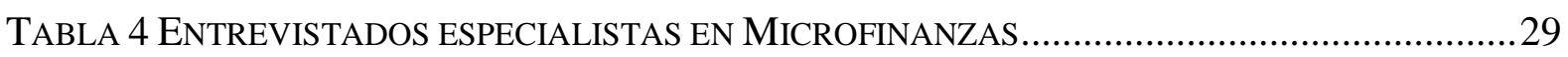

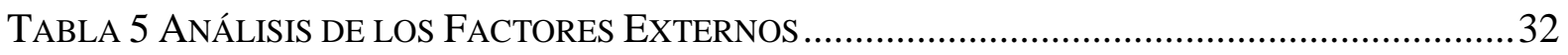

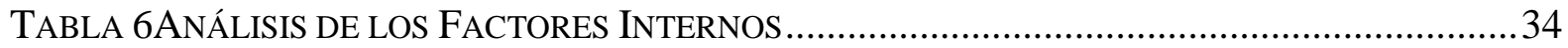

Tabla 7 Variedad de Producto, Ámbito Influencia, Calidad de PROducto y PRecio 35

Tabla 8Horario de Atención, Servicios, Canales de Atención, Promociones. ............35

Tabla 9Nivel de reputación, Calidad de Productos, Disponibilidad de Productos,

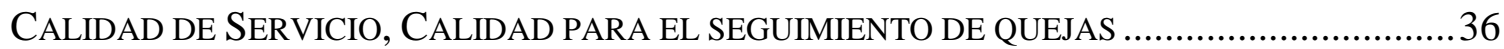

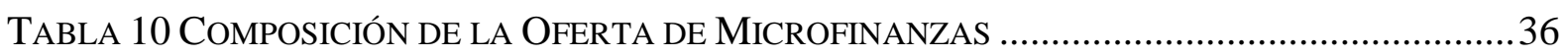

TABla 11 SALDO DE CRÉDITOS EN SAN JUAN DE LuRIGANCHO AL 31 DE DICIEMBRE DE 2015 EN

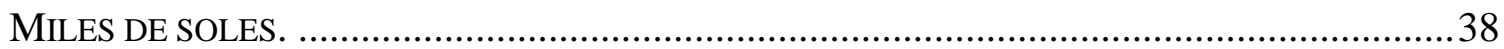

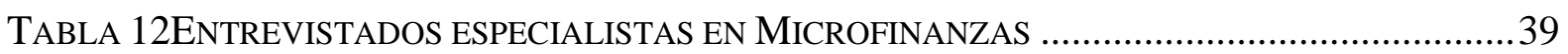

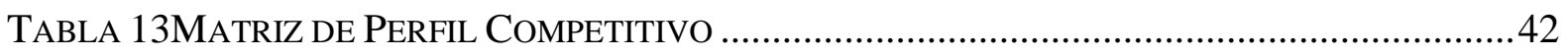

TABla 14PROPUESTAS DEl CANDIDATO Y ACTUAL PRESIDENTE PARA El PERIODO 2016-2021

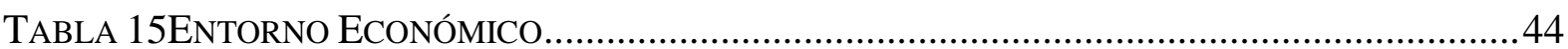

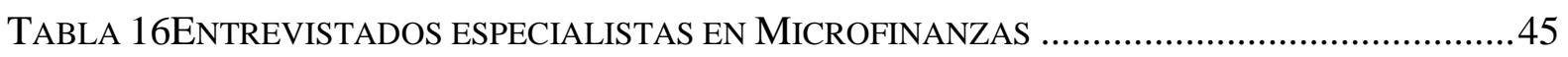

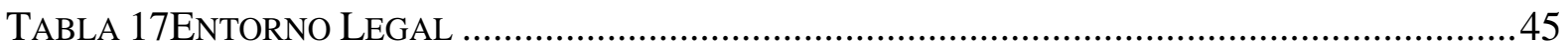

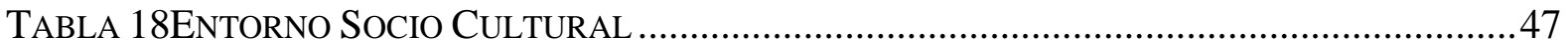

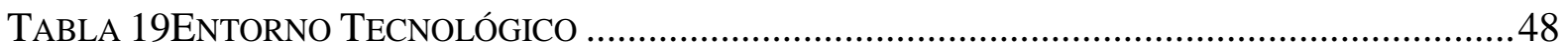

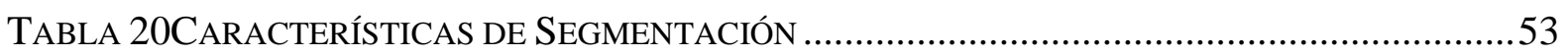

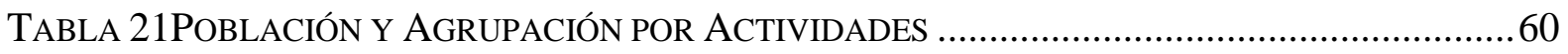

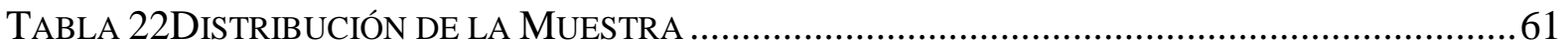

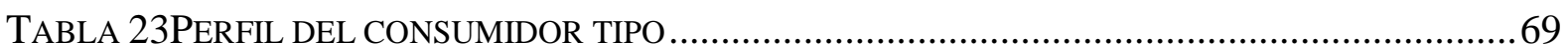

TABla 24Equipo de Asesores, CRÉdito Promedio, NúMERo de Clientes y CARTERA ......72

TABLA 25EQUiPO DE OPERADORES, ATENCIÓN DIARIA CRÉDITO POR MES Y CARTERA ............72

TABLA 26MODELO DE ASIGNACIÓN DE TRABAJO EN ZONA....................................................... 73

TABla 27PRONÓSTICO DE VENTAS, CRECIMIENTO DE CARTERA, INGRESOS DEL PRIMER AÑO. 80

TABla 28Pronóstico de Ventas, CRECIMIENTO de CARTERA, INGRESOS DE CINCO AÑos... 80

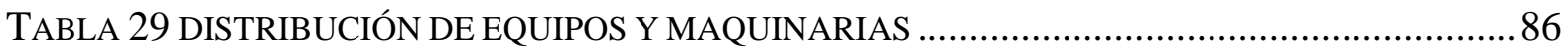

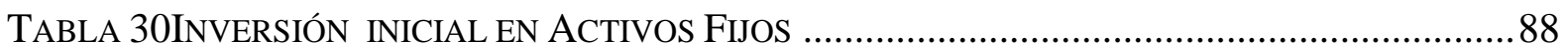

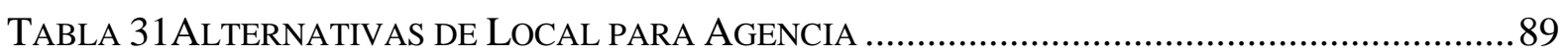

TABLA 32PERSONAL, PUESTOS, REMUNERACIÓN Y RÉGIMEN LABORAL. .................................. 90

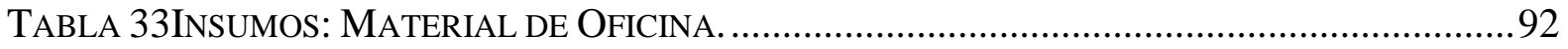

TABLA 34ALTERNATIVAS DE ELECCIÓN Y PONDERACIÓN DE FACTORES. ....................................97

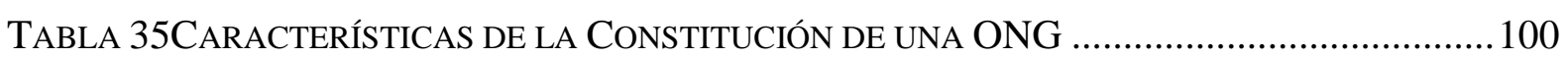

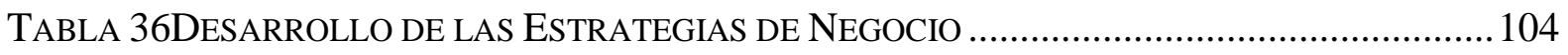

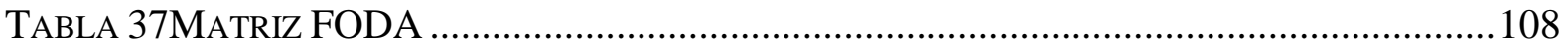

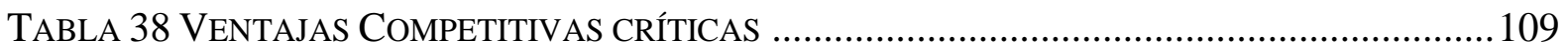

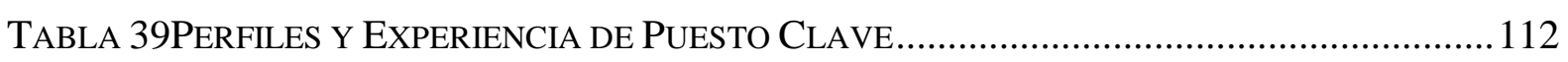

TABLA 40CANTIDAD DE PERSONAL, REMUNERACIÓN Y RÉGIMEN LABORAL ............................. 113

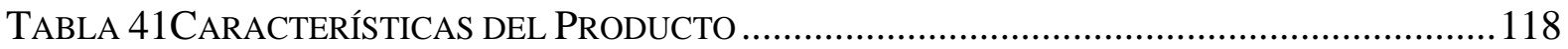

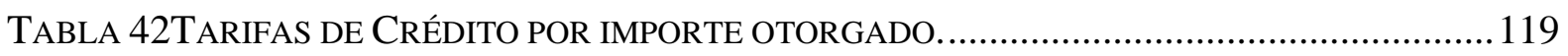

TABLA 43PRINCIPALES MERCADOS Y UBICACIÓN GEOGRÁFICA EN EL DISTRITO .....................125 
TABLA 44ESTRATEGIAS DE VENTAS Y PROCESO TÁCTICO DE IMPLEMENTACIÓN ....................127

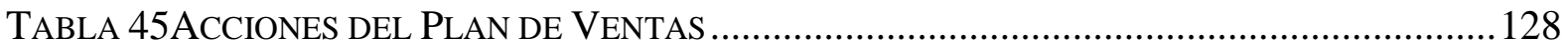

TABla 46 COLOCACIONES, NÚMERO DE ASESOR, NúMERO DE CliENTES Y ESTADO DE RESUlTADO AÑo 1 Y AÑo 2

TABla 47Evolución del SAldo de CARTERA, Colocaciones, NúMERo de AsEsor,

NÚMERO DE CLIENTES Y ESTADO DE RESULTAdO AÑo 3 Y AÑO 4

Tabla 48Evolución del Saldo de CARTERA, Colocaciones, NúMERo de ASESOR,

NÚMERO DE CliENTES Y ESTADO DE RESUlTAdo AÑo 5.

TABLA 49PRESUPUESTO DE GASTOS DE VENTAS PRIMER AÑO................................................ 135

TABLA 50PRESUPUESTO DE GASTOS DE VENTAS DE CINCO AÑOS .......................................... 136

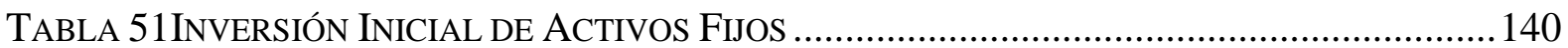

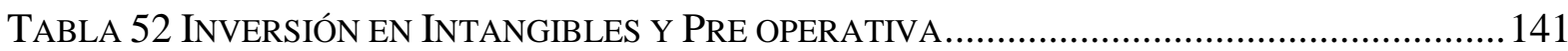

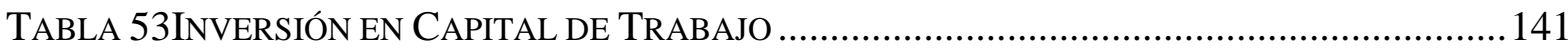

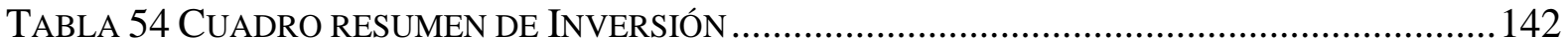

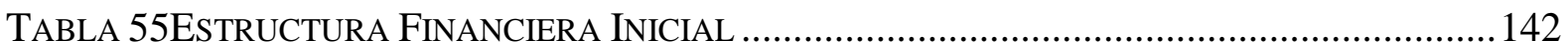

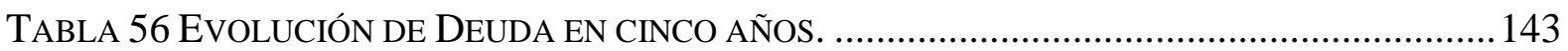

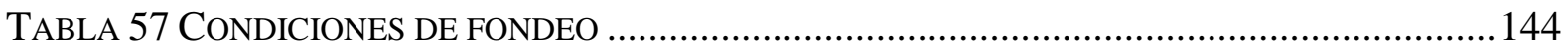

TABLA 58 COK DEL SISTEMA MICROFINANCIERO EN EL PERÚ............................................ 145

TABLA 59 ESTRUCTURA DE COLOCACIÓN POR MONTOS, TASA Y NÚMERO DE CRÉDITOS. ......... 145

TABLA 60 SALDO DE CARTERA, INGRESOS FINANCIEROS BRUTOS Y NETOS AJUSTADOS POR

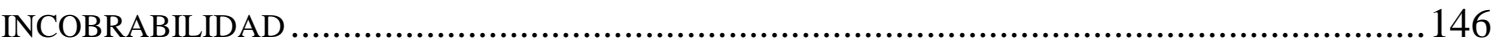

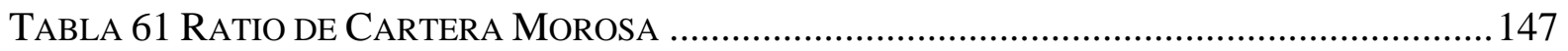

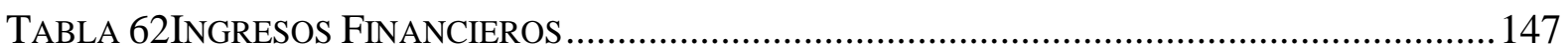

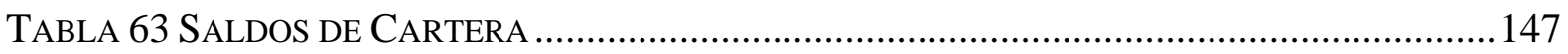

TABla 64 Montos de Gasto Financiero (COSTO DE FondeO DE DinERO)......................... 148

TABla 65TASAS DE AHORRos POR GRUPO DE ENTIDAdES FinANCIERAS ............................... 149

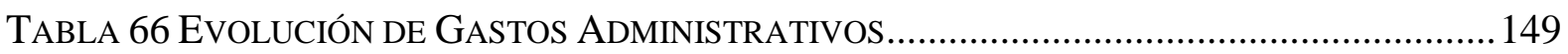

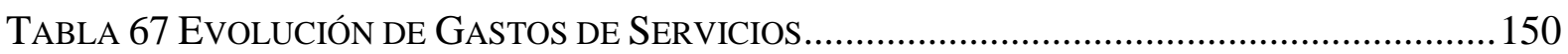

TABla 68 Estructura de Costos De Servicios (SERVicios de CONSUltoría Y

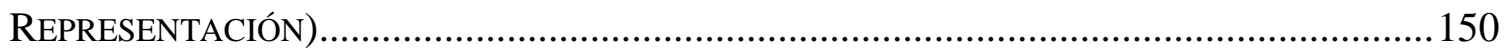

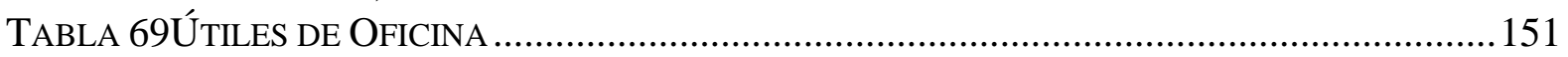

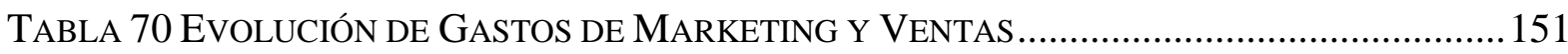

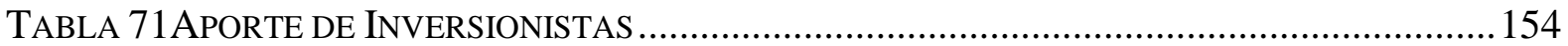

TABLA 72ESTADO DE GANANCIAS Y PÉRDIDAS PROYECTADO EN SOLES .................................. 155

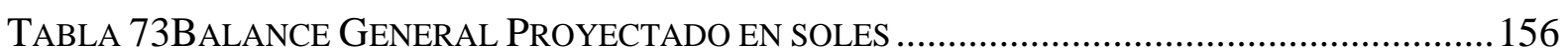

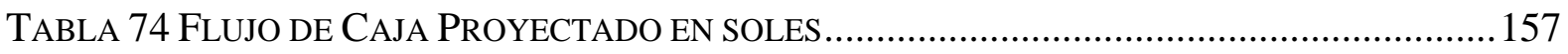

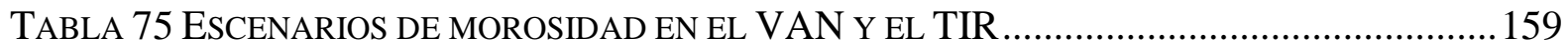

TABLA 76ESCENARIO 1: ESCENARIO OPTIMISTA CON ÍNDICE DE MORA DEL 3\% ........................ 160

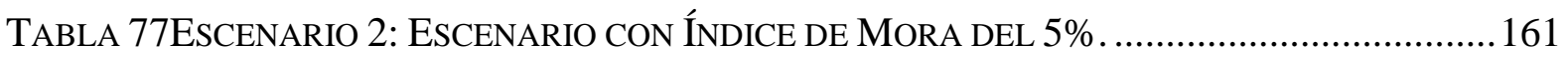

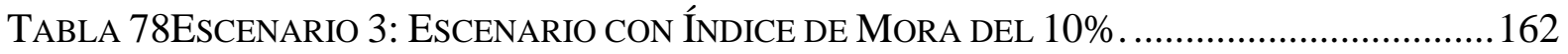

TABLA 79ESCENARIO 4: ESCENARIO CON ÍNDICE DE MORA DE 43.66\% CON VAN $=0 \ldots \ldots . . . .163$ 


\section{LISTA DE FIGURAS}

FigURA 1. ATRACTIVO DE LA INDUSTRIA DE CRÉDITOS Y MICROFINANZAS .............................34

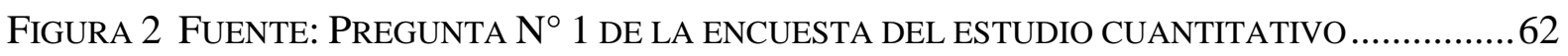

Figura 3 Fuente: Pregunta N ${ }^{\circ} 4$ DE LA ENCUESTA DEL ESTUdio CUANTITATIVo..................63

Figura 4 Fuente: PREgunta N ${ }^{\circ} 10$ DE LA enCUESTA DEL ESTUdio CUANTITATIVO...............63

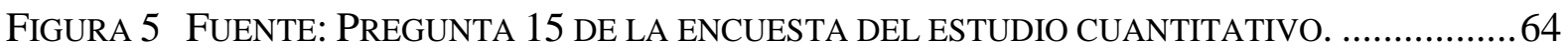

Figura 6 Fuente: Pregunta N 12 DE LA ENCUESTA DEL ESTUdio CUANTITATIVO ..............65

Figura 7 FUENTE: Pregunta N 2 DE LA ENCUESTA DEL ESTUdio CUANTITATIVo ................66

Figura 8 Fuente: Pregunta 19 de la EnCUESTA DEL estudio CUANTITATIVo ...................66

Figura 9 FuENTE: PREgunta 22 DE LA ENCUESTA DEL ESTUdio CUANTITATIVo ...................67

Figura 10 Fuente: Pregunta 24 de LA ENCUESTA DEL ESTUdio CUANTITATIVo .................67

FigURA 11 MAPA DE MODELO DE TRABAJO EN ZONA EN EL DISTRITO DE SJL ........................74

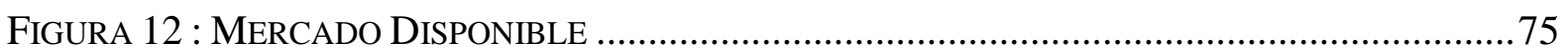

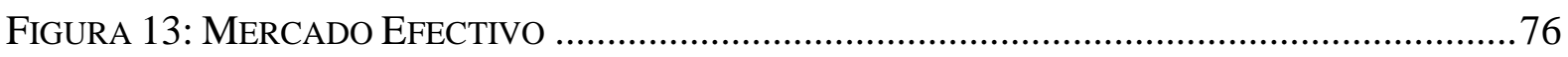

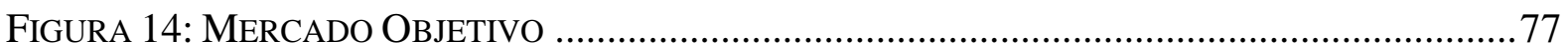

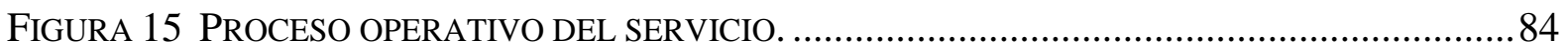

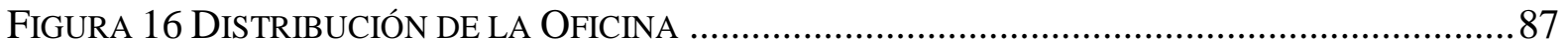

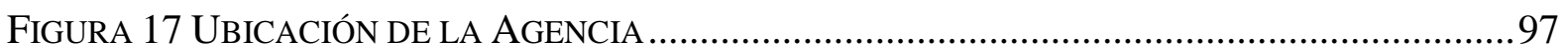

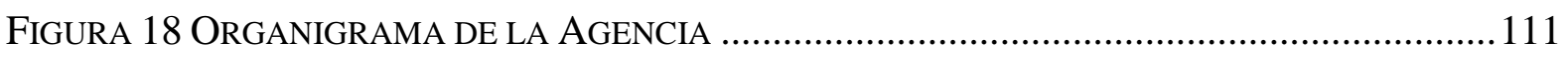

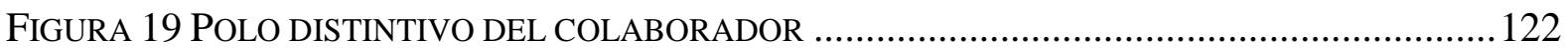

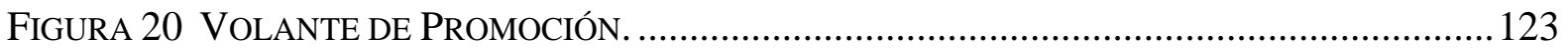

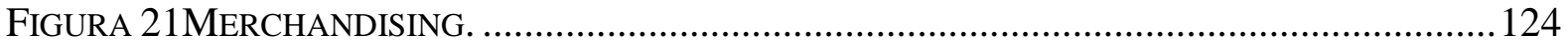

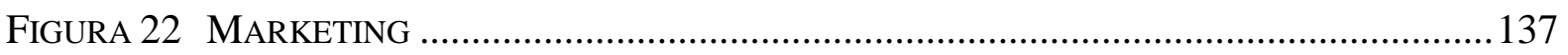




\section{INTRODUCCION}

El Perú fue uno de los países menos afectado por la crisis internacional y esto tiene que ver mucho con el bajo nivel de formalización de los negocios, cosa que parece contradictoria pues lo más saludable para toda economía es justamente tener un mayor nivel de recaudación para la sostenibilidad y el desarrollo de un país.

El alto nivel de desempleo obligó a muchas personas a generar sus propios recursos, para ello idearon distintas formas de hacer negocios en los diversos rubros de servicio, comercio y producción con niveles de inversión bastante bajos, por esa razón es que también pueden de manera sencilla cambiar el giro de su actividad sin que esto resulte muy costoso.

Actualmente el distrito de San Juan de Lurigancho, según el INEI, es el distrito con mayor población en Lima Metropolitana y del Perú, con 1 millón 069 mil 566 residentes.

Siendo uno de los conos con mayor concentración de inmigrantes a nivel nacional, contiene una gran cantidad de comerciantes a nivel formal e informal, además cuenta con todos los recursos para que las personas no tengan que moverse del distrito para obtener un trabajo o crear el suyo.

La respuesta de generación de autoempleo ante el déficit de demanda de trabajo requiere de la alianza de entidades especializadas dedicadas al financiamiento que resuelvan las necesidades de liquidez y permita el crecimiento de las microempresas.

El interés del presente trabajo se fundamenta en la experiencia vivida por los integrantes del proyecto y la observación de la expansión de la oferta micro financiera.

En el primer capítulo se ha revisado los antecedentes del sector micro financiero, encontrando una oportunidad de negocio, proponemos objetivos generales y específicos para este proyecto de inversión, así como sus alcances y limitaciones. 
En el segundo capítulo se ha revisado el contexto socio económico, cultural, tecnológico y político que evidencia condiciones favorables para el desarrollo de la oferta de PrestaMas, se entendió que la oferta más apropiada es de una entidad autorregulada y supervisada como la industria formal, en tanto que sea ágil y flexible como la industria informal, la cual aproveche además el desarrollo de la infraestructura de la oferta crediticia.

En el tercer capítulo se ha desarrollado el estudio de mercado, a fin de poder corroborar los hallazgos del capítulo anterior y de las entrevistas realizadas con especialistas, permitiendo determinar la propuesta de oferta tanto en los productos, condiciones y precios como el formato.

Con el desarrollo del estudio cuantitativo y cualitativo del mercado, en el capítulo cuatro se determinó el mercado potencial y objetivo con lo cual realizamos la proyección de ventas, que se fue ajustando su crecimiento de acuerdo a los estándares históricos de la industria.

En el quinto capítulo se determinó la ingeniería del proyecto, se definió el tamaño, localización y consideraciones legales de creación y operación de la propuesta de entidad crediticia.

El capítulo sexto se definió la misión y visión de la empresa, la estructura organizacional adecuada al mercado objetivo que se va atender. Teniendo en cuenta la industria y sus características, se determinó la estrategia del negocio

En el séptimo capítulo se desarrolló el Plan de Marketing definiendo las estrategias específicas para cada una de las 4 P. Asimismo se determinó el Plan de ventas.

El octavo capítulo expresa nuestra propuesta de negocio en estados financieros, la proyección que tenemos resume los capítulos anteriores expresados en sus respectivos presupuestos, así como la inversión requerida y su fuente de financiamiento. 
En el capítulo nueve se desarrolla la evaluación financiera de nuestro proyecto (TIR, VAN y ROE) así como el análisis de sensibilidad respecto a diferentes escenarios de morosidad para determinar la viabilidad de nuestro proyecto. 


\section{CAPITULO I. GENERALIDADES}

\subsection{Antecedentes:}

La industria micro financiera formal supervisada, no supervisada e informal evidencia el crecimiento sostenido de la industria. El entorno favorable destaca por el apropiado manejo de la tecnología crediticia reconocida en el ámbito local e internacional. La solidez de las instituciones por el apropiado manejo de la supervisión, regulación, inclusión y educación financiera. El grado de desarrollo alcanzado resulta con el florecimiento de un mercado segmentado, especializado y competitivo. La competencia se ha trasladado en esfuerzos de los participantes por alcanzar mayor participación del mercado concentrando créditos de mayor cuantía en pocos demandantes de créditos con antecedentes crediticios, pero descuidando a los demandantes que carecen de crédito. Diversos estudios del BCRP, SBS, MEF, Cámara de Comercio de Lima, CEPAL, BM, FEPMAC, FENACREP, COPEME indican que el incremento de la oferta por la presencia de más participantes y la pugna en pocos ha conllevado sin embargo a una reducción de beneficios económicos de las empresas por: (1) otorgar créditos de mayor cuantía a menor tasa de interés (precio) debido a que más de una institución potencialmente persigue a un mismo cliente, presionando las empresas a ganar el cliente con el incentivo de reducirle el costo financiero; (2) por la evidencia de exposición de sobreendeudamiento que lleva a provisiones por incobrabilidad y asumir pérdidas por ser irrecuperable; y, (3) contar con colaboradores que rotan entre empresas crediticias que sobre endeudan al público que atendieron, sobre los cuales tienen poder de influencia así como la práctica nociva de compartir información de la empresa que laboran con ex compañeros.

Pugnar por la atención de clientes con antecedentes denominados bancarizados y otorgar créditos de mayor cuantía en busca de reducir costos fijos, explica y marca la tendencia en caída de las ratios de rentabilidad de las empresas año a año, así como registrar un bajo índice 
de bancarización en la región de América Latina y El Caribe. La industria micro financiera evidencia pérdida de poder de negociación aprovechada por los clientes y potenciales clientes. Surgen en este entorno ofertas micro crediticias no supervisadas e informales que alcanzan un alto grado de rentabilidad y mantienen el ámbito de atención a solicitantes de créditos que no están bancarizados, quienes recién se inician o solo trabajan con alguna empresa y solicitan montos bajos y aceptan tasas de créditos elevadas (precio alto), pero carecen del conocimiento de la tecnología micro crediticia, sustentan las decisiones de otorgar créditos basadas en la exigencia de garantías, desarrollan procesos ineficientes y no atienden las reglas de regulación o supervisión aunque legalmente no les sea exigidas.

\subsection{Determinación de la Oportunidad:}

Existe la oportunidad de participar en la industria financiera con la creación de una ONG de micro finanzas, que brinde exclusivamente oferta micro crediticia para atender necesidades de financiamiento destinado a la producción de micro y pequeños empresario, dado que se aprecia una brecha en la oferta formal supervisada que limita el acceso a microempresarios no bancarizados, así como de otorgar montos de menor cuantía que son atendidas por empresas formales no supervisadas e informales sin el conocimiento apropiado de la tecnología de micro crédito, que se desenvuelven sin autorregulación ni una adecuada exposición de sus resultados para que conlleva a captar inversionistas o prestamistas potenciales; a su vez, hay una sobre oferta crediticia para microempresarios bancarizados y de financiamientos de créditos mayor cuantía que expone a una concentración de créditos con riesgo de sobreendeudamiento e irrecuperabilidad, que desalienta al ahorro del público en estas empresas frente a noticias de intervención por el ente regulador de la Superintendencia de Banca y Seguros, que gozan con capacidades de fondeo por captaciones de ahorros por ser reguladas y por las cuales el ente regulador elevó los requisitos para ser una entidad regulada constituyéndose en una barrera de entrada al mercado. 


\subsection{Justificación}

La propuesta de creación de una entidad micro financiera busca aprovechar el conocimiento y la experiencia de la tecnología de micro crédito, para la atención de créditos de baja cuantía cuya predisposición de sus solicitantes es pagar tasa de interés elevadas; la propuesta a su vez busca practicar autorregulación que observe la legislación de los entes reguladores y comunicar al público el ejercicio del resultado de nuestras operaciones, para captar potenciales asociados y financistas, que hoy solo consiguen aprovechar el rendimiento del ahorro de ofertas de tasas pasivas bajas de entidades financieras o una baja rentabilidad en la inversión de fondos mutuos o de inversión. A diferencia de los pioneros de la industria de créditos que enfrentaron altos costos fijos por apertura agencias que desarrollaban todo el proceso de desembolso y cobros en las agencias, se busca aprovechar la tecnología de red cajeros automáticos (ATM), la presencia masiva de agentes corresponsales de la competencia, así como el dinero electrónico, la banca móvil que brinda actualmente las empresas de la industria financiera, permitiendo ahorro al trasladar costos fijos a variables.

- Teórica: Modelo de Plan de Negocio para empresas nuevas, bajo el marco teórico de Lydia Arbaiza Fermini con su libro Cómo Elaborar un Plan de Negocio.

- Mercado: La base ancha estructura de pirámide poblacional, el desempleo estructural en el distrito de San Juan de Lurigancho, el bajo crecimiento económico no absorbe la mano de obra disponible de la PEA, el emprendimiento de algunos desempleados e inclusive en quienes lo son, garantiza crecimiento del sector microempresario formal y no formal que evidencia necesidades de financiamiento productivo, lo cual está siendo atendido por la banca informal, pero no se abastece, suscitándose una demanda insatisfecha de micro créditos (base de créditos de menor cuantía). 


\subsection{Objetivos General del Proyecto}

- Elaborar un Plan de Negocios para la creación una ONG dedicada a brindar soluciones financieras al ofrecer créditos a microempresarios.

\subsection{Objetivos Específicos del Proyecto}

- Determinar la viabilidad de mercado para la creación de ONG dedicada a ofrecer dinero a microempresarios.

- Determinar la viabilidad Técnica/Operativa

- Determinar la viabilidad Organizacional

- Determinar la viabilidad Económica/Financiera

- Establecer una ventaja competitiva entre la oferta actual y nuestra propuesta

- Establecer un adecuado perfil para la selección de profesionales

\subsection{Alcance y Limitaciones}

El proyecto se enfocará en el distrito de San Juan de Lurigancho que cuenta con más de un millón de habitantes convirtiéndolo en el distrito más poblado de Lima - Perú y concentra la mayor cantidad de microempresarios.

- El estudio se realizó de enero a octubre del 2016

- Por tratarse de un estudio académico tenemos las limitaciones económicas por lo cual citaremos fuentes secundarias para complementar el proyecto.

- La información recopilada de las fuentes primarias tendrá limitaciones debido a que el segmento no está muy acostumbrada a formar parte de procesos de investigación y probablemente no tengamos una aceptación total. 


\section{CAPITULO II: $\quad$ ESTRUCTURA ECONÓMICA DEL SECTOR}

\subsection{Descripción del estado actual de la industria}

El Perú es considerado “durante cuatro años consecutivos; de 2008 a 2011, por The Economist Intelligence Unit como el país con las mejores condiciones de negocios para las microfinanzas a nivel mundial" (Revista Moneda BRCP -N 151, 2012, p 14-15), la medición de la evaluación considero las buenas prácticas de negocios y de interacción con los clientes. La industria de las microfinanzas ofrece al Perú un entorno favorable para su crecimiento sostenido, se fortalece la aseveración con reconocimientos públicos como:

"Perú es líder en el desarrollo de estrategias innovadoras y coordinadas en la promoción de la inclusión financiera con objetivos como una creciente penetración bancaria, una mejora de la educación financiera, la reducción de costos de transacción y el fomento del uso de la tecnología” (Informe Microscopio Global 2014, p. 61)

El escenario alentador y de reconocimiento del Perú con un rol destacado durante ocho años consecutivos, resalta sin embargo que:

“Nuestro país adolece de un bajo índice de bancarización, situación que amenaza el proceso de inclusión financiera, el cual se ve también atacado por el incremento en los niveles de sobreendeudamiento en la cartera de clientes de microcrédito y la poca penetración de productos generadores de valor añadido para los clientes de microcrédito, tales como los micro seguros" (Chunga, 2014, p. 4)

Se evidencia que existe una elevada concentración en el servicio financiero en las zonas urbanas de capital de ciudad y provincias exponiendo la sobreoferta a los clientes y potenciales clientes a riesgos de sobreendeudamiento con créditos recurrentes y simultáneos por mayores montos otorgados por más de una entidad financiera, desatendiendo la base de la pirámide de créditos denominados "micro créditos"- cuya demanda se encuentran en la 
periferia y zona rural de las ciudades del país. Un sin número de empresas formales no reguladas e informales atienden demandas por necesidades de microcrédito, para Iguíñiz y León, 2011, "el microcrédito para poblaciones rurales o pobres en general parece provenir, además de los canales informales, en parte de ONG y cooperativas que operan localmente, y en parte de algunos de los denominados programas sociales como FONCODES” (p 307); los canales informales comprenden: (a) prestamistas informales conocidos como agiotistas/usureros; (b) empresas de créditos como casas de préstamo, casas de cambio de moneda que no sin ser intermediarias financiera; es decir, que no captan ahorros y trabajan con capital propio; (c) asociaciones espontáneas organizadas por grupos de familiares, de barrio, de mercado o mixtas organizadoras panderos o juntas entre otras son parte de la oferta crediticia de micro y pequeños créditos desatendida por empresas reguladas y no reguladas del sistema financiero.

\subsubsection{Segmentación de la industria.}

Una parte de las micro finanzas son atendida por empresas reguladas según SBS a setiembre del 2015, el sistema financiero formal se compone por 60 empresas que realizan operaciones múltiples y poseen activos por S/. 378 mil millones, tal como se indica en la Tabla 1.

La segmentación de la industria de las microfinanzas en San Juan de Lurigancho para objeto del proyecto es de: (a) empresas formales supervisadas, las mismas que están autorizadas para captar fondos de depósitos; (b) empresas formales no supervisadas sin autorización para captar fondos y las empresas informales con capital propio, tal como se indica en la Tabla 2.

Otro enfoque para la segmentación de la industria en el distrito es de acuerdo "al tipo de producto", "cliente por el lado de la demanda"; y, "la exigencia de especializarse por las empresas", dado los diferentes segmentos de mercado financiero y micro financiero específicamente definidos por el tipo de del cliente, estrato socioeconómico, grado de 
exposición y aversión al riesgo, tamaño o monto de crédito, plazo convenido de la operación, cultura de pago, frecuencia de pago, demás colaterales y tipo de garantía individual, solidaria, propia o de aval, utilización o destino del crédito, entre otras por el lado de la demanda, hace “posible definir distintas particiones de mercado según las propiedades y características que se busque enfatizar". Por el tipo de créditos, la SBS reconoce 8 tipos distintos de créditos en el Perú ("Emprendedor.pe”,2016), lo que dista al segmento de ser competitivo:

\section{Tabla 1}

Tipo de Empresa Financieras en el Perú, Nivel de Activos y Participación

\begin{tabular}{lrrr}
\hline \multicolumn{1}{c}{ Empresas de Operaciones Múltiples } & $\begin{array}{c}\text { Activos a Setiembre 2015 } \\
\text { Número de } \\
\text { empresas }\end{array}$ & $\begin{array}{r}\text { Monto (S/. } \\
\text { Millones) }\end{array}$ & $\begin{array}{r}\text { Participación } \\
\text { (\%) }\end{array}$ \\
\hline Banca Múltiple & 17 & 346683 & 91.71 \\
Empresa financiera & 12 & 10581 & 2.80 \\
Caja Municipal de ahorro y crédito & 12 & 18455 & 4.88 \\
(CMAC) & 8 & 709 & 0.19 \\
Caja Rural de ahorro y crédito (CRAC) & 11 & 1596 & 0.42 \\
Entidad de desarrollo de la pequeña y & & & 100 \\
microempresa (Edpyme) & 60 & 378024 & \\
Total & & & \\
\hline
\end{tabular}

Fuente: SBS https://intranet1.sbs.gob.pe/estadistica/financiera/2015/Setiembre/SF-0003-se2015.PDF

Se resalta a las dos clasificaciones diferenciadoras en la Resolución SBS No 14353-2009:

Modifica el Nuevo Reglamento para la Evaluación y Clasificación del Deudor y la Exigencia de Provisiones, aprobado por Resolución SBS N 11356-2008

(“http://www.fenacrep.org/web/st_center.php?id_subtitulo=9”, 2009), ya que anteriormente se consideraban solamente seis tipos:

En el mercado peruano de créditos se puede distinguir al menos seis segmentos: corporativo, mediana empresa, pequeña empresa, hipotecario, consumo y 
Microfinanzas. Sin embargo, para propósitos del presente estudio, se asume que las entidades financieras en el mercado de créditos focalizan sus operaciones de manera excluyente en dos grandes segmentos: corporativo y Microfinanzas (Estudios Económicos BCRP, 2002, p .1)

\section{Tabla 2}

Tipo de Empresa Financieras en el Perú y Productos Crediticios

\begin{tabular}{lll}
\hline Por Nivel de Supervisión & Tipo de Empresa & Producto que Ofrece \\
\hline Empresas Formales & Edpymes & Crédito microempresa \\
& Cooperativas & Crédito microempresa y consumo \\
& CMACs, CRACS, CML & Crédito microempresa y consumo \\
& Financiera & Crédito microempresa y consumo \\
Empresas Formales No & Cooperativas & Crédito microempresa y consumo \\
Supervisadas & ONG & Crédito microempresa y consumo \\
& Casa de Prestamos & Crédito microempresa y consumo \\
Empresas Informales & Prestamistas & Crédito microempresa y consumo
\end{tabular}

Fuente: Elaboración Propia

La tipología de Créditos de acuerdo a la Resolución SBS Nº 14353-2009

1. Créditos corporativos.

2. Créditos a grandes empresas.

3. Créditos a medianas empresas.

4. Créditos a pequeñas empresas.

5. Créditos a microempresas.

6. Créditos de consumo Revolvente.

7. Créditos de consumo no Revolvente. 
El objeto principal de interés de PrestaMas es créditos a microempresas y créditos a pequeñas empresas.

- Créditos a microempresas:

Es un crédito otorgado a personas jurídicas o naturales para fines iguales a los de las pequeñas empresas, salvo que en este caso el endeudamiento en el SF debe ser menor de S/. 20 mil.

- Créditos a pequeñas empresas:

Es un crédito otorgado a personas jurídicas o naturales para fines de prestación de servicios, comercialización o producción, cuyo endeudamiento en el SF sea de al menos S/. 20 mil y menor a S/. 300 mil en los últimos seis meses.

\subsubsection{Empresas que conforman}

Más de 50 empresas financian a la microempresa, tal como se indica en la Tabla 3.

\subsection{Tendencias de la Industria}

Una tendencia crecimiento de la industria el distrito de San Juan de Lurigancho, en el número de agencias por empresa, en el volumen de cartera por agencias, cada vez con menor crecimiento el número de clientes. En general hay una política de inversiones sostenidas en la apertura de agencias, cajeros automáticos y red de cajeros corresponsales para poder cubrir la geografía, en menor medida con la banca electrónica, banca móvil y banca por internet. Además del servicio de intermediación financiera del micro crédito, la plataforma de las agencias brinda servicios de: (1) servicios de cambio de moneda extranjera, (2) pago de servicios como: teléfono, agua, energía eléctrica, (3) pago impuestos a la Sunat, (4) pagos de tasas por especies valoradas para trámites ante la RENIEC, Comisarias, (5) servicio de cobro y recaudación por terceros, pagos de internet, cable, pensiones de institutos, entre otros. 
Tabla 3

Empresa Financieras en San Juan de Lurigancho.

\begin{tabular}{lcc}
\hline \multicolumn{1}{c}{ Empresas Formales } & Empresas Formales No & Empresas Informales \\
\multicolumn{1}{c}{ Supervisadas } & Supervisadas & \\
\hline Edpymes & Cooperativas & Prestamistas \\
Raíz & San Cristobal & Corporación El Padrino \\
Credijet del Perú S.A. & Primero de Mayo Ltda. & Corporación Vega \\
Inversiones La Cruz S.A. & Kuskalla cambio de \\
Cooperativas & La Cantuta Ltda. & Moneda extrajera \\
San Hilarión & ONG & Casas de empeño \\
Nueva Alternativa & PRISMA & \\
Mi Sol Diario. & FINCA PERU & \\
CMACs, CRACS, CML & CREDIMUJER - & Prestamistas Locales de \\
Arequipa & manuela ramos & barrio \\
Cusco & CREDIVIDA - FOVIDA & Los Colombianos \\
Huancayo & EDAPROSPO & \\
Piura & CARE PERU & \\
Trujillo & Casa de Prestamos & \\
Sullana & & \\
Prymera & & \\
Nuestra Gente & & \\
Financieras & & \\
Pro empresa & & \\
Compartamos & & \\
Crediscotia & & \\
Banco & & \\
MiBanco & & \\
\hline
\end{tabular}

Fuente: Elaboración Propia

Por los servicios adicionales prestados, a los financieros, por los que cobran pequeñas comisiones "se han alejado del modelo de banca tradicional, que consiste en la intermediación de fondos entre ahorristas y tomadores de créditos, para enfocarse en la 
provisión de productos y servicios financieros especializados que demandan una infraestructura financiera particular" (Documentos de Trabajo SBS, 2013, p. 2)

Con esto, se ha dado un impulso en la generación de ingreso por el lado de operaciones en las ventanillas de las entidades financieras y red de atención convirtiendo ahora el modelo tradicional en una tienda donde la velocidad de atención permite un mayor ingreso que se fomenta con el establecimiento de metas por operador (cajero).

El crecimiento poblacional en el distrito de San Juan de Lurigancho; para el año 1993 tenía 582975 habitantes, ha pasado a ser para el año 2007 a 898443 habitantes, según las proyecciones para el año 2014 el distrito cuenta con 1069566 habitantes; de este punto de crecimiento de la población presenta una tendencia creciente.

(Municipalidad de San Juan de Lurigancho, 2014, p 181)

\subsection{Análisis Estructural del Sector industrial}

El segmento de micro finanzas es un segmento dinámico en constante crecimiento, agresivo, marcado por la parte comercial de cada empresa de alcanzar metas altas de participación de mercado. La permanencia en el mercado se refleja en alcanzar indicadores de gestión, solvencia y liquidez bastante razonables, así como en mantener una cartera saludable, lo que ha conllevado a una salida de empresas del sector con mal manejo como Caja Luren, Credinka en el distrito de San Juan de Lurigancho.

La regulación y supervisión por entidades como SBS, INDECOPI, BCRP y SUNAT impacta en el desarrollo de toda la industria, modelando a las empresas formales reguladas, modificando reglas de juego para ser percibidas por los demandantes de micro crédito e internalizadas, luego transmitidas a la población, exigiendo a partir de ello de manera directa o indirecta a las empresas formales no supervisadas e informales como por ejemplo la transparencia de información, formas de cobranza, etc. 
Se aprecia reducción del número de empresas participantes, por concentración geográfica la oferta ha sobrepasado las necesidades de financiamiento en algunas localidades del distrito, descuidando zonas de menor dinamismo y segmentos de menor monto de demanda de créditos. La concentración de empresas formales reguladas a través de fusiones empresariales por absorción de entidades bancarias a través de subsidiarias:

"Hay varias entidades micro financieras con problemas importantes por el lado de la generación y rentabilidad (principalmente en las Cajas Rurales), lo cual genera una oportunidad para las entidades micro financieras más grandes y sólidas para que mediante fusiones y adquisiciones puedan incrementar el volumen de operaciones y así ser más competitivas”. (Equilibrium Clasificadora de Riesgo S.A., 2015, p. 7)

En el distrito se han dado casos recientes como: (a) Edyficar y MiBanco, (b) Financiera Confianza y Caja Nuestra Gente, (c) Caja Arequipa y Caja Luren, (d) la compra de CRAC CrediChavin por Edpyme Raíz. Con la evolución de normativas, los entes supervisores y reguladores han creado una barrera de entrada de mercado para nuevas empresas, lo que ha conllevado a la aparición de nuevas empresas formales no reguladas e informales.

Cooperativas de Ahorro y Créditos como San Hilarión, Nuevo Milenio, San Pedro de Andahuaylas entre las que más destacan en San Juan de Lurigancho y otras menores como San Cristóbal de Huamanga, Primero de Mayo Ltda., Kuskalla, La Cantuta Ltda. y Crédito Mi Sol Diario. Además, la oferta crediticia tiene a las casas comerciales de préstamo e informales prestamistas con dominio local por la inmediatez y conocimiento.

\subsection{Análisis de la Competencia}

Considerando el modelo de una gestión completa de las cinco Fuerzas de Michael Porter, en base a las entrevistas desarrolladas a tres especialistas consultores independientes en el rubro de las microfinanzas, elaboramos Modelo del Diamante de Porter y Clústeres, tal 
como indica la Tabla 4. Para los entrevistados, evidencias de poco éxito de empresas y reciente creación como CRAC Centro, desincentiva iniciativas de ingresos de empresas formales reguladas y supervisadas y favorece la aparición de iniciativas de empresas como la Cooperativa Kuskalla formales no reguladas y supervisadas que surgió de ex colaboradores de la Cooperativa San Hilarión. Aunque la facilidad de ingreso al mercado está identificada, la permanencia y el crecimiento de estas empresas; sin embargo, es insegura pues su salida del mercado por perdidas por incobrabilidad de clientes, e intervención de entes reguladores por encontrarse captando ahorros sin permisos es latente según Luis Rivera Villegas. Hay necesidad de mejorar indicadores de gestión, solvencia y liquidez aun cuando no son empresas reguladas.

\section{Tabla 4}

Entrevistados especialistas en Microfinanzas

\begin{tabular}{lll}
\hline Nombre & Empresa & Cargo \\
\hline Darío Emilio Enriquez & Servicios Financieros & $\begin{array}{l}\text { Consultor independiente y ex gerente } \\
\text { regional CMAC }\end{array}$ \\
Luis Rivera Villegas & BCP & $\begin{array}{l}\text { Consultor independiente y gerente } \\
\text { agencia BCP }\end{array}$ \\
Roger Arévalo & Servicios Financieros & Consultor independiente, ex gerente \\
Herreros & & regional CMAC Cusco, Huancayo, \\
& & Edpyme Crear y Raíz
\end{tabular}

Fuente: Elaboración propia

El poder de la negociación de los diferentes proveedores, principalmente de fondos, evidencia una oferta de ahorro, supera a la demanda de créditos y con el latente incremento de retiro fondos de las AFP's con el fin de ser trasladados a empresas de créditos a través de ahorros, préstamos directos o inversión en la industria, conlleva a que la industria tenga poder sobre sus proveedores según los tres entrevistados.

En cuanto a la capacidad para negociar es baja con los clientes bancarizados, sin embargo, con aquellos que están no bancarizados el poder de negociación es alto, las empresas tienen el 
poder de discriminar precios para alcanzar un mayor margen de ganancia con dichas operaciones, según Luis Rivera Villegas.

En cuanto a la amenaza de ingresos por productos secundarios, coinciden los entrevistados que siempre ha existido el crédito de casas comerciales de empresas mayoristas, de empresas de muebles y de artefactos con formato de venta al crédito, cuya participación no ha sustituido a la actividad de créditos, y aun cuando ha crecido, solo complementa a la industria financiera con mayores precios y exigencia de más condiciones de crédito, evidenciándose una mínima amenaza de productos secundarios, según los tres entrevistados.

En cuanto a la rivalidad entre los competidores, el mercado se aprecia un escenario competitivo, con dominio de mercado en saldo de colocaciones concentradas en mayores montos y un segmento sin líder dominante en créditos de menor cuantía.

A partir de la revisión del diamante de Porter y las entrevistas realizadas a los especialistas, se elabora el modelo del atractivo de la industria para la industria de créditos y del sistema financiero.

De acuerdo al análisis de los Factores Externos: (a) el tamaño de mercado tiene un peso elevado de $20 \%$ por ser relativamente grande y estar desatendido por la oferta actual en los créditos más pequeños, ONG PrestaMas tiene la máxima puntación debido a que existe baja bancarización y que la competencia se concentra en créditos de mayor cuantía dejando el nicho de mercado de los microcréditos la empresa sin atender, apropiado para nuestra oferta; (b) los precios en la industria tienen un peso relativamente bajo de $10 \%$ al ser competitivos, pero en el segmento de los microcréditos no lo es, debido a que los potenciales clientes valoran más la rapidez sobre el importe del interés en montos pequeños y se evidencia desatención en la demanda de los mismos, por ser de arduo trabajo para los analista y de poca recompensa en la consecución de sus metas; sin embargo, PrestaMas prevé ofertar a precios altos respecto a la media, conlleva a una baja calificación de la empresa en la expectativa de 
los clientes; (c) El crecimiento del mercado adquiere un peso del 10\% debido a la desaceleración económica; sin embargo, PrestaMas tiene la máxima puntación debido a ser un segmento desatendido y del cual se puede depurar efectos la desaceleración por el tamaño de los crédito; (d) la industria atiende a un mercado heterogéneo la ponderación es de 10\%, en tanto para PrestaMas tiene una puntación de tres debido a que solo atenderá a con solo un producto; (e) la intensidad de la competencia alcanza un peso elevado de $10 \%$ por ser relativamente de alta competitividad, PrestaMas tiene la puntación de tres por ser nueva; (f) la rentabilidad de la industria tiene un peso de $15 \%$ por ser atractiva, PrestaMas tiene la máxima puntación de cinco basado en la operación a través de la infraestructura de otras entidades financieras que llevaría a un ahorro en costos fijos; (g) el nivel tecnológico un peso de $10 \%$ porque la industria micro financiera tienen una tecnología crediticia desarrollada y PrestaMas tiene la puntación de tres debido a que prevé contar con personal de experiencia en cajas municipales y cooperativas de ahorro y crédito; (h) en cuanto al impacto ambiental el peso de 5\% por ser relativamente bajo y está asociado al financiamiento de actividades responsables, PrestaMas registra tres de puntación; (i) en cuanto al entorno de la empresa hay un peso moderado de $10 \%$, por la baja injerencia en la actividad de PrestaMas, para la empresa PrestaMas la puntación es de tres, tal como indica la Tabla 5.

De acuerdo al análisis de los Factores Internos: (a) la participación en el mercado representa un peso elevado de $15 \%$, la industria tiene una madurez de cerca de 30 años lo que ha permitido a las entidades alcanzar un grado de participación exclusiva y compartida con otra entidad financiera, observándose hoy que se atiende solicitudes a quienes en conjunto no superen tres entidades, PrestaMas tiene la mínima puntación de uno debido a que es una empresa nueva; (b) referente a los Costos unitarios tienen un peso relativamente bajo de 5\% debido al grado de madurez de las carteras, que ha permitido distribuir los altos costos fijos en los créditos otorgados. 
Tabla 5

Análisis de los Factores Externos

\begin{tabular}{lcr}
\hline \multicolumn{1}{c}{ Entidad Financiera } & Saldo de Cartera & Participación \\
\hline Tamaño del mercado & $20 \%$ & 5 \\
Precios & $10 \%$ & 2 \\
Crecimiento del Mercado & $10 \%$ & 5 \\
Diversidad del Mercado & $10 \%$ & 3 \\
Intensidad de la Competencia & $10 \%$ & 3 \\
Rentabilidad de la Industria & $15 \%$ & 5 \\
Nivel tecnológico & $10 \%$ & 3 \\
Impacto ambiental & $5 \%$ & 3 \\
Entorno político, social, legislativo, & $10 \%$ & 3 \\
económico & $100 \%$ & 3.8
\end{tabular}

Fuente: Elaboración propia. Adaptado de "La Matriz atractivo del mercado- Posición del Negocio", www.deguate.com.

PrestaMas tiene la mínima puntación de tres debido a que evitará inversiones en costos fijos aprovechando las plataformas de las otras entidades para sus operaciones; (c) en lo concerniente a los canales de distribución la industria alcanza una ponderación baja de 5\%, en tanto para PrestaMas tiene la puntación de cinco dado a que usará las plataformas de todas las entidades financieras debido a que no hay impedimento de trasladar los costos del uso a sus clientes; (d) en lo concerniente a la calidad del producto o servicio la industria alcanza una ponderación baja de 10\%, exigido a la estricta reglamentación y supervisión de los entes reguladores y a los esfuerzos alcanzados por las empresas del sistema micro financiero en tanto para PrestaMas, tiene la puntación de elevada de cuatro dado que el recurso humano a contar, quienes tienen la experiencia y solvencia moral comprobada superior a 12 años en el mercado; (e) en lo concerniente a la imagen de la marca la industria alcanza una ponderación de $15 \%$ debido al cuidado en el buen nombre de las empresas de mostrarse solventes, liquidas, rentables, transparentes y socialmente responsables, en tanto para PrestaMas tiene la puntación de tres asociado a ser nueva y a la crítica de sujetos bancarizados por las tasas de 
interés a cobrar, entendiéndose que aquellos sujetos no son objeto de atención, sino los no bancarizados e informales;(f) la capacidad productiva de la industria alcanza una ponderación de $10 \%$ entendiéndose por la disponibilidad de fondeo por captación de ahorros para la posterior colocación de créditos permitiéndose apalancar hasta nueve el patrimonio, en tanto para PrestaMas tiene la puntación de cuatro asociado a que el segmento de microcréditos no exige apalancarse al nivel de la banca y se cuenta con los recursos financieros al 100\% por los asociados accionistas y hay potenciales interesados en invertir principalmente son funcionarios de otras entidades financieras, interesados en elevar el rendimientos de sus fondos de ahorro que oscilan entre $2 \%$ y $8 \%$; (g) la capacidad gerencial de la industria muestra una ponderación de $20 \%$ debido a los logros alcanzados en el crecimiento de la industria en las últimas dos décadas y los reconocimientos internacionales, para PrestaMas tiene la puntación de cuatro asociado a que se cuenta con respaldo de jefaturas y gerencias con gran experiencia entre sus asesores; y , la facilidad de acceso y entendimiento de capacitaciones, revisión de literaturas de artículos académicos de la industria; (h) el nivel tecnológico de la industria muestra una ponderación de 15\%, adicional a las oficinas, la banca por teléfono, banco electrónica, banca por internet así como por la disponibilidad de equipos ATM, cajeros corresponsales, entre otros medios de pago descentralizados para operar con efectivo, con tarjeta de crédito o débito, para PrestaMas tiene la puntación de cuatro asociado a que la oferta de la industria y la banca permite operar con la asistencia de un buen software en red en la infraestructura de la industria; (i) el desempeño en investigación y desarrollo de la industria muestra una ponderación de 5\% en tanto que para PrestaMas tiene la puntación de tres por no requerir modificaciones sobre un solo producto, como e indica en la Tabla 6.

La matriz atractiva del mercado-posición competitivo de la unidad estratégica de negocios que se muestra en la Figura 3 basada en el análisis de dos dimensiones principales factores internos y factores externos identifica la intersección de los valores totales obtenidos de las tablas de valoración, tal como indica la Tabla 6. 
El análisis coloca a la industria en una posición competitiva alta del negocio de créditos y un alto atractivo de los mercados de del negocio de créditos que se muestra en la Figura 1

\section{Tabla 6}

Análisis de los Factores Internos

\begin{tabular}{lrr}
\hline \multicolumn{1}{c}{ Entidad Financiera } & Saldo de Cartera & Participación \\
\hline Participación en el mercado & $15 \%$ & 1 \\
Costos unitarios & $5 \%$ & 3 \\
Canales de distribución & $5 \%$ & 5 \\
Calidad del producto o servicio & $10 \%$ & 4 \\
Imagen de la marca & $15 \%$ & 3 \\
Capacidad productiva & $10 \%$ & 4 \\
Capacidad gerencial & $20 \%$ & 4 \\
Nivel tecnológico & $15 \%$ & 4 \\
Desempeño en investigación y desarrollo & $5 \%$ & 3 \\
& $100 \%$ & 3.4
\end{tabular}

Fuente: Elaboración propia. Adaptado de "La Matriz atractivo del mercado- Posición del Negocio", www.deguate.com.

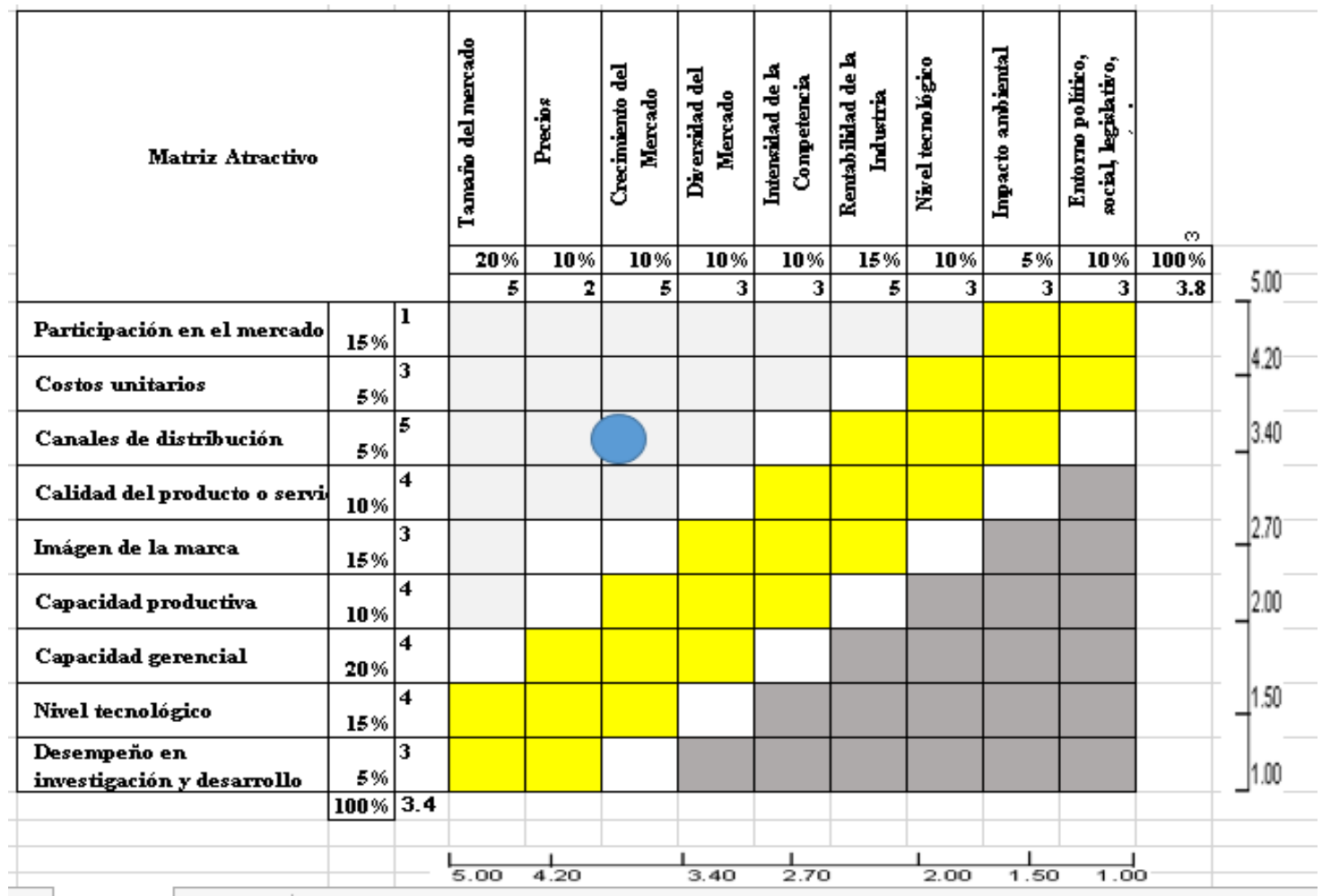

Figura 1. Atractivo de la Industria de Créditos y microfinanzas

Fuente: Elaboracion Propia con información de los especianlistas entrevistados 
Con la base de las entrevistasse elaboró la clasificacion de modulos de empresa de acuerdo a indicadores de variedad de producto, ámbito influencia, calidad de producto - precio, horario de atención, servicios, canales de atención, promociones; nivel de repútacion, calidad de productos, disponibilidad de productos, calidad de servicio, calidad para el seguimiento de quejas, tal como indica la Tabla 7,8, y 9.

Tabla 7

Variedad de Producto, Ámbito Influencia, Calidad de producto y Precio

\begin{tabular}{llllc}
\hline & Variedad & Ambito de Influecia de Competidores & Calidad & Precio \\
\hline Bancos & Bueno & Todos los segmentos excepto informales & Bueno & Bajo \\
Financiera & Regular & Mediana, pequeña empresa y consumo & Bueno & Medio \\
Caja Municipal & Regular & Mediana, pequeña empresa , consumo e & Bueno & Medio \\
Caja Rural & Regular & informales & Regular & Medio \\
Edpymes & Regular & Mediana, pequeña empresa y consumo e & Regular & Medio \\
Cooperativas & Regular & Mediana, pequeña empresa y consumo & Regular & Medio \\
ONGs & Malo & Mediana, pequeña empresa y consumo & Regular & Alto \\
Banco Comunal & Malo & Informales y no bancarizados & Regular & Alto \\
Casa Comercial & Malo & Informales y no bancarizados & Regular & Alto \\
PrestaMas & Malo & Todos los segmentos & Regular & Alto \\
& & Todos los segmentos & &
\end{tabular}

Fuente: Elaboración propia de entrevistas con especialistas.

\section{Tabla 8}

Horario de Atención, Servicios, Canales de Atención, Promociones.

\begin{tabular}{lllll}
\hline & Horario & Servicios & $\begin{array}{l}\text { Canal de } \\
\text { Distribución }\end{array}$ & Promoción \\
\hline Bancos & Oficina & Ahorro, creditos, cobros y recaudo & Propio - terceros & Alta \\
Financiera & Oficina & Ahorro, creditos, cobros & Propio - terceros & Media \\
Caja Municipal & Oficina & Ahorro, creditos, cobros & Propio - terceros & Media \\
Caja Rural & Oficina & Creditos, cobros & Propio - terceros & Media \\
Edpymes & Oficina & Ahorro en sociedad, créditos & Propio - terceros & Alta \\
Cooperativas & Oficina & Créditos, ahorro garantía & Propio - terceros & Media \\
ONGs & Oficina & Créditos, ahorro pandero - junta & Propio - terceros & Baja \\
Banco Comunal & Oficina & Créditos, empeño & Terceros & Baja \\
PrestaMas & Oficina & Crédito. & Propio - terceros & Baja
\end{tabular}




\section{Tabla 9}

Nivel de reputación, Calidad de Productos, Disponibilidad de Productos, Calidad de Servicio, Calidad para el seguimiento de quejas

\begin{tabular}{llllll}
\hline & Reputación & $\begin{array}{l}\text { Calidad de } \\
\text { Productos }\end{array}$ & $\begin{array}{l}\text { Disponibilidad } \\
\text { de Productos }\end{array}$ & $\begin{array}{l}\text { Calidad } \\
\text { Servicio }\end{array}$ & $\begin{array}{l}\text { Calidad } \\
\text { Seguimiento } \\
\text { Quejas }\end{array}$ \\
\hline Bancos & Alta & Alta & Alta & Alta & Alta \\
Financiera & Media & Media & Alta & Alta & Media \\
Caja Municipal & Alta & Alta & Alta & Alta & Alta \\
Caja Rural & Media & Media & Alta & Media & Media \\
Edpymes & Media & Media & Alta & Media & Alta \\
Cooperativas & Baja & Alta & Alta & Alta & Media \\
ONGs & Media & Alta & Media & Media & Media \\
Banco Comunal & Media & Media & Media & Media & Media \\
Casa Comercial & Media & Media & Alta & Media & Media \\
PrestaMas & Media & Media & Alta & Media & Media \\
& & & & & \\
\hline
\end{tabular}

Fuente: Elaboración propia de entrevistas con especialistas.

\subsubsection{Empresas que la conforman y su participación de mercado}

A diciembre del 2015 en San Juan de Lurigancho se registra una atomización de ofertantes informales y formales no supervisados que atienden más del $10 \%$ respecto la oferta formal de S/ 735,214.47 (Semana Económica - Verónica Zapata), en cuanto a la participación de mercado formal supervisado hay presencia de 19 entidades financieras tal como indica la Tabla 10 y 11.

\section{Tabla 10}

Composición de la Oferta de Microfinanzas

\begin{tabular}{lcc}
\hline \multicolumn{1}{c}{ Entidad Financiera } & Saldo de Cartera & Participación \\
\hline Total Entidades Financieras & $735,214.47$ & $100.00 \%$ \\
Empresas Formales no supervisadas e & $73,521.45$ & $10 \%{ }^{1}$ \\
informales & \\
\hline${ }^{1}$ Porcentaje Empresas Formales no supervisadas e informales respecto Saldo Entidades Financieras Formales
\end{tabular}




\subsubsection{Matriz de perfil competitivo}

A fin de identificar, evaluar los objetivos, estrategias, debilidades y fortalezas de los competidores la herramienta de "entrada" que resume la información decisiva sobre los competidores es la Matriz de Perfil Competitivo, la cual responde a las siguientes cuestiones:

¿Quiénes son nuestros competidores?,

¿Qué factores claves son los de mayor importancia para tener éxito en la industria?, ¿Cuál es la importancia relativa de cada factor decisivo para el éxito de la industria?, Hasta ¿qué punto es importante cada competidor fuerte o débil en cada factor decisivo del éxito? y en general

¿Qué tan fuerte o débil es cada competidor importante?

Las ponderaciones otorgadas en la evaluación de la matriz de perfil competitivo se han determinado a raíz de las entrevistas desarrolladas a 7 especialistas en el rubro de micro finanzas.

Sólo se considera una ponderación de $10 \%$ en el aprovechamiento de la plataforma de operaciones para brindar servicios que generen otros ingresos, para la Gerente de Agencia del MI Banco Janet Roque Bernabel y Jefe de Agencia Raul Quispe Soncco es atractivo por la variedad de productos que ofrecen de la entidades financieras y el tamaño de la empresa en la cual laboran en tanto que para el resto de entrevistados consideran que distrae la operatividad de créditos, ahorros, tal como indica la Tabla 12.

Se considera una ponderación de $10 \%$ en la dilución de costos fijos por uso de plataformas externas, por el celo de compartir la data de clientes que manifiestan nueve de los siete encuestados. 


\section{Tabla 11}

Saldo de Créditos en San Juan de Lurigancho al 31 de diciembre de 2015 en Miles de soles.

\begin{tabular}{|c|c|c|}
\hline Entidad Financiera & Saldo de Cartera & Participación \\
\hline MiBanco & $291,127.73$ & $39.60 \%$ \\
\hline Crediscotia & $63,443.48$ & $8.63 \%$ \\
\hline Financiera Confianza & $60,605.16$ & $8.24 \%$ \\
\hline CMAC Huancayo & $57,473.90$ & $7.82 \%$ \\
\hline Compartamos Financiera & $45,597.85$ & $6.20 \%$ \\
\hline CMAC Arequipa & $38,147.68$ & $5.19 \%$ \\
\hline CMAC Sullana & $37,455.92$ & $5.09 \%$ \\
\hline Financiera Pro empresa & $26,829.51$ & $3.65 \%$ \\
\hline Edpyme Raíz & $22,683.10$ & $3.09 \%$ \\
\hline CMAC Trujillo & $19,113.24$ & $2.60 \%$ \\
\hline Financiera Qapaq & $18,955.06$ & $2.58 \%$ \\
\hline Crac Prymera & $12,021.40$ & $1.64 \%$ \\
\hline CMAC Cusco s a & $11,119.29$ & $1.51 \%$ \\
\hline Financiera Efectiva & $10,564.12$ & $1.44 \%$ \\
\hline CML & $7,975.72$ & $1.08 \%$ \\
\hline GMG servicios Perú & $6,901.16$ & $0.94 \%$ \\
\hline CMAC Piura & $3,574.07$ & $0.49 \%$ \\
\hline Inversiones la Cruz & $1,343.11$ & $0.18 \%$ \\
\hline Financiera TFC SA & 283.00 & $0.04 \%$ \\
\hline \multirow[t]{2}{*}{ Total Entidades Financieras } & $735,214.47$ & $100.00 \%$ \\
\hline & $73,521.45$ & $10 \%^{1}$ \\
\hline
\end{tabular}

Elaboración Propia. Fuente. Estadísticas SBS a Diciembre 2015. Información por Tipo de Institución Financiera.http://www.sbs.gob.pe/principal/categoria/sistema-financiero/148/c-148 


\section{Tabla 12}

Entrevistados especialistas en Microfinanzas

\begin{tabular}{lll}
\hline Nombre & Empresa & Cargo \\
\hline Alex Lenin Letona & Cooperativa FinanSur & Administrador de Agencia \\
García & Mi Banco & Ex Asesor de créditos en SJL \\
Janet Roque Bernabel & & Gerente Agencia Mi banco \\
& Kuskalla e Independiente & Ex Asesor y ex Gerente Coop. San Hilarión \\
Jorge Efraín Peralta Cruz & & Gerente Kuskalla y Consultor. \\
& Financiera Confianza & Ex gerente general Cooperativa San Hilarión \\
José Muñoz Fernández & & Jefe Regional Arequipa \\
& Caja Arequipa & Ex Asesor y administrador de créditos en SJL \\
Jorge Merma Lobatón & Crediscotia & Asesor Sénior de Créditos \\
Raúl Quispe Soncco & & Jefe de Agencia \\
& Caja Arequipa & Ex Asesor de créditos en SJL \\
Rafael León Velarde & & Jefe Zonal Centro \\
& & Ex Administrador de créditos en SJL
\end{tabular}

Fuente: Elaboración propia

El nivel de morosidad representa un 10\%, debido a que hay profundidad en las evaluaciones de los créditos con un trabajo arduo en la elaboración de estados financieros que determinan la capacidad de pagos y en la visita al domicilio para determinar voluntad de pago que representa la parte cualitativa, respondiendo la mora a otros factores externos. Para el Jefe de Agencia Raul Quispe Soncco minimiza el impacto por contar con SCI como canal de recuperaciones, en tanto que la Gerente de Agencia MiBanco Janet Roque Bernabel considera que es mejor concentrar esfuerzos en el crecimiento de la cartera y en créditos de mayor cuantía, sobre concentrarse exclusivamente en la recuperación, optando por el castigo de cartera como herramienta para sincerar la cartera de créditos con problema de recuperación (provisionar al 100\% la cartera en morosidad) los demás encuestados por el 
contrario indican que el control de la morosidad obedece a las actividades realizadas por los asesores de créditos dentro de sus funciones y la asociación con sus ingresos variables.

La tecnología aplicada a los procesos tiene un peso del 10\%, exige desde consultar centrales de riesgos, evaluación crediticia e inspección in situ y exposición de propuestas en comités de créditos, asegura una cartera sana de crecimiento sostenido, el Analista Sénior de Créditos Jorge Merma Lobatón y el Jefe Zonal Centro Rafael León Velarde inciden en el cumplimiento de la tecnología, en tanto que, para el Gerente de Agencia del MI Banco Janet Roque Bernabel y Jefe de Agencia Raul Quispe Soncco, ambos valoran el crédito pre aprobado por uso del scoring de crédito dado que les permite un mayor volumen de colocaciones sin cumplir el circuito de evaluación de créditos descrito, los demás encuestados consideran importante el circuito del crédito con el aprovechamiento por campañas, el uso de un scoring interno. El consultor, ex Gerente General Cooperativa San Hilarión Jorge Efraín Peralta Cruz enfatiza que obviar tecnología aplicada a los procesos, al cual denomina la piedra angular en las empresas financieras conlleva a problemas en las CRACs en el alto indicie de morosidad, provisión y registro de pérdida en ejercicios financieros.

Los productos acordes a la necesidad del mercado representan un $8 \%$, para las empresas micro financieras, para el Gerente de Agencia de MiBanco Janet Roque Bernabel y Jefe de Agencia Raul Quispe Soncco son el mayor el atractivo por la disponibilidad de ofertas y más variedad de productos. La rentabilidad tiene un peso del 10\%, es resaltado por el Analista Sénior de Créditos Jorge Merma Lobatón y el Jefe Zonal Centro Rafael León Velarde, ambos entrevistados de Caja Municipal, en tanto que los demás resaltan la participación del mercado y la mayor cantidad de servicios financieros que puedan brindar.

El servicio post venta con un peso del 8\%, resalta la valoración de la Gerente de Agencia del MI Banco Janet Roque Bernabel y Jefe de Agencia Raul Quispe Soncco, en tanto que el Jefe Regional Arequipa José Muñoz valora la venta cruzada de productos en los clientes en el 
servicio post venta. El conocimiento y dominio de la plaza del negocio por concentración geográfica adquiere un peso del 8\%, destacan el Administrador de Agencia Alex Lenin Letona García, Analista Sénior de Créditos Jorge Merma Lobatón, Consultor - ex Gerente General Cooperativa San Hilarión Jorge Efraín Peralta Cruz, enfatizando el respeto irrestricto de la zonificación, en tanto que para el resto indican que contar con el scoring es una alternativa rápida, que permite atender sin necesidad de conocimiento y dominio de la plaza del negocio.

La rapidez en la atención impacta en un $10 \%$ en, pues el dinamismo alcanzado por los clientes exige una atención de horas para montos mínimos y una semana en los créditos con garantía hipotecaria, siendo el estándar de la atención en 24 horas. Todos los entrevistados coinciden la importancia de brindar rapidez en la atención.

El posicionamiento alcanza un $8 \%$, para la gerente de agencia Janet Roque Bernabel es inclusive de mayor valor por la presencia en el mercado, en tanto que los demás entrevistados observan que el posicionamiento es relativo por la alta competencia, observándose una alta rotación de clientes, compras de deudas asociadas con los pase de funcionarios de créditos entre entidades financieras.

El nivel de satisfacción del cliente adquiere un peso de 8\%, los especialistas; Jorge Efraín Peralta Cruz Consultor / ex Gerente General Cooperativa San Hilarión y Rafael León Velarde Jefe Zonal Centro valoran la calidad de atención, los demás entrevistados valoran la satisfacción del cliente como parte del servicio, reforzando las capacitaciones entre sus colaboradores como herramienta de trabajo. Janet Roque Bernabel Gerente de Agencia del MI Banco y Raul Quispe Soncco Jefe de Agencia que las metas altas llevan a los funcionarios a descuidar el nivel de calidad en la atención al cliente por incurrir en omisiones en la explicación de los beneficios del producto. Las clasificaciones otorgadas a cada módulo de empresa financiera son: 1 = Debilidad grave; 2 = Debilidad menor; 3 = Fortaleza menor; y, 4 = Fortaleza importante. 


\section{Tabla 13}

Matriz de Perfil Competitivo

\begin{tabular}{|c|c|c|c|c|c|c|c|c|c|c|c|c|c|}
\hline \multirow{2}{*}{ Factores de Éxito } & \multirow{2}{*}{ Peso } & \multicolumn{2}{|c|}{ CMAC'S } & \multicolumn{2}{|c|}{ CRAC's } & \multicolumn{2}{|c|}{ Financiera } & \multicolumn{2}{|c|}{ Cooperativas } & \multicolumn{2}{|c|}{ ONG's } & \multicolumn{2}{|c|}{ Informales } \\
\hline & & C. & P. & C. & P. & C. & P. & C. & P. & C. & P. & C. & P. \\
\hline $\begin{array}{l}\text { Aprovechamiento de plataforma de } \\
\text { operaciones para brindar servicios } \\
\text { que generan otros ingresos }\end{array}$ & $10 \%$ & 2 & 0.20 & 2 & 0.2 & 3 & 0.30 & 3 & 0.30 & 3 & 0.30 & 3 & 0.30 \\
\hline $\begin{array}{l}\text { Dilución de Costos Fijos por uso } \\
\text { de plataformas externas }\end{array}$ & $10 \%$ & 2 & 0.20 & 1 & 0.1 & 3 & 0.30 & 2 & 0.20 & 4 & 0.40 & 2 & 0.20 \\
\hline Nivel de morosidad & $10 \%$ & 3 & 0.30 & 1 & 0.1 & 2 & 0.20 & 3 & 0.30 & 3 & 0.30 & 2 & 0.20 \\
\hline Tecnología aplicada a procesos & $10 \%$ & 4 & 0.40 & 2 & 0.2 & 3 & 0.30 & 2 & 0.20 & 3 & 0.30 & 2 & 0.20 \\
\hline $\begin{array}{l}\text { Producto acorde a las necesidades } \\
\text { de mercado }\end{array}$ & $8 \%$ & 3 & 0.24 & 2 & 0.16 & 4 & 0.32 & 3 & 0.24 & 2 & 0.16 & 3 & 0.24 \\
\hline Rentabilidad & $10 \%$ & 4 & 0.40 & 2 & 0.2 & 3 & 0.30 & 2 & 0.20 & 3 & 0.30 & 4 & 0.40 \\
\hline Servicio Post- Venta & $8 \%$ & 3 & 0.24 & 2 & 0.16 & 4 & 0.32 & 3 & 0.24 & 3 & 0.24 & 2 & 0.16 \\
\hline $\begin{array}{l}\text { Conocimiento y dominio de la } \\
\text { plaza de negocio por concentración } \\
\text { geográfica }\end{array}$ & $8 \%$ & 3 & 0.24 & 3 & 0.24 & 2 & 0.16 & 3 & 0.24 & 4 & 0.32 & 4 & 0.32 \\
\hline Rapidez en la atención & $10 \%$ & 3 & 0.30 & 2 & 0.20 & 4 & 0.40 & 4 & 0.40 & 3 & 0.30 & 4 & 0.40 \\
\hline Posicionamiento & $8 \%$ & 4 & 0.32 & 2 & 0.16 & 3 & 0.24 & 4 & 0.32 & 4 & 0.32 & 4 & 0.32 \\
\hline Nivel de satisfacción del cliente & $8 \%$ & 4 & 0.32 & 3 & 0.24 & 2 & 0.16 & 4 & 0.32 & 4 & 0.32 & 3 & 0.24 \\
\hline TOTAL & $100 \%$ & & & & 96 & & & & & & & & \\
\hline
\end{tabular}

Fuente: Elaboración Propia. Entrevistados 
Obtienen mayor puntaje las CMACs con 3.16 y las Financieras con 3.00, en tanto que el menor puntaje se registra con CRACs con 1.96. Las CMACs destacan por el cumplimiento de la tecnología financiera y la transparencia de sus operaciones, como indica la Tabla 13.

\subsection{Análisis del Contexto Actual y Esperado}

\subsubsection{Análisis Político Gubernamental}

Se considera para nuestro estudio la propuesta del presidente electo en su plan de gobierno en mejora para la micro empresa, y el impacto que puede tener en nuestro Plan de Negocios, como indica en la Tabla 14.

\section{Tabla 14}

Propuestas del candidato y Actual Presidente para el periodo 2016-2021

\begin{tabular}{lll}
\hline \multicolumn{1}{c}{ Agrupación } & \multicolumn{1}{c}{ Aportes y prouestas } & Impacto en PrestaMas \\
\hline Peruanos por el Kambio & Régimen especial tributario para las empresas & Mejora de identificación de \\
& pequeñas que se formalicen. & actividades económicas. \\
& Infraesrtructura pistas, veredas, agua, desagüe. & Demanda de servicios de \\
& Inversión pública para la construcción de & Estas obras se desarrollan en \\
& colegios, infraestructura de primer nivel así & zonas donde PrestaMas \\
como la masificación del servicio de agua & identifica su nicho, ello \\
potable & conlleva a la creación y \\
& desarrollo de actividades
\end{tabular}

Elaboración Propia. Fuente: Planes de Gobiernos 2016-2021

\subsubsection{Análisis Económico}

La demanda interna sostiene la actividad de los pequeños y micro empresarios, contrarresta la caída del crecimiento del PBI, como se indica en la Tabla 15. 


\section{Tabla 15}

Entorno Económico

\begin{tabular}{lll}
\hline \multicolumn{1}{c}{ Suceso-Tendencia } & Clientes-Proveedores & Impacto en PrestaMas \\
\hline PBI crece a 4.8\% 2016 (e) & Nueva oportunidad de & Demanda de créditos de las empresas locales \\
& negocio & \\
Confianza del consumidor & Transacciones comerciales & Incremento de la demanda de créditos de las \\
eleva la demanda interna & recurrentes & empresas locales \\
Inflación de 3.5\% 2016 (e ) & Poder adquisitivo estable. & Mínimo sobre costo por inflación. \\
\hline Fuente: MEF MME 2016-202. Elaboración Propia. & \\
\hline
\end{tabular}

Expectativas de crecimientos del PBI de 3,28\% en el 2016, con posible sesgo a elevarse hasta un $4.8 \%$ para el 2016 con un fenómeno del Niño moderado y la fortaleza de los indicadores macroeconómicos del país.

Para el MEF, la inflación esperada hacia el 2016 y 2017 es del 2.0\%, se encuentra afectada con expectativa al alza del 3,5\% por: (a) el incremento de los costos de materias primas importadas por el incremento de tipo de cambio; y, (b) el Fenómeno del Niño que generó escasez de productos por afectación en las cosechas, la disponibilidad de pastos y temperaturas extremas que diezman el ganado. Decae la proyección de los ingresos, costos y ganancias esperadas nominales y reales para las IFIS, los clientes no alcanzan a incorporar distorsión de precios en sus costos asociados a pérdida de poder adquisitivo, las expectativas menores, costos de energía por la caída del precio del petróleo no alienta la expectativa de reducción de la inflación. Los entrevistados argumentan que con la experiencia de los 80`s, las instituciones micro financieras hoy pasan índices de rentabilidad mayor al 20\% anual. La disciplina macroeconómica del país favorece el entorno de las microfinanzas, para el ex Gerente General de la Cooperativa San Hilarión Jorge Efraim Peralta, tal como se indica en laTabla 16.

Para San Juan de Lurigancho que adolece de un plan de formalización de empresas cuenta con 184 establecimientos asociados a entidades financieras y seguros que facilitan el acceso 
de transferencias de dinero para las diferentes transacciones comerciales que se desarrollan en el distrito más de 100000 unidades micro económicas

\section{Tabla 16}

Entrevistados especialistas en Microfinanzas

\begin{tabular}{|c|c|c|}
\hline Nombre & Empresa & Cargo \\
\hline Dario Emilio Enriquez & Independiente & $\begin{array}{l}\text { Consultor independiente, ex } \\
\text { gerente regional CMAC }\end{array}$ \\
\hline Jorge Efraim Peralta Cruz & Independiente & $\begin{array}{l}\text { Ex General Coop San Hilarión } \\
\text { Consultor independiente, }\end{array}$ \\
\hline Luís Rivera Villegas & $\mathrm{BCP}$ & $\begin{array}{l}\text { Gerente Agencia } \\
\text { Jefe Zonal Centro }\end{array}$ \\
\hline $\begin{array}{l}\text { Rafael León Velarde } \\
\text { Roger Arevalo Herreros }\end{array}$ & $\begin{array}{l}\text { Caja Arequipa } \\
\text { Independiente }\end{array}$ & $\begin{array}{l}\text { Consultor independiente, ex } \\
\text { gerente regional CMAC }\end{array}$ \\
\hline
\end{tabular}

Elaboración Propia. Fuente: Planes de Gobiernos 2016-2021

\subsubsection{Análisis Legal}

Mayor incidencia de regulaciones y supervisiones, incentiva el acceso de empresas al segmento de microcréditos no regulado y supervisado, que no requiere mayor capital inicial y más de tres a cinco años de existencia para alcanzar el punto de equilibrio por la exigencia de más puestos de trabajo por empresa, más recursos económicos y financieros para más infraestructura física de inmueble, maquinaria y equipos, tal como se indica en laTabla 17

\section{Tabla 17}

\section{Entorno Legal}

\begin{tabular}{lll}
\hline Suceso-Tendencia & Clientes Proveedores & Impacto en PrestaMas \\
\hline Mayor reglamentacion, regulación & Menor oferta formal crediticia, & Oportunidad de participar como \\
y supervisión de empresa & decrecimiento de empresas por & empresa formal no supervisada. \\
regulada. & fusión. & Incentivo a operar como empresa \\
$\begin{array}{l}\text { Exigencia de mas departamentos y } \\
\text { puestos de trabajo de empresa }\end{array}$ & Tiempos de atención mayores & no regulada, dedicada solo al \\
regulada. & & microcredito. \\
\hline
\end{tabular}

Elaboracion: Propia. 
El presidente del Banco Central de Reserva del Perú Julio Velarde Viernes, afirmó que la adquisición de micro financieras por bancos grandes redujo la cantidad de créditos a las pequeñas y medianas empresas por criterios de otorgamientos de créditos más exigentes. Diario Gestión (2014) Recuperado de: http://gestion.pe/economia/adquisicion$\underline{\text { microfinancieras-bancos-grandes-redujo-creditos-pyme-y-subio-morosidad-2102727, }}$ favoreciendo la presencia de empresas como PrestaMas.

\subsubsection{Análisis Socio y Cultural}

Los conflictos sociales son la variable de menor control sobre la cual las instituciones microfinancieras y empresas dedicadas al crédito.

El manejo político condiciona situaciones que enfrentan a la población en escenario de protestas que obligan a la paralización temporal de todas sus actividades de las ciudades, provincias y departamentos, con ello el desarrollo de actividades en las plazas donde las instituciones microfinancieras y empresas dedicadas al crédito están presentes, frenando el crecimiento en las colocaciones y amenazando con el incremento en la cartera atrasada.

La delincuencia, sicariato, mafias y extorsiones inciden fundamentalmente en el incremento en costos de seguridad y pérdidas por robo en las unidades empresariales, desincentivando la actividad empresarial, PrestaMas tiene la oportunidad de brindar seguros y micro seguros, atender necesidades de financiamiento de actividades asociadas al servicio de vigilancia, video vigilancia, seguridad y comercialización de equipos de seguridad; así como de impulsar el uso de la banca móvil y el dinero electrónico como medidas de seguridad, como indica en la tabla 18 .

\subsubsection{Análisis Tecnológico}

Las oportunidades tecnológicas son herramientas fundamentales de bancarización que permitirá desconcentrar las operaciones en pocos clientes y reduciendo el promedio de 
colocación al ampliar la base de clientes. Sin embargo, la educación financiera y los niveles de seguridad que brinde la empresa son vitales para su éxito.

El uso de los celulares y Smart phones en el día a día, la oferta de mayor cobertura en telecomunicaciones (telefonía e internet), es oportunidad de negocios en banca móvil permitiendo a los cliente el ahorro en tiempo en realizar transacciones de manera presencial, se puede acondicionar y desarrollar el modelo exitosos de banca móvil en Kenya (Centro de Innovación del BBVA, 2015), la cual ha logrado el desarrollo de las Microfinanzas en muy corto tiempo elevándola a estándares de la banca tradicional en los países desarrollados.

\section{Tabla 18}

\section{Entorno Socio Cultural}

\begin{tabular}{lll}
\hline Suceso-Tendencia & Clientes Proveedores & Empresa \\
\hline Incremento de la delincuencia & Pérdida por robos, sobrecostos por & Demanda de polizas de seguros y \\
& seguridad. & microseguros. \\
Incremento del sicariato, mafias y & Pago de cupos, asaltos a mano & Menor rentabilidad por: (1) pago \\
extorsiones. & armada . & de cupos, (2) pérdidas de equipos \\
Incremento de Organizaciones & Servicios de seguridad y & de colaboradores de campo \\
delictivas de origen de Huascar, & vigilancia en crecimiento & (trabajo en la calle) y (3) costos de \\
Bayovar, San Hilarion. & Demanda de polizas de seguros y & Deguridad. \\
& microseguros & peligrosa. \\
& & actividades de seguridad.
\end{tabular}

Fuente: Elaboracion Propia.

Para el Perú, el dinero móvil es una oportunidad de explotación considerando la infraestructura y cobertura de telecomunicaciones existente, la cual no requiere de apertura de cuentas de débito o crédito previas y menos un Smart pone, solo un celular básico 2G, para 
aquellas personas no usuarias de celulares, queda la opción de transferencia por banco con la apertura previa de cuentas de débito, crédito o el solo el DNI vigente y sin multas pendientes por no haber sufragado a través de las plataformas de los bancos en agencias, cajeros ATM o banca corresponsal como los agentes, como indica en la tabla 19.

\section{Tabla 19}

\section{Entorno Tecnológico}

\begin{tabular}{lll}
\hline Suceso-Tendencia & Clientes Proveedores & Empresa \\
\hline "Dinero Móvil": 60 mil afiliados & Afiliación “Tu Dinero Móvil” & Transferencias por celuares, \\
(2015), (e) 16,5 millonres (2018) & anexada al número celular de & penetración de la telefonía móvil \\
en un mercado de 30 millones de & montos con importes promedio S/ & es 80\%, sin cuenta bancaria, ni \\
líneas activas (2014). & 300 mes. & smartphone. \\
Transferencia de dinero bancaria & Trasnferencia a cuenta bancaria, & Transferencias por canal bancario. \\
& de crédito o DNI. & Atencion a traves de plataformas \\
& Requerimiento de saldos de dinero & moviles y dienro electronico. \\
& con cargo a créditos y traslado de & \\
& pagos desde negocio o & Oferta de canal de pagos ágil con
\end{tabular}

Elaboracion: Propia . Fuente Gestion y Perú 21

\subsection{Oportunidades}

Fomentar en la zona de influencia San Juan de Lurigancho la educación e inclusión financiera a través de PrestaMas, la cultura de pago, basada en la confianza y en el empleo de tecnologías de crédito adecuadas con rigurosidad en la evaluación.

Recuperar la pérdida de identidad de los asesores de crédito quienes se encargan de la evaluación de sus prestatarios y todo el ciclo del crédito: (a) promoción, (b) evaluación, (c) seguimiento y recuperación de los créditos otorgados, conviniendo que cada analista de créditos se ocupa de una cartera de 300 clientes aproximadamente, con apoyos del área de 
riesgos en la colocación, gestores de cobranza en la recuperación; que en conjunto a mermando la rentabilidad de las organizaciones crediticias.

Sustituir la falta de información y la carencia de garantías reales, por el desarrollo de las competencias del analista de créditos para especializarse en la generación de su propia información, procesamiento y evaluación con la finalidad de escoger a los verdaderos sujetos de crédito. El riesgo crediticio se gestiona a partir de la estimación de la probabilidad de la intención de pago y de incumplimiento/ pérdida y la selección de clientes idóneos.

Compensar los altos costos fijos del trabajo hormiga de la reducida escala de operación con una tasa de interés en los créditos superior a la media por ser característica de los microcréditos, PrestaMas fija sus márgenes de ganancia al eludir la estructura de competencia perfecta, al no ser tomadora de precios por gozar de poder de negociación con los clientes y atender a los solicitantes del segmento micro financiero que usualmente no acceden o cuentan con fuentes de financiamiento alternativo más costosas.

Generar ingresos al ofrecer el servicio de medios de recaudación con el cobro de comisiones, las cuales ofrecen ventajas al competir con el costo de transporte y el tiempo de demora en la transacción.

Atención de transacciones mediante los teléfonos móviles permitirá una mayor inclusión financiera (https://dineroenmovimiento.wordpress.com/tag/inclusion-financiera/page/2/, 2012), este mecanismo abarata el sistema de medios de pago, además de impulsar la inclusión de grandes grupos poblacionales que se encuentran alejados geográficamente o que tradicionalmente no han sido incorporados al sistema financiero.

Brindar la plataforma de ahorro o la modalidad de inversión a interesados en lograr rendimientos superiores a los que la actual oferta de ahorros en la modalidad de depósitos a plazo fijo ofrece la industria que alcanza un techo de $8 \%$. 


\subsection{Conclusiones}

- La influencia política favorece poco al segmento de la industria a través del control de precios o apertura una empresa estatal al microcrédito.

- La SBS y el BCRP, aportan innovaciones legales que permiten ofrecer nuevos productos financieros, pero frenan el acceso de más empresas micro financieras, por el contrario fomenta la concentración de la industria y alienta el desarrollo de organizaciones crediticias no supervisadas que favorece a la inclusión, pero expone un financiamiento paralelo al sistema financiero regulado.

- Los gobiernos locales influyen en las actividades comerciales en zonas ambulantes como avenidas o espacios libres cuyos permisos se condicionan a la adhesión al gobierno local.

- La demanda de microcréditos aumentará hasta el nivel del pleno empleo, permitiendo otorgar créditos en condiciones estables lejos de escenario de procesos de hiperinflación por recalentamiento de la economía.

- La tecnología de celular permite la incursión del dinero móvil desde las plataformas comerciales.

- Las agencias financieras, las tecnologías de cajeros automáticos, cajeros corresponsales, agentes, el internet permite la incursión de la banca por teléfono, banca móvil, y banca por internet.

- Los fenómenos sociales, favorecen la oferta crediticia a actividades de seguridad y brindar servicio en transacciones con otras formas alternativas de dinero físico a través de dinero móvil y la banca. 
- La estructura de mercado en el segmento del microcrédito deja espacio para incursión de PrestaMas con dominio local y atención rápida con precios altos de tasa de interés que permiten márgenes de ganancia y capitalizaciones de patrimonio sobre el $30 \%$.

- Las reglas de fortalecimiento y mecanismos de supervisión del sistema no contemplan el impacto en la creación de empresas que exige mayor capital inicial y más tiempo al promedio histórico de tres años para recuperar la inversión, alcanzar el punto de equilibrio y brindar rentabilidad para el crecimiento de nuevas empresas. 


\section{CAPITULO III: $\quad$ ESTUDIO DE MERCADO}

\subsection{Descripción del servicio o producto}

PrestaMas brindará un producto financiero denominado crédito directo, para actividades económicas con exigencia de fondos para capital de trabajo o activo fijo denominados "créditos productivos", en montos desde 300 a 1000 soles para la micro empresa con plazos promedio de 12 semanas de rápido retorno.

\subsection{Selección del segmento de mercado}

La segmentación demográfica comprende a personas de 18 a 70 años de edad de ambos sexos, respecto a la segmentación socioeconómica está constituida el segmento C, D y E del distrito, cuyos ingresos superen los 35 soles diarios (resultado neto superior de 17 soles). Correspondiente a los aspectos psicográficos el mercado corresponde a emprendedores con estilos de vida, proactivos progresistas, quienes son micro empresarios formales e informales en proceso de formalización cuya demanda de montos de créditos es muy pequeña, inmediata y sencilla. La especialización micro financiera de la ONG asegura su crecimiento y desarrollo considerando que países con mayor PBI per cápita ala del peruano tienen un crédito promedio mucho más bajo:

Si bien el Perú presenta la tercera penetración más alta en el segmento de la región (es atendido el $33.9 \%$ de los potenciales clientes), dicha penetración dista de ser homogénea, manteniendo una concentración en ambientes urbanos y en los estratos altos del segmento. El crédito promedio en Perú es de US\$2,209, más de seis veces que los US\$ 348 que tiene el crédito promedio en México. Fernández, G (2012) El costo de ser primero: el dilema de la industria de las microfinanzas en el Perú. Recuperado de: http://www.esan.edu.pe/conexion/actualidad/2012/05/15/industria$\underline{\text { microfinanzas-peru/ }}$ 
Se desarrolla la opción de downsizing "por los segmentos inferiores o bajos" permiten obtener un mayor margen de beneficios y son la base de crecimiento de la cartera de créditos.

\section{Tabla 20}

Características de Segmentación

\begin{tabular}{|c|c|}
\hline Características & Descripción \\
\hline Necesidades por satisfacer & $\begin{array}{l}\text { Crédito de menor cuantía para actividades productivas de micro y } \\
\text { pequeñas empresas. }\end{array}$ \\
\hline Ingresos de las Actividades & Personas con ingresos diarias de 35 soles a más con \\
\hline Económicas & Necesidades financieras de montos de 300 a 1000. \\
\hline Demanda de Créditos & $\begin{array}{l}\text { Distrito de San Juan de Lurigancho: } 1069000 \text { habitantes con } 117 \\
435 \text { micro empresas. }\end{array}$ \\
\hline Distribución Geográfica & Mujeres y hombres de 18 a 70 años de edad. \\
\hline Segmentación Demográfica & Segmento C, D y E. \\
\hline Segmentación Socioeconómica & \\
\hline Estilo de Vida & Proactivos progresistas. \\
\hline Predisposición a la evaluación, & La Tecnología basada en el seguimiento del ciclo completo del \\
\hline verificación de negocio y & crédito realizado por una sola persona o área. Implica un \\
\hline domicilio & fortalecimiento de las relaciones crediticias. \\
\hline Modalidad de Pago & $\begin{array}{l}\text { Frecuencia de pagos diaria, inter diaria o semanal con retornos de } \\
\text { cuatro a } 12 \text { semanas. }\end{array}$ \\
\hline
\end{tabular}

Fuente: Elaboración Propia

\subsection{Investigación Cualitativa}

Entrevistas a especialistas y focus groups desarrolladas, nos permiten obtener información, entender y modelar la oferta con una comprensión más profunda de las percepciones, sentimientos, motivaciones y deseos íntimos de las personas y por su adaptabilidad a cualquier tema. Se buscaron los siguientes objetivos de estudio:

- Determinar la percepción "insight”, captar, internalizar y comprender los fundamentos que revelan la demanda del micro crédito y los hábitos, gustos y 
preferencias del público objetivo (segmentos NSE C, D y E) del proyecto que se encontraría ubicado en San Juan de Lurigancho para negocios del distrito en términos de búsqueda y adquisición de una alternativa de financiamiento de crédito.

- Determinar el proceso de búsqueda y satisfacción de una necesidad de financiamiento de crédito que va desde la solicitud, evaluación, adquisición y repago de un crédito, las personas que intervienen ( el Asesor o funcionario y el gestor de recuperaciones y la imagen de la organización que brinda el servicio de créditos) y están a cargo de la búsqueda, quienes ejercen influencia (los usuarios de créditos y vecinos del solicitante), sus expectativas, anhelos, factores críticos de solicitar un crédito, así como sus miedos y barreras.

- Determinar quiénes influyen, así como el proceso, la determinación que cada uno tiene y cumple en el proceso de acceder a un financiamiento crediticio.

- Determinar con precisión la competencia relevante y las tácticas de marketing para la captación de prospectos de financiamiento de créditos y ventas.

- Determinar el nivel de aceptación y/o rechazo del proyecto financiamiento de créditos PrestaMas a nivel del distrito de San Juan de Lurigancho para el target definido.

\subsubsection{Proceso de Muestreo}

Se aplicaron las técnicas no probabilísticas por conveniencia, a fin de reclutar de los participantes voluntarios. Del universo de personas entre 18 y 70 años de edad con actividad económica propia con más de un año de antigüedad en el distrito San Juan de Lurigancho o residentes del distrito con actividad económica fuera del distrito con necesidades de financiamiento de créditos entre de S/ 300 a S/ 1500 para atender necesidades de Capital de Trabajo, Activo Fijo u otras necesidades. Se procedió a elegir la muestra de cuatro Focus Groups de seis participantes por cada grupo respondiendo a criterios de practicidad a fin de 
evitar riesgo de obtener resultados limitados, incompletos y/o sesgados, que conduzcan a conclusiones y decisiones erróneas.

\subsubsection{Diseño de Instrumento}

Respecto a la entrevista con los especialistas, se desarrolló entrevista a profundidad Semi estructurada o focalizada a expertos en Microfinanzas del distrito de San Juan de Lurigancho y Lima de ONGs, cooperativas, casas de préstamo, prestamistas informales y cajas municipales a fin de conocer acerca del mercado y la operatividad de la industria. En cuanto al Focus group, se plantearon preguntas por los miembros del grupo, validadas por la $\mathrm{Mg}$. Rodríguez Román Patricia; seleccionándose aquellas que permitían reconocer una empresa de créditos, identificando atributos e imagen de las empresas de créditos, la marca empresarial, crédito y preferencias de uso. Se desarrollaron cuatro Focus groups en el distrito de San Juan de Lurigancho cada uno a un grupo de 6 personas de 18 a 70 años de edad con una actividad micro económica del segmento C, D y E en el mes de marzo del 2016.

Se buscó a través de la investigación cualitativa del Focus group entender la concepción de la industria micro financiera, posicionamiento y agrupamiento de las empresas, encontrar diferencias, atributos valorados, así como identificar rechazo de prácticas empresariales. Posteriormente se evaluó el nivel de aceptación de los productos financieros de PrestaMas y se recabo información de lo que los clientes consideran se debe brindar.

\subsubsection{Análisis y procesamiento de datos}

- Destaca la Cooperativa San Hilarión como una alternativa de créditos con pagos diarios, inter diarios y principalmente semanales además de la forma tradicional de pago mensual al cual se accede asociándose con un aporte equivalente del $10 \%$ del crédito a solicitar, le siguen casas de Préstamo como Inversiones de la Cruz, prestamistas particulares y algunas ONGs de créditos. 
- El cobro de intereses y la exigencia de documentarios para la atención es mayor en las entidades formales y flexibles en las no formales.

- Por afluencia, los plazos de atención de desembolso y pagos de cuotas en las agencias son de 25 minutos hasta una hora, resultando incómodo a los clientes quienes y carecen de alternativas para realizar sus operaciones.

- Los atributos valorados de las empresas: la calidad de atención sin discriminación, rapidez, transparencia de información en costos de créditos, simplicidad de requisitos y la relación cordial con la entidad inclusive en situaciones difíciles del cliente (visita de cobradores por gestión de recuperación o mora).

- El asesoramiento es reconocido como un valor agregado de la empresa de créditos.

- Usuarios de créditos en entidades formales, acceden a créditos no formales por la rapidez y como alternativa de última instancia.

- Prima la solicitud de créditos es para invertir en los negocios.

\subsection{Investigación Cuantitativa}

Encuesta de demanda de micro créditos a establecimientos comerciales en el distrito de San Juan de Lurigancho, para determinar los factores de la demanda del microcrédito: precio, gustos y preferencias, ingresos, precios de bienes complementarios y precios de bienes sustitutos, tiempo de espera en la atención. Las encuestas son financiadas y desarrolladas por el grupo de estudio en una semana calendario. Para la elaboración del cuestionario se ha solicitado el apoyo de algunos especialistas a fin de interrogar y obtener respuestas que proporcionen información que pueda ser procesada de modo sencillo. 


\section{Objetivo general:}

Determinar la demanda existente de microcréditos y la viabilidad de la oferta que PrestaMas en el distrito de San Juan de Lurigancho, para impulsar el desarrollo de las transacciones financieras y comerciales que hoy implican gastos y pérdidas de tiempo.

\section{Objetivos específicos:}

- Determinar la magnitud de la población de 18 a 70 años de edad que demanda microcréditos.

- Definir e identificar los clientes idóneos de la demanda de microcréditos según género, edad, nivel educativo y rama de actividad de la población de 18 años y más de edad.

- Determinar las formas de acceso al microcrédito por ONG, cooperativa, casa de empeño, prestamista informal o empresas financieras.

- Determinar el tipo de competencia.

- Determinar el tipo de cliente por antigüedad.

- Identificar los patrones de demanda de microcrédito tradicional, según área geográfica urbana céntrica o de periferia y tipo de actividad económica.

- Determinar la accesibilidad al microcrédito, según área geográfica urbana céntrica o de periferia y tipo de actividad económica.

- Establecer los factores de la demanda del microcrédito y el grado de importancia relativo de cada uno.

- Conocer la percepción que tiene la población sobre la oferta del microcrédito

- Identificar qué medios de comunicación son los de mayor audiencia entre la población, a fin de establecer estrategias de difusión relacionada a la oferta de crédito de PrestaMas. 
- Identificar las promociones de mayor agrado entre la población, a fin de establecer estrategias, suvenires, relacionada a la captación de créditos nuevos o recurrentes de PrestaMas.

\subsubsection{Proceso de Muestreo}

La población de estudio es de 117435 unidades de negocio, como indica la Tabla 22. El proceso de determinación parte de trabajar con los registros de negocios identificados en el distrito de San Juan de Lurigancho y estimar la proporción de actividades informales sobre las formales, estudios del BCRP, MEF, CEPAL, INEI destaca que solo el 35\% de todas las actividades económicas se encuentran formalizadas y el $65 \%$ son informales. La encuesta se dará en áreas de mercados, paraditas, distribución de comercios en avenidas y calles. La información básica proviene de la cartografía e información estadística del Censo Nacional de Población y Vivienda de 2007, con actualización al año 2016 en el distrito de San Juan de Lurigancho Perú, Estimaciones y Proyecciones de Población 1950-2050.Instituto Nacional de Estadística e Informática (2009) Perú: Estimaciones y Proyecciones de Población Total, por Años Calendario y Edades Simples, 1950-2050 Perú. Por cuestiones de costo, la muestra es, no probabilísticos de conveniencia, las unidades de muestreo son seleccionadas dada la conveniente accesibilidad y proximidad de los sujetos para el investigador.

El tamaño de la muestra es de 383 personas con actividades económicas. Esta muestra es de tamaño suficiente lo que debe permitir tener estimaciones confiables de la población investigada. Para determinar el tamaño de la muestra, es decir, el número de encuestas que se realizaran, se tomó en cuenta la siguiente información:

- El mercado objetivo está conformado por negocios de personas mayores de 18 años de edad y menores de 70 años de edad en San Juan de Lurigancho y es de 117435 personas, según fuentes estadísticas externas.

- Con un nivel de confianza de $95 \%$ y un grado de error de $5 \%$. 
Aplicando la fórmula de la muestra:

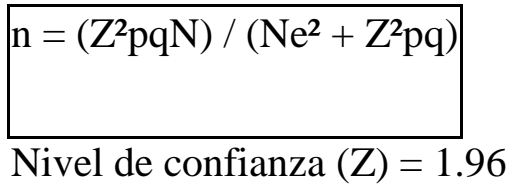

Grado de error $(e)=0.05$ (corresponde a una muestra aleatoria simple de ese tamaño)

Universo $(\mathrm{N})=117435$

Probabilidad de ocurrencia $(\mathrm{P})=0.5$

Probabilidad de no ocurrencia $(\mathrm{Q})=0.5$

$$
\begin{aligned}
& \mathrm{n}=\left((196)^{2}(0.5)(0.5)(117435)\right) /\left((117435)(0.05)^{2}+(196)^{2}(0.5)(0.5)\right) \\
& \mathrm{n}=((3.84)(0.25)(117435)) /((117435)(0.0025)+(3.84)(0.25)) \\
& \mathrm{n}=112784.81 /(293.59+0,96) \\
& \mathrm{n}=112784.81 / 294.55 \\
& \mathrm{n}=383
\end{aligned}
$$

Para grado de error $5.22 \%$ se considera un $n=345$ 


\section{Tabla 21}

Población y Agrupación por Actividades

\begin{tabular}{|c|c|}
\hline Actividades & Número \\
\hline Explotación de Minas y Canteras & 2 \\
\hline Industrias Manufactureras & 2156 \\
\hline Suministro de Electricidad & 3 \\
\hline Suministro de Agua, Alcantarillado & 67 \\
\hline Construcción & 56 \\
\hline Comercio al por Mayor y Menor & 15214 \\
\hline Transporte y Almacenamiento & 257 \\
\hline Alojamiento y Servicio de Comida & 2142 \\
\hline Información y Comunicación & 1860 \\
\hline Actividades Financieras y de Seguros & 59 \\
\hline Actividades Inmobiliarias & 37 \\
\hline Actividades Profesionales, Científicas y Técnicas & 281 \\
\hline Actividades Administrativas y Servicios de Apoyo & 421 \\
\hline Enseñanza Privada & 576 \\
\hline Servicios Sociales y Relacionados con la Salud & 480 \\
\hline Humana & 183 \\
\hline Artes, Entretenimiento y Recreación & 1658 \\
\hline Otras Actividades de Servicios & 25452 \\
\hline \multicolumn{2}{|l|}{ Actividades Económicas en el Distrito con Licencia } \\
\hline Municipal & 1507 \\
\hline Paradas, Mercados y Campos Feriales. (274 Lima x & 9934 \\
\hline 11\% SJL/Lima x 50) & 4209 \\
\hline \multicolumn{2}{|l|}{ Taxistas } \\
\hline Moto taxistas & 15650 \\
\hline \multicolumn{2}{|l|}{ Actividades de transporte y paradas } \\
\hline \multicolumn{2}{|l|}{ Actividades Económicas en el Distrito con permisos } \\
\hline \multicolumn{2}{|l|}{ alternos a Licencia Municipal } \\
\hline Empresas Informales $65 \%$ del Total & 76333 \\
\hline Actividades Económicas de SJL & 117435 \\
\hline
\end{tabular}

Fuente. Elaboración Propia. Extraído del Plan Municipal de SJL 2014 - 2018 
Tabla 22

Distribución de la Muestra

\begin{tabular}{lrr}
\hline \multicolumn{1}{c}{ Actividades } & Número & Estratos \\
\hline Explotación de Minas y Canteras & 2 & 0 \\
Industrias Manufactureras & 2.156 & 7 \\
Suministro de Electricidad & 3 & 0 \\
Suministro de Agua, Alcantarillado & 67 & 0 \\
Construcción & 56 & 0 \\
Comercio al por Mayor y Menor & 15.214 & 50 \\
Transporte y Almacenamiento & 257 & 1 \\
Alojamiento y Servicio de Comida & 2.142 & 7 \\
Información y Comunicación & 1.860 & 6 \\
Actividades Financieras y de Seguros & 59 & 0 \\
Actividades Inmobiliarias & 37 & 0 \\
Actividades Profesionales, Científicas y Técnicas & 281 & 1 \\
Actividades Administrativas y Servicios de Apoyo & 421 & 1 \\
Enseñanza Privada & 576 & 249 \\
Servicios Sociales y Relacionados con la Salud Humana & 480 & $\mathbf{3 8 3}$ \\
Artes, Entretenimiento y Recreación & 183 & 2 \\
Otras Actividades de Servicios & 1.658 & 1 \\
Paradas, Mercados y Campos Feriales. & 1.507 & 5 \\
Taxistas & 9.934 & 5.209 \\
Moto taxistas & 76.333 \\
Empresas Informales 65\% del Total & & 2.435 \\
Actividades Económicas de SJL & & 5 \\
& & 5 \\
\hline
\end{tabular}

Fuente: Elaboración propia

\subsubsection{Análisis y procesamiento de datos}

Se encontró que las variables de análisis presentan baja correlación, evidenciando independencia entre ellas y su influencia en el resultado de acceder al crédito y una preferencia del desembolso en efectivo o en cuenta de ahorro. 
- El 95\% de los encuestados declaro ser usuarios de créditos, lo que afirma la existencia de una demanda de microcréditos factible de atender. De ellos, se percibe que la mayor demanda de créditos de mujeres de un $54 \%$ sobre un $46 \%$ de varones, lo cual no nos da indicios de que requieren un producto específico en la oferta crediticia por género.

\begin{tabular}{|l|r|r|r|}
\cline { 2 - 4 } \multicolumn{1}{c|}{} & \multicolumn{1}{c|}{ Varón } & \multicolumn{1}{c|}{ Mujer } & \multicolumn{1}{c|}{ Total } \\
\hline Cantidad & 177 & 206 & 383 \\
\hline Porcentaje & $46.21 \%$ & $53.79 \%$ & $100 \%$ \\
\hline
\end{tabular}

ESTRUCTURA POR GENERO

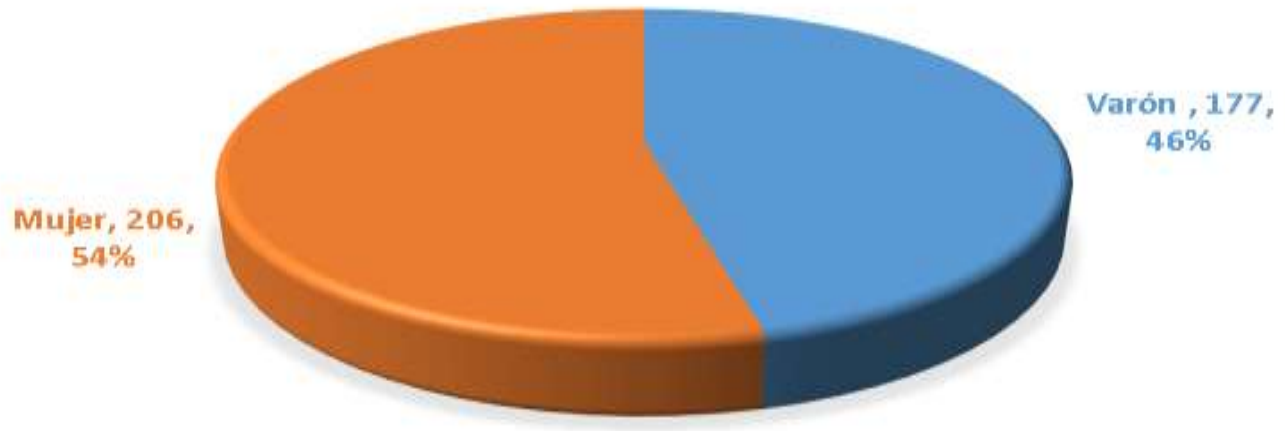

Figura 2 Fuente: Pregunta $N^{\circ} 1$ de la encuesta del estudio cuantitativo

- Las actividades de seis meses a dos años de antigüedad representan el $83 \%$ de la demanda, evidencia una respuesta de reubicación de la PEA desempleada en el desarrollo de actividades propias, sobre quienes se debe identificar la propuesta de crédito a otorgar, el comercio, transporte y servicio representan el $86 \%$ de la demanda, por lo que se requiere mantener presencia estratégica dirigida a estos rubros. 


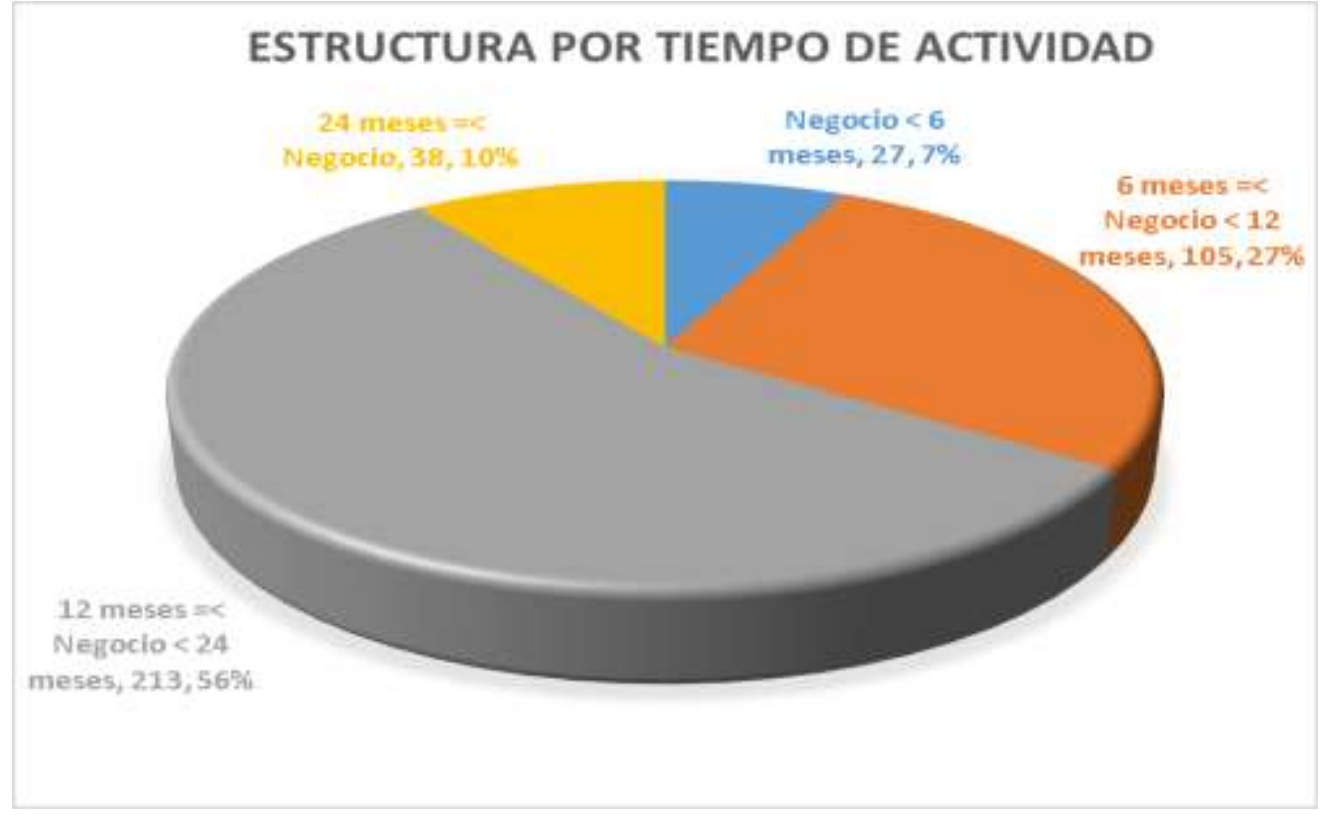

Figura 3Fuente: Pregunta $N^{\circ} 4$ de la encuesta del estudio cuantitativo

- Un $88 \%$ valora la simplicidad de requisitos, la rapidez en la atención y la calidad del servicio como el principal determinante para acceder al crédito, tendencia de mercado factible a brindar por PrestaMas asociada a la tecnología micro financiera representa una gran oportunidad de mercado que representa una oportunidad de negocio.

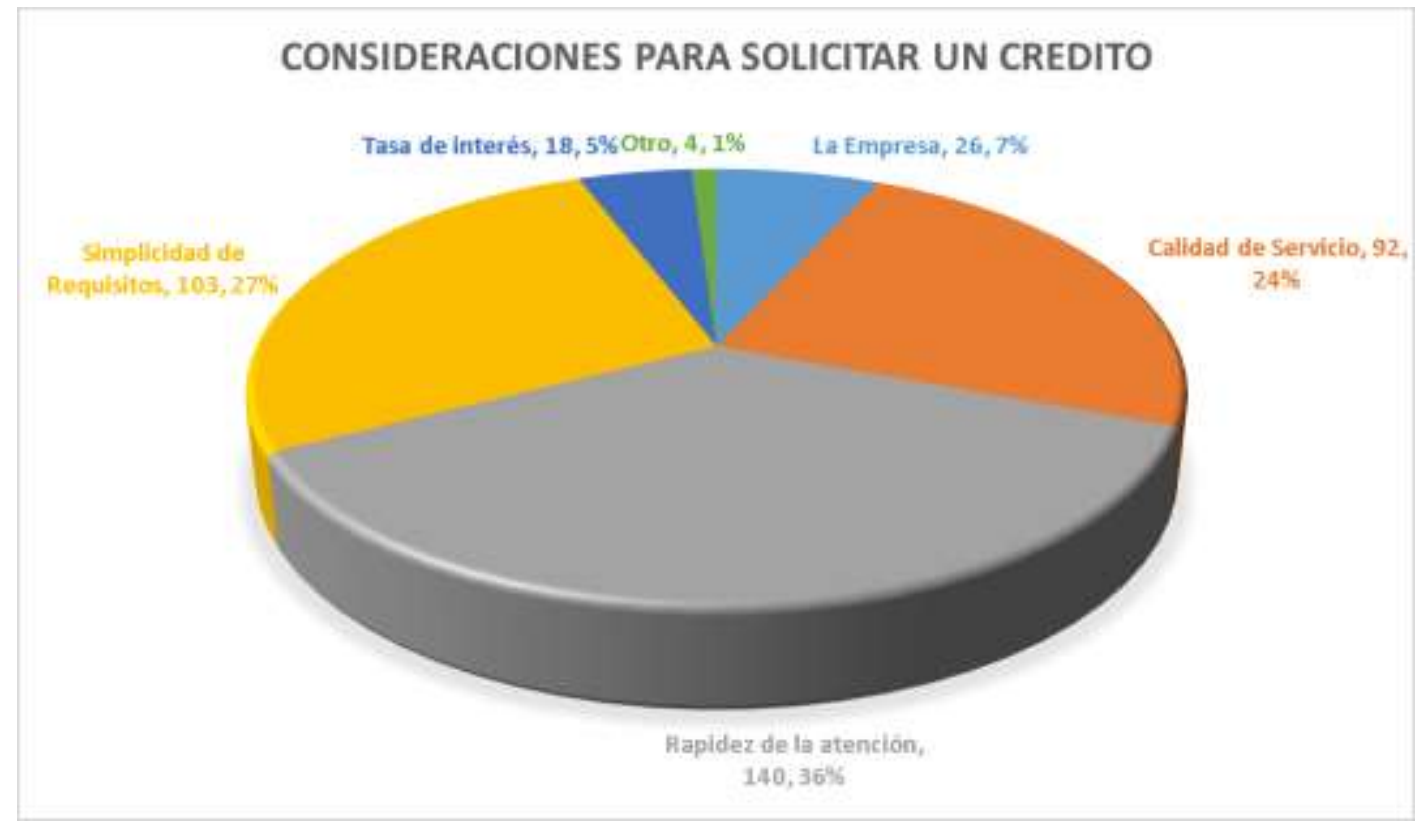

Figura 4 Fuente: Pregunta $N^{\circ} 10$ de la encuesta del estudio cuantitativo 
- Un 98\% prefiere realizar pagos en agencia, agentes o en el mismo negocio, siendo desaprovechada la recaudación a través de agentes y cajeros corresponsales y en el mismo negocio, en tanto que el $84 \%$ prefiere pagos de corte diario y semanal, evitando inmovilizar mucho dinero para el pago de cuota si es mensual.

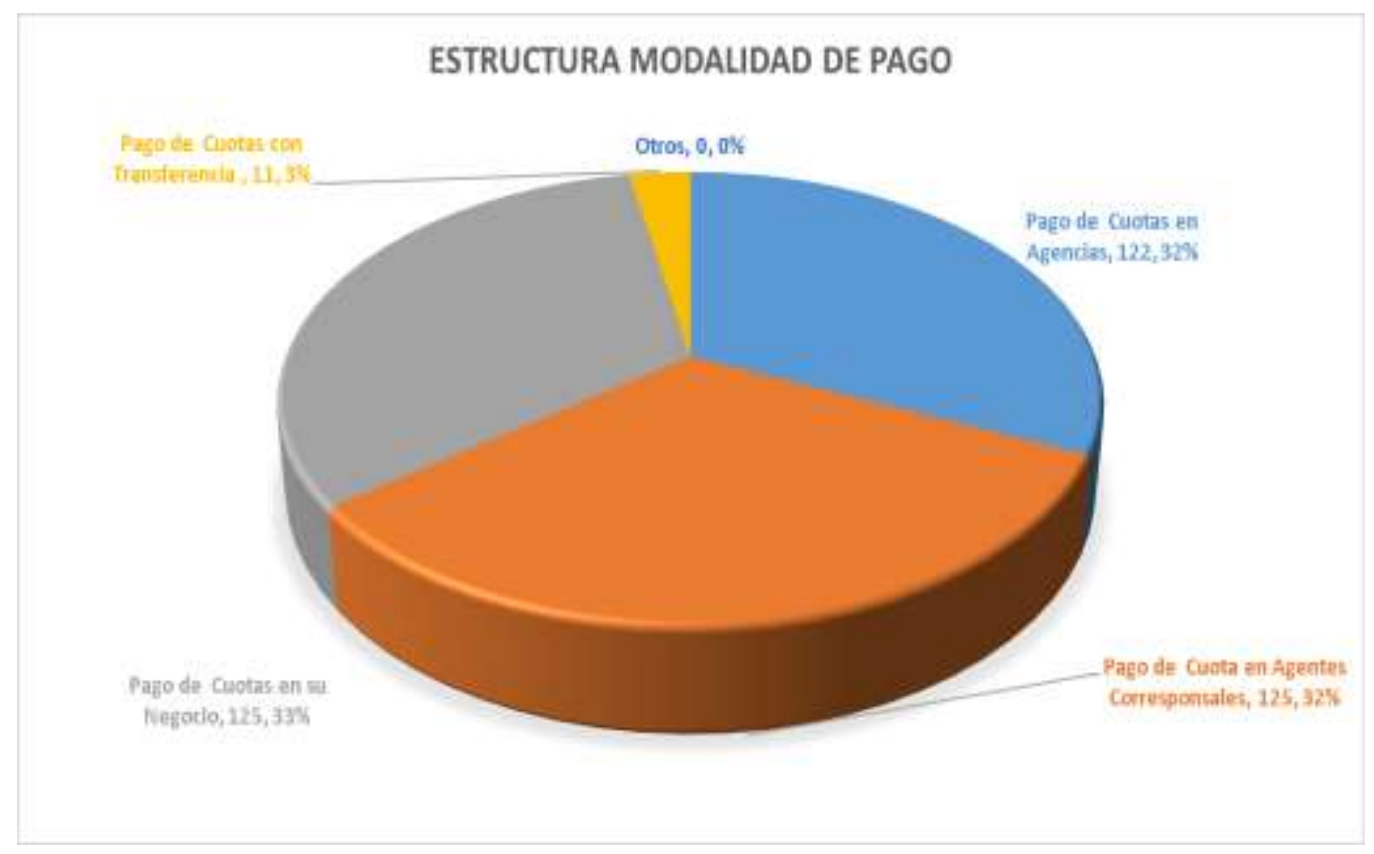

Figura 5 Fuente: Pregunta 15 de la encuesta del estudio cuantitativo.

- El 35\% accede a prestamistas, principalmente contra inmovilización de garantía, el 57\% a ONG o cooperativas, principalmente en créditos grupales; y $4 \%$ a entidades financieras, principalmente créditos mayores a un mil soles, careciendo una oferta de crédito individual menor a un mil soles sin inmovilización de garantías. A su vez, un $88 \%$ fue promocionado directamente o referido por un cliente, el marketing apropiado exige una técnica publicitaria bajo la línea "below the line". 


\begin{tabular}{|c|c|c|c|c|c|c|}
\hline & ONG & Cooperativa & Prestamista & \begin{tabular}{|c|} 
Entidades \\
Financieras \\
\end{tabular} & Otros & Total \\
\hline Cantidad & 114 & 105 & 135 & 16 & 13 & 383 \\
\hline Porcentaje & $29.77 \%$ & $27.42 \%$ & $35.25 \%$ & $4.18 \%$ & $3.39 \%$ & $100 \%$ \\
\hline
\end{tabular}

ACCESO AL CREDITO POR TIPO DE OFERTANTE

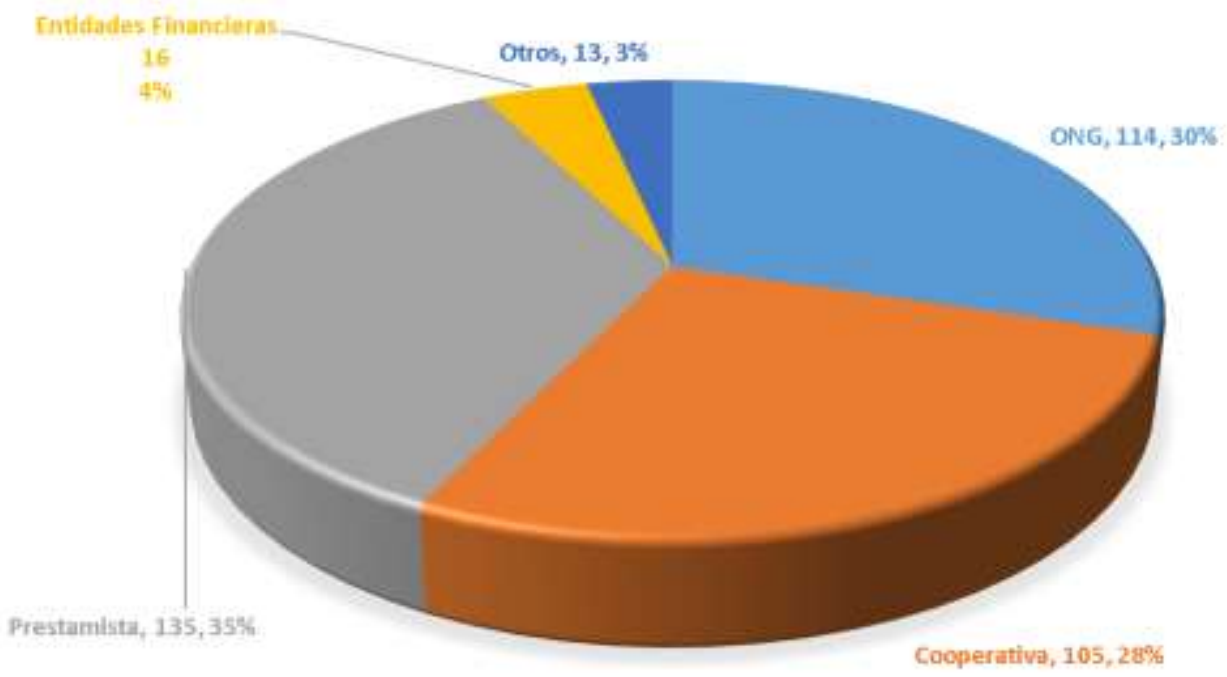

Figura 6 Fuente: Pregunta $N^{\circ} 12$ de la encuesta del estudio cuantitativo

- Respecto al giro de su negocio, de los 383 encuestados 148 corresponde a actividades de comercio lo que representa un $39 \%$, le siguen las actividades de transporte y servicios con 90 personas encuestadas cada una, lo que representa un $24 \%$, las actividades de producción se encuentran en cuarto lugar con 42 personas encuestadas lo que representa un $11 \%$. Por otras actividades, trabajos eventuales respondieron 13 personas lo que representa un $3 \%$. 


\begin{tabular}{|l|r|r|r|r|r|r|}
\cline { 2 - 7 } & Comercio & Transporte & \multicolumn{1}{|c|}{ Servicio } & Producción & \multicolumn{1}{l|}{ Otros } & Total \\
\hline Cantidad & 148 & 90 & 90 & 42 & 13 & 383 \\
\hline Porcentaje & $38.64 \%$ & $23.50 \%$ & $23.50 \%$ & $10.97 \%$ & $3.39 \%$ & $100 \%$ \\
\hline
\end{tabular}

\section{ESTRUCTURA POR TIPO DE ACTIVIDAD}

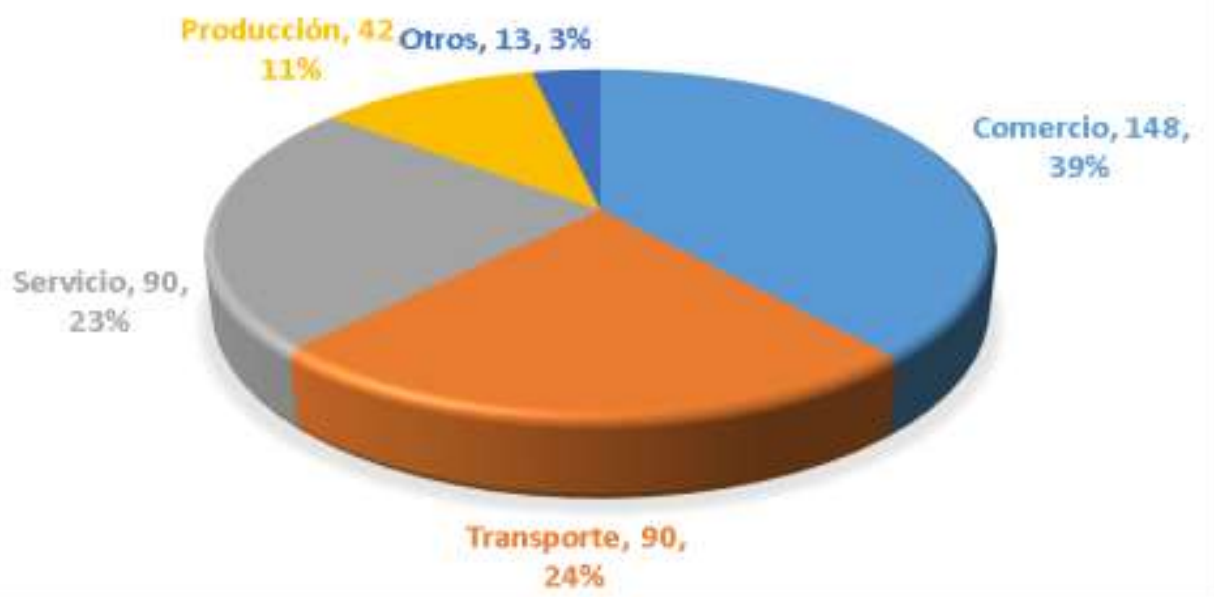

Figura 7 Fuente: Pregunta $N^{\circ} 2$ de la encuesta del estudio cuantitativo

- Un $62 \%$ prefiere créditos de 500 soles promedio, son créditos de rápido retorno con frecuencias de pagos diaria o semanal, en tanto que el 52\% opta por el crédito de 500 soles a 12 semanas, percibiendo los clientes un menor costo por el tiempo de permanecía con el crédito.

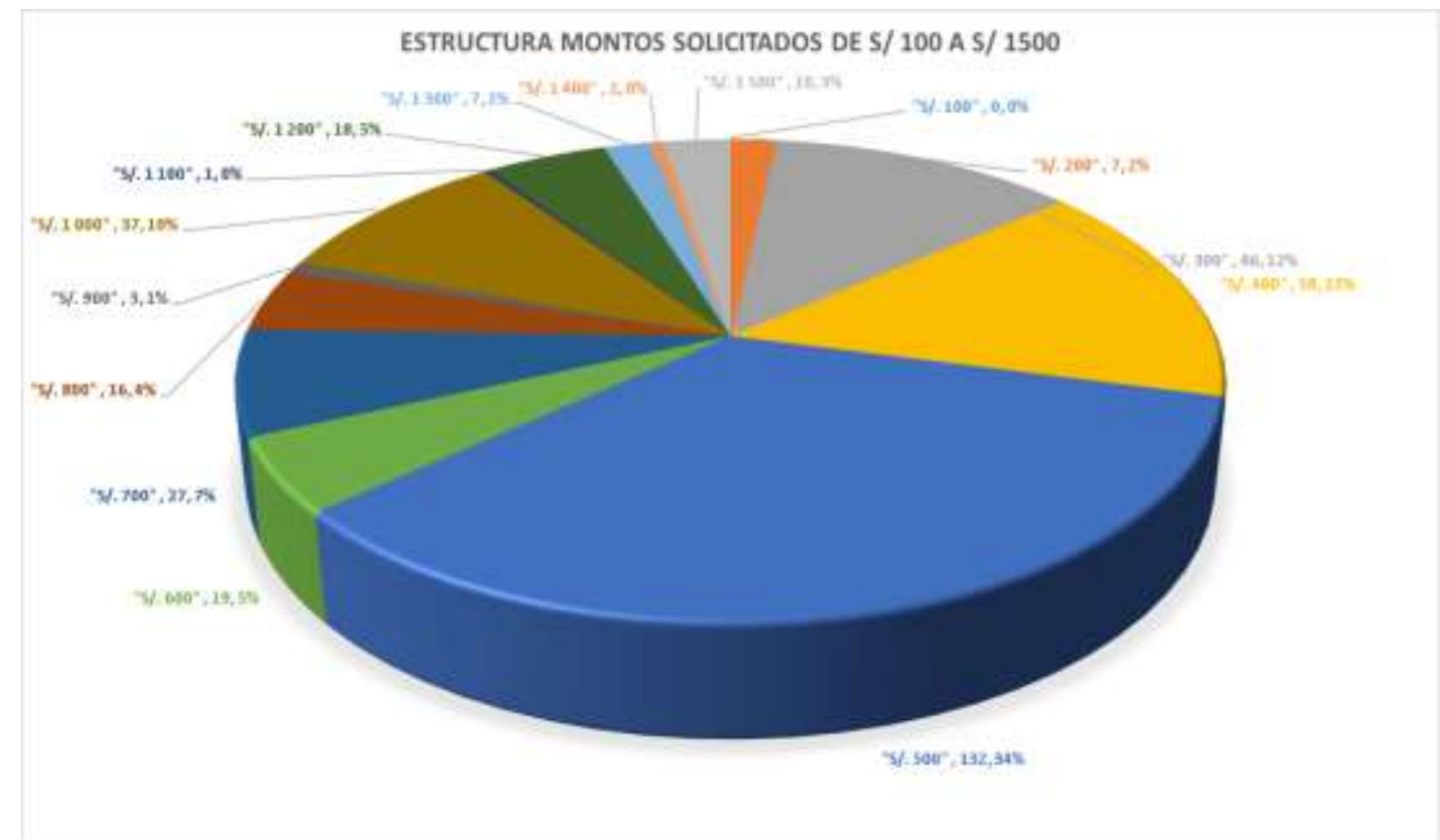

Figura 8 Fuente: Pregunta 19 de la encuesta del estudio cuantitativo 
- Un $78 \%$ ha usado créditos más de 3 veces en los últimos seis meses, establece una relación de mediano y largo plazo con los clientes, también el $89 \%$ cuenta con uno hasta tres créditos, observándose una alta bancarización en los centros comerciales encuestados.

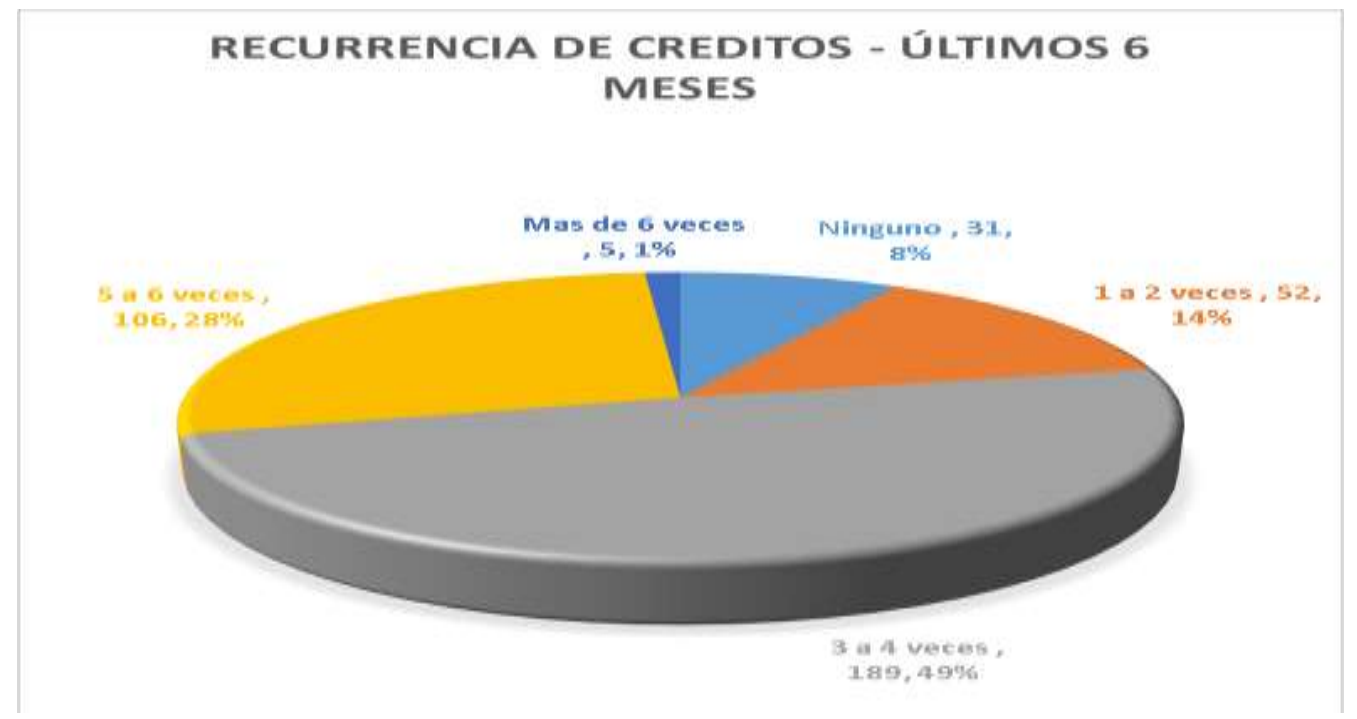

Figura 9Fuente: Pregunta 22 de la encuesta del estudio cuantitativo

- Un $51 \%$ se encuentra insatisfecho por alguna razón con la entidad financiera en condiciones, requisitos, tiempos de atención etc., dada la rigidez del producto el proceso se torna tedioso a los clientes.

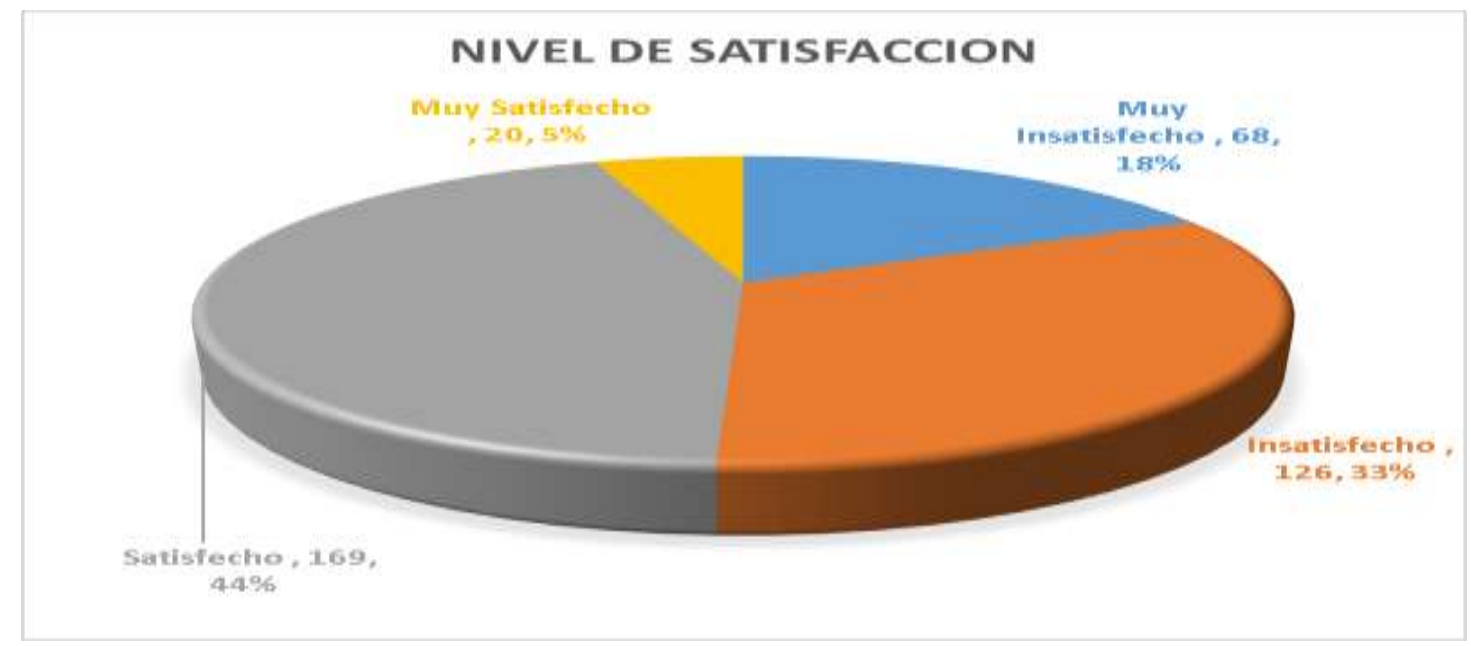

Figura 10 Fuente: Pregunta 24 de la encuesta del estudio cuantitativo 


\subsection{Conclusiones y recomendaciones del Estudio Cualitativo y Cuantitativo}

- Existe una demanda de créditos para negocios impulsada por el crecimiento de las pymes, a la vez hay una demanda insatisfecha de micro créditos, lo que genera una oportunidad de oferta de servicio para PrestaMas.

- Los giros de negocios de seis meses a dos años son los demandantes de créditos que defienden su conducta de pago en el retorno de sus primeros créditos, sobre los que PrestaMas desarrollará su mercado.

- Las necesidades financieras son de capital de trabajo y activo fijo principalmente sea planeado por el solicitante de crédito o por aprovechar alguna oferta.

- La competencia está distribuida principalmente entre Cooperativas, ONGs y prestamistas respecto a los créditos de retorno diario o semanal, en tanto que los retornos mensuales son de las Edpymes, Cajas Rurales y Municipales y Financieras.

- La flexibilidad de requisitos y de evaluación son mayores para los prestamistas y ONGs, en tanto que las cooperativas, Edpymes, Cajas Rurales y Municipales y Financieras es mucho menor.

- La oferta informal carece de tecnología crediticia micro financiera y de ventas.

- La simplicidad de requisitos y rapidez son atributos valorados por los solicitantes de créditos.

- La asesoría en el manejo de caja para evitar caer en riesgo de liquidez es valorada por los clientes.

- Hay oportunidad de atención en créditos promedio de 500 soles con retornos de 12 semanas en promedio. 


\subsection{Perfil del consumidor tipo y sus variantes}

Tabla 23

Perfil del consumidor tipo

\begin{tabular}{ll}
\hline \multicolumn{1}{c}{ Perfil del cliente } & \multicolumn{1}{c}{ Segmento } \\
\hline Género & Mujeres y Hombres \\
Edad & De 18 a 70 años \\
Segmento Socioeconómico & C, D y E \\
Fuente de Ingresos & Todas las actividades micro \\
& empresariales \\
Necesidad de Financiamiento & Capital de Trabajo y/o Activo Fijo \\
Plazos de Financiamiento & Corto plazo menos a 12 semanas \\
Ocupabilidad y saturación de tiempo & Demandantes de atención rápida, \\
& desconcentrada y simplificada. \\
Plazos de atención esperada. & Rápida respuesta en un día. \\
Periodo de pago preferido & Pagos semanales \\
Dependencia al puesto de trabajo & No cuentan con personal adicional, \\
& valoran mucho el tiempo ausente. \\
\hline
\end{tabular}

Fuente: Elaboración Propia

Se ha identificado demandantes de créditos progresistas, emprendedores, quienes responden a la exclusión de la PEA con la creación de su negocio, se constituyen informalmente con el mínimo capital, tras la experiencia descubren y gustan ser independiente en cuanto al manejo de sus recursos de tiempo, dinero, así como a la gestión empresarial, inclusive aquellos que son trabajadores dependientes y poseen una actividad económica. Los micros empresarios establecen sus actividades en condiciones precarias, frágiles e informales agrupados en zonas de comercio, asumen retos que el mercado les plantea, son trabajadores con horarios mayores 
a las ocho horas diarias y las 48 horas semanales, no se asignan vacaciones ni entienden de para en feriados. Son optimistas, evidenciando probar suerte reiteradas veces; asocian el éxito a su esfuerzo y sacrificio, son conscientes que nada se consigue gratis y están dispuesto a pagar precios elevados por conseguir financiamiento, el cual procuran devolver en el menor tiempo, buscan practicidad, calidad y rendimiento sobre el giro de negocio, restan importancia a la exclusividad de un cliente o proveedor, analizan el costo/beneficio, privilegian el rendimiento a alcanzar con el crédito antes que el precio a pagar. 


\section{CAPITULO IV. PROYECCIÓN DEL MERCADO OBJETIVO}

\section{1 Ámbito de la proyección}

El ámbito de proyección de PrestaMas es el financiamiento de micro créditos en el distrito de San Juan de Lurigancho es a 5 años para micro y pequeños empresarios.

\subsection{Selección del método de proyección}

Se proyecta en base a al método subjetivo de pronóstico visionario combinado con el de la analogía histórica que considera la opinión de expertos, se manifiesta cuando los métodos cuantitativos basados en que la información histórica no puede explicar por si sola el comportamiento futuro esperado de alguna de sus variables, o cuando no existen suficientes datos históricos. Se ha apreciado cambios en la industria que han implicado fusiones empresariales como Mi Banco y Edyficar, CNG y Financiera Confianza, cierres e intervenciones por la SBS como Caja Pisco y Caja Luren, aunque el sistema registra una tendencia de desaceleración hay empresas cuyo desenvolvimiento es bastante favorable con un ROE cerca del $20 \%$ y una tasa de crecimiento de mercado del $20 \%$ anuales como CMAC Arequipa, Huancayo, Cusco. En el lado formal e informal no supervisado, no se cuenta con mayor data por lo que se cree conveniente contactara con los expertos de ONGs Cooperativas y Prestamistas, basado en ello el método se desarrolla de la investigación de mercado.

De acuerdo a los especialistas se cree prudente llegara a atender una cartera de 300 clientes por Asesor de crédito con crédito de 500 a 1500 soles por Asesor. Precisan que cada agencia puede tener hasta 20 Asesores y una cartera de clientes de 6000 clientes con una cartera vigente de 1080000 soles a 3240000 soles que representa el 36\% de la cartera colocada de 3000000 soles a 9000000 soles, administrado por una persona quien hace de gerente de agencia, un gestor de cobranza por cada cinco Asesores, un abogado por agencia, como se indica en la Tabla 24. En cuanto al soporte operativo se requiere seis cajeros u operadores y un supervisor, entendiendo que la capacidad de atención por operador de 200 clientes lo que 
equivale a 5200 por mes, con seis operadores atendería 31200 operaciones, requiriéndose con 6000 clientes 24000 operaciones de cobranza y 6000 de desembolso, como se indica en la Tabla 24. Se contará también con el soporte de agentes y cajeros corresponsales para las cobranzas y desembolsando a través de depósitos cuenta de ahorro, cheques, o dinero electrónico a cuentas en empresas de telefonía celular.

Tabla 24

Equipo de Asesores, Crédito Promedio, Número de Clientes y Cartera

\begin{tabular}{llcccc}
\hline Asesor & Crédito Promedio & $\begin{array}{c}\text { Número de } \\
\text { Clientes }\end{array}$ & $\begin{array}{c}\text { Saldo Crédito } \\
\text { Colocado }\end{array}$ & $\begin{array}{c}\text { Saldo Crédito } \\
\text { de Cartera } \\
\text { Vigente }\end{array}$ \\
\hline 20 & Mínimo & 500 & 300 & 3000000 & 1080000 \\
20 & Máximo & 1500 & 300 & 9000000 & 3240000 \\
\hline
\end{tabular}

Fuente: Elaboración Propia

Tabla 25Equipo de Operadores, Atención diaria Crédito por mes y Cartera

\begin{tabular}{cccc}
\hline Operaciones & $\begin{array}{c}\text { Número de } \\
\text { atención por } \\
\text { día }\end{array}$ & $\begin{array}{c}\text { Número de } \\
\text { Días }\end{array}$ & Cartera por Agencia \\
\hline 6 & 200 & 26 & 31200 \\
\hline
\end{tabular}

Fuente: Elaboración Propia

Los especialistas refieren que concentrar la atención en zonas por Asesor mejora la productividad por colaborador y permite ahorro en costos de desplazamiento, consideran que cada zona comprende entre 500 y 1000 clientes potenciales, de fácil dominio y en cinco kilómetros cuadrados de las siguientes zonas se pueden atender entre 2900000 y 4800000 soles con 4 a 5 Asesores, como se indica en la Tabla 26 y se aprecia en la Figura 2. 


\section{Tabla 26}

Modelo de Asignación de Trabajo en Zona

\begin{tabular}{lccl}
\hline Zona & $\begin{array}{l}\text { Potencial de } \\
\text { Clientes }\end{array}$ & Crédito Promedio & Monto Por Zona \\
\hline Huáscar & $500-1000$ & 500 soles & $250000-500000$ \\
San Martin & 500 & 500 soles & 250000 \\
Bayoyar & 500 & 500 soles & 250000 \\
Santa María & $500-1000$ & 500 soles & $250000-500000$ \\
Canto Rey & 500 & 800 soles & 400000 \\
Mariscal Cáceres & $500-1000$ & 800 soles & $400000-800000$ \\
Juan Pablo II & $500-1000$ & 500 soles & $250000-500000$ \\
JCM - José Carlos & & & $250000-500000$ \\
Mariátegui & $500-1000$ & 500 soles & $250000-500000$ \\
Otros menores & $500-1000$ & 500 soles & \\
Total ocho zonas & $4500-8000$ & $500-800$ soles & $2250000-6400$ \\
& & & 000 \\
\hline
\end{tabular}

Fuente: Elaboración Propia

El distrito cuenta con 1218 tipos de poblados:
(1) Asentamiento Humanos 414,
(2)Urbanizaciones 110,
(3)APV 95,
(4) Pueblos Jóvenes 81,
(5) Agrupaciones Familiares 342,
(6) Cooperativas 35,
(7) Asociaciones 66,
(8) Programas 27,
(9) Parcelas 7,
(10) Parcelas Semi rústicas 6,
(11) Fundo Otros 5; y.
(12) Otros 30. 


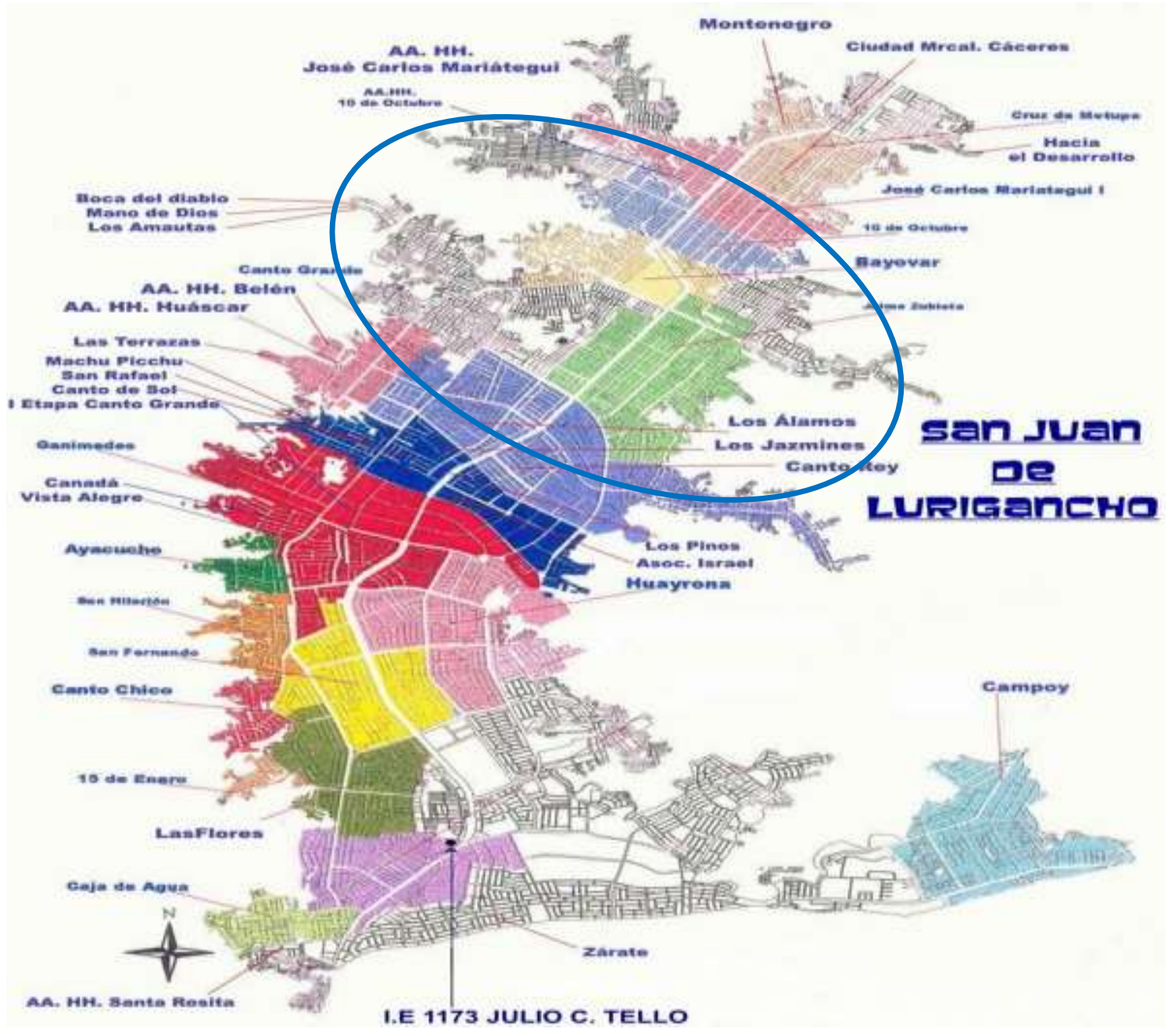

Figura 11 Mapa de Modelo de trabajo en zona en el distrito de SJL

Fuente:

https://www.google.com.pe/search?q=san+juan+de+lurigancho\&newwindow=1\&rlz=1C2VFKB enP E651PE651\&biw=1821\&bih=902\&source=lnms\&tbm=isch\&sa=X\&ved=0ahUKEwilt mPveTMAh WBXyYKHW_-Dq0Q_AUIBigB \&dpr=0.75\#imgrc=kFCD0Tu5ksO7-M\%3A

\subsubsection{Mercado Potencial:}

San Juan de Lurigancho, según estadísticas del INEI cuenta con una población de más un millón de habitantes, con 117435 actividades económicas que generen ingresos propios por lo cual requieren de un nivel de inversión en activo fijo o capital de trabajo, que se han iniciado con un nivel de patrimonial propio; sin embargo, requieren de algún tipo de crédito para crecer, constituyendo el mercado potencial de microcréditos. 


\subsubsection{Mercado Disponible:}

El mercado disponible es de 111610 personas, se obtuvo a partir del cálculo de las actividades en el distrito en el proceso de muestreo y la proporción de personas encuestadas que tienen crédito. Corresponde al $95.04 \%$ de las 117435 personas que es mercado total estimado en el proceso de muestreo, como se indica en la Tabla 22, toda vez que en las encuestas registra que un $4.96 \%$ no son usuarios de créditos y comprende a los que nunca han solicitado créditos. Así mismo, los especialistas que se indican en la Tabla 12 y 16 estiman que existen más de 100000 clientes micro y pequeños que comprenden el mercado disponible en San Juan de Lurigancho.

La pregunta cinco del cuestionario: ¿Usa usted créditos?, de la encuesta nos indica que los 383 encuestados 364 declararon hacer usos de créditos lo que representa un 95\%, en tanto que 19 personas declararon no usar créditos lo que representas un 5\%.

\begin{tabular}{|c|c|c|c|}
\hline & $\begin{array}{c}\text { Usa } \\
\text { Créditos }\end{array}$ & $\begin{array}{l}\text { No Usa } \\
\text { Créditos }\end{array}$ & Total \\
\hline Cantidad & 364 & 19 & 383 \\
\hline Porcentaje & $95.04 \%$ & $4.96 \%$ & $100 \%$ \\
\hline
\end{tabular}

\section{ESTRUCTURA POR USO DE CREDITOS}

No Usa

Créditos, 19 $5 \%$

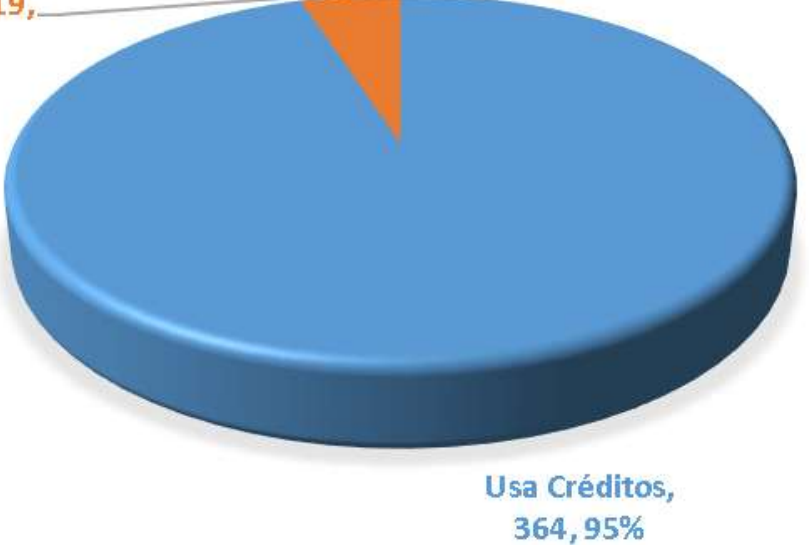

Figura 12 : Mercado Disponible

Fuente: Pregunta 5 de la encuesta del estudio cuantitativo 


\subsubsection{Mercado Efectivo:}

Para PrestaMas el mercado efectivo es de 71107 clientes. Corresponde al $63.71 \%$ de los 111 610personas que es mercado total estimado en el proceso de muestreo, como se indica en la Tabla 22, toda vez que en las encuestas registra que un $63.71 \%$ que si estarían dispuestos o dispuesto a probar una nueva oferta de crédito.

La pregunta 27 del cuestionario: ¿Estaría dispuesto a probar una nueva oferta de crédito? registro que de los 383 encuestados respecto a la apertura para probar una nueva oferta de crédito 244 personas indican que si lo que representa un $63.71 \%$, en tanto que 36 personas indican que no lo que representa un 54.31\%, 29 personas indican siempre reciben lo que representa un $9.40 \%$ y 103 personas se muestran indecisos lo que representa un $26.89 \%$

\begin{tabular}{|l|r|r|r|r|}
\cline { 2 - 5 } & \multicolumn{1}{c|}{ Si } & \multicolumn{1}{c|}{ No } & $\begin{array}{c}\text { No Sabe / No } \\
\text { Opina }\end{array}$ & \multicolumn{1}{l|}{ Total } \\
\hline Cantidad & 244 & 36 & 103 & 383 \\
\hline Porcentaje & $63.71 \%$ & $9.40 \%$ & $26.89 \%$ & $100.00 \%$ \\
\hline
\end{tabular}

APERTURA A NUEVA OFERTA DE CREDITO

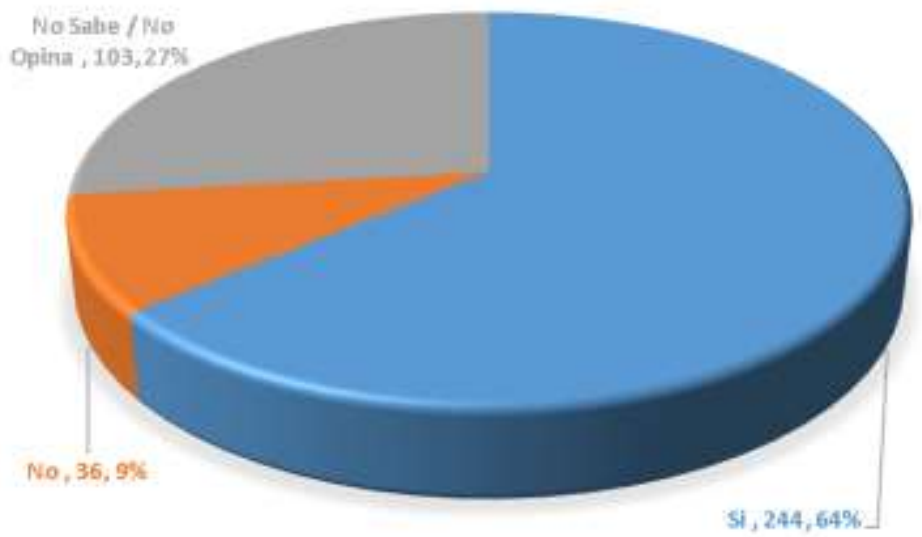

Figura 13: Mercado Efectivo

Fuente: Pregunta $\mathrm{N}^{\circ} 27$ de la encuesta del estudio cuantitativo. 


\subsubsection{Mercado Objetivo:}

PrestaMas tiene previsto atender créditos para Capital de trabajo y Activo fijo, tomando como referencia la pregunta $\mathrm{N}^{\circ} 8$ de nuestra encuesta de determina un mercado objetivo de 46973 clientes que resulta de considerar sólo el $66.06 \%$ de los encuestados que destina sus créditos para esos fines con respecto al mercado efectivo. Aplicando el índice de Mac Daniel nuestro mercado objetivo lo representan 22,211 comerciantes.

\begin{tabular}{|l|r|r|r|r|r|r|r|}
\hline & $\begin{array}{c}\text { Crédito } \\
\text { para } \\
\text { Mercadería }\end{array}$ & $\begin{array}{c}\text { Crédito } \\
\text { para } \\
\text { Mueble } \\
\text { Maquinaria } \\
\text { y Equipo }\end{array}$ & $\begin{array}{c}\text { Crédito } \\
\text { para } \\
\text { Oportunida } \\
\text { des } \\
\text { (remates) }\end{array}$ & $\begin{array}{c}\text { Crédito } \\
\text { Personal }\end{array}$ & $\begin{array}{c}\text { Crédito } \\
\text { para } \\
\text { Vivienda }\end{array}$ & Ninguno & \\
\hline Cantidad & 171 & 82 & 91 & 24 & 12 & 3 & 383 \\
\hline Porcentaje & $44.65 \%$ & $21.41 \%$ & $23.76 \%$ & $6.27 \%$ & $3.13 \%$ & $0.78 \%$ & $100 \%$ \\
\hline
\end{tabular}

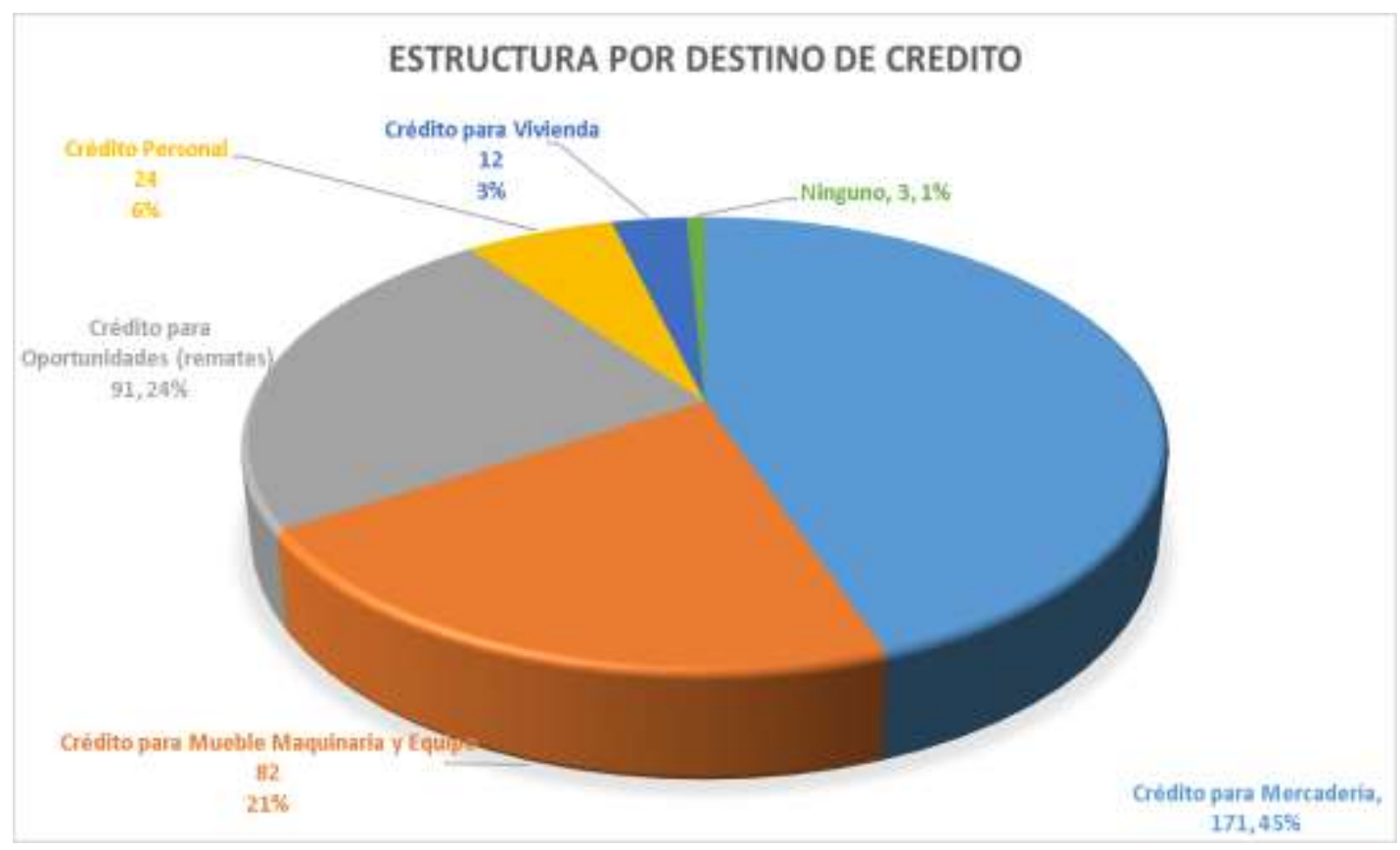

Figura 14: Mercado Objetivo

Fuente: Pregunta $\mathrm{N}^{\circ} 8$ de la encuesta del estudio cualitativo.

$\checkmark$ Mercado Objetivo por segmento geográfico:

Mercados, Paradas y Ferias del distrito ubicados en AAHH, PPJJ, Agrupaciones Vecinales, Cooperativas y Asociaciones de Vivienda, por ser pueblos jóvenes cuya pirámide estructural 
de composición por edad es joven sobre las Urbanizaciones con una estructura de edad con personas de más avanzada edad e ingresos dependientes, cesantes o de jubilación.

$\checkmark$ Mercado Objetivo por nivel de Actividad Económica y Fuente de Ingreso:

Pequeñas y microempresas del distrito, quienes identifican a PrestaMas como apoyo al impulso de la actividad económica sobre las entidades bancarias y de créditos con garantía prendaria en joyas, artefactos, vehículos e inmuebles.

$\checkmark$ Mercado Objetivo por Estructura de Edad.

De 18 a 70 años de edad, por comprender a la población que se inserta a la actividad económica y ser la población que demanda créditos para la micro empresa con más dinamismos.

Argumento de Beneficios potenciales.

- Mitigar la escasez de capital de los microempresarios.

- Apoyar en gestionar la previsión o visión de futuro de los microempresarios.

- Permitir una mayor dimensión de la pyme sin financiamiento.

- Dar a conocer los productos y las alternativas financieras.

Módulos alternativos de oferta con regulaciones vigentes.

Por el tipo de desembolso

En efectivo en agencia / oficina

En efectivo en negocio / domicilio

En cuenta bancaria o cheque, en cuenta comercial - dinero móvil

Por tipo de recaudación o recuperación

Cobros en agencia

Cobros en agentes o cajeros corresponsales 
Cobros en el negocio / domicilio

Cobros a través de cuenta bancaria

\subsection{Pronóstico de Ventas-Colocaciones, Crecimiento de Cartera, Ingresos}

Basados en los criterios de colocación por Asesores, costo de dinero, gastos administrativos, morosidad, impuesto a la renta son los valores más críticos tomados de la industria, como se indica en la Tabla 27 mes a mes para el primer año y se indica en la Tabla 28 para los cinco años.

\subsection{Aspectos críticos que impactan el pronóstico de ventas}

Factores externos

- Incursión de competencia con tasas reducida

- Flexibilización de la competencia de las condiciones crediticias.

- Restricciones del gobierno u oferta estatal de micro crédito a través del Banco de la Nación.

- Capitación de fondos menores a los planificados.

Factores internos

- Colocaciones erradas que eleven la mora o sean incobrables y por ende las provisiones y genere una menor utilidad e incluso genere perdidas.

- Alta rotación laboral por deserción de colaboradores

- Actos dolosos de los empleados, fraudes en la organización.

- Proceso lento por un software débil que soporte el desarrollo del proceso de los créditos, caídas constantes de la red de internet.

Identificación, medición y mitigación de riesgos

Aplicación estricta de las "cinco c del crédito": capacidad, capital, colateral, carácter y conveniencia. 
Tabla 27

Pronóstico de Ventas, Crecimiento de Cartera, Ingresos del primer año.

\begin{tabular}{lrrr}
\hline Meses & $\begin{array}{c}\text { Pronostico de } \\
\text { Ventas- } \\
\text { Colocaciones }\end{array}$ & $\begin{array}{c}\text { Crecimiento de } \\
\text { Cartera "S.C." } \\
\text { Proyectado }\end{array}$ & $\begin{array}{c}\text { Ingresos } \\
\text { Proyectados } \\
\text { "S.CxTEM" }\end{array}$ \\
\hline Enero & 108,000 & 75,805 & 9,283 \\
Febrero & 108,000 & 115,748 & 14,175 \\
Marzo & 108,000 & 115,748 & 14,175 \\
Abril & 108,000 & 115,748 & 14,175 \\
Mayo & 108,000 & 115,748 & 14,175 \\
Junio & 108,000 & 115,748 & 14,175 \\
Julio & 144,000 & 141,016 & 17,269 \\
Agosto & 153,600 & 161,069 & 19,725 \\
Septiembre & 153,600 & 164,620 & 20,160 \\
Octubre & 153,600 & 164,620 & 20,160 \\
Noviembre & 153,600 & 164,620 & 20,160 \\
Diciembre & 153,600 & 164,620 & 20,160 \\
\hline Fuente: Elaboración Propia & & &
\end{tabular}

Fuente: Elaboración Propia

\section{Tabla 28}

Pronóstico de Ventas, Crecimiento de Cartera, Ingresos de cinco años.

\section{Pronostico de Crecimiento de}

Año Ventas- Cartera Ingresos

\section{Colocaciones}

\begin{tabular}{lrrr}
\hline Año 1 & $1,560,000$ & 164,620 & 197,790 \\
Año 2 & $4,211,400$ & 486,143 & 539,149 \\
Año 3 & $10,554,600$ & $1,131,761$ & $1,357,984$ \\
Año 4 & $20,565,000$ & $2,122,051$ & $2,657,262$ \\
Año 5 & $36,867,600$ & $3,703,944$ & $4,761,941$ \\
\hline
\end{tabular}




\subsection{Conclusiones}

- ONG PrestaMas tiene un mercado amplio sobre el cual alcanzaría una participación de un 25 a $30 \%$ en los primeros 5 años.

- La estrategia de crecimiento concentrado por dominio de zonas por Asesor favorece al dominio de conocimiento de la zona y la atención rápida evitando la dispersión y con ello pérdidas de tiempo en desplazamiento y costos de transportes

- El manejo de la tecnología crediticia para la mitigación de riesgos en consideración que los créditos no se otorgan solo por garantías exigidas. Con una estructura de ventas diarias por colaborador y una tasa alta de repago, sobre los saldos de cartera promedio se espera una rentabilidad asegurada con los promedios de gasto de la industria.

- Los datos del mercado objetivo tienen mucha relación con el tamaño de la población y las estimaciones de los especialistas. 


\section{CAPITULO V. INGENIERIA DEL PROYECTO}

\subsection{Estudio de Ingeniería}

Para determinar los procesos, requerimiento de equipos, recurso humano, mobiliario y equipo de oficina, terrenos, construcciones, distribución de equipo, obras civiles, organización y eliminación o aprovechamiento del desperdicio, etc., la ingeniería del proyecto resulta la herramienta fundamental para la toma de decisiones como precisa,

“el objetivo general del estudio de ingeniería del proyecto es resolver todo lo concerniente a la instalación y el funcionamiento de la planta. Desde la descripción del proceso, adquisición de equipo y maquinaria, se determina la distribución óptima de la planta, hasta definir la estructura de organización y jurídica que habrá de tener la planta productiva”. (Baca G., 2014, p.124)

\subsubsection{Modelamiento y selección de procesos productivos}

Un proceso de producción es el conjunto de actividades orientadas a la transformación de recursos o factores productivos en bienes y/o servicios. El servicio de otorgamiento de créditos a producir responde por la colocación de dinero a solicitantes de micro créditos con ingresos por alguna actividad económica dentro del distrito de San Juan de Lurigancho. El proceso productivo prevé.

- Promoción y prospección de créditos- Validación del perfil

- Recepción de documentos física o virtual Evaluación de centrales de riesgo y toma de referencias crediticias - consulta en línea o a oficina - precalificación.

- Decisión de continuar o rechazar el crédito.

- Evaluación de Campo: Evaluación cuantitativa del crédito (desarrollo del flujo caja) y de la evaluación cualitativa del crédito (evaluación psicométrica).

- Registro automático a sistema (por móvil) y generación de informe (expediente) 
- Aprobación de comité de créditos en línea o en físico - supervisión aleatoria antes del desembolso.

- Generación de documentos contractuales, cronograma, hoja resumen y títulos valores.

- Toma de firmas contractuales (en agencia)

- Desembolso del crédito: (1) Depósito en cuenta, o (2) Transferencia con DNI, (3)

Orden de Pago, o (4) En ventanilla de agencia

- Cobranza de acuerdo al cronograma y monitores de recuperación del crédito (gestión de cobranza)

- Renovación de crédito

El ejecutivo comercial promociona el crédito toma sus datos y envía al Asesor comercial para que valide el perfil del cliente y consulte la central de riesgos, toma la documentación física del cliente o captura en digital y envía para la pre calificación esta solicitud para que el supervisor de créditos realice una precalificación del crédito, si es satisfactoria, el Asesor asesor comercial evalúa el crédito, ingresa la información y registra los datos en el sistema vía móvil, se crea en el sistema el informe para la revisión en comité de créditos para su aprobación o rechazo del crédito sobre la cual aleatoriamente se realiza la supervisión, luego se genera los documentos contractuales para la toma de firmas en la agencia y operaciones, así se produce la operación de desembolso con la cual el cliente puede recibir el crédito, como se aprecia en la Figura 15. 


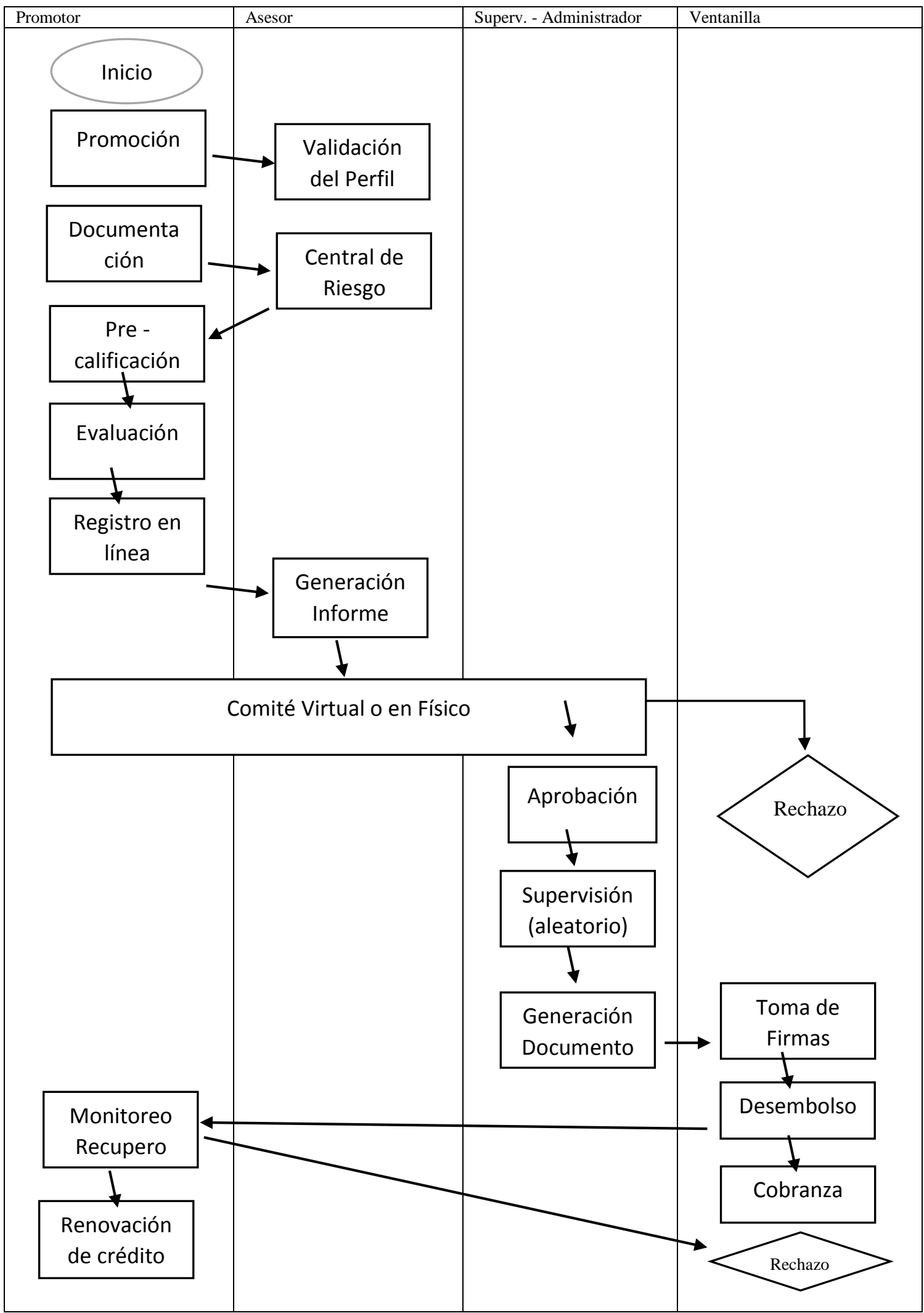

Figura 15 Proceso operativo del servicio.

Fuente: Elaboracion Propia. 
El asesor monitorea la recuperación de créditos con atraso y renueva los créditos con pagos realizados de acuerdo al cronograma o con atrasos moderados o deniega solicitudes de renovación.

Luego el Asesor Comercial realiza el seguimiento y monitoreo de los pagos de acuerdo al cronograma de pagos y realiza las cobranzas con los reportes de cobranzas.

Inicialmente las labores de promoción las realiza el Asesor - Asesor y las de supervisión el administrador.

Modelamiento y selección de procesos productivos de otorgamiento del crédito

Comprende

- Promoción y Prospección

- Documentación

- Evaluación Cuantitativa y Cualitativa

- Presentación y Aprobación del Crédito en Comité

- Desembolso

- Monitoreo de Recuperación de Crédito Gestión de Cobranza

- Renovación de Crédito.

\subsubsection{Selección del equipamiento}

El desarrollo de una oficina comprende

- Ambiente de custodia de bóveda principal y

- Módulos de operaciones con bóvedas auxiliares

- Equipos de Computo

- Módulos de Atención

- Oficina Gerencial 


\subsubsection{Lay Out}

Para determinar la distribución de la oficina se tiene el criterio de la zona de atención al público, la zona de operaciones, el ambiente administrativo. Las actividades comerciales y operativas se desarrollarán principalmente en el trabajo de campo o a través de terceros, las necesidades de infraestructura son de una agencia - oficina:

- 01 oficina principal - gerencial,

- 01 ambiente sala para reuniones, comités de créditos, recuperaciones

- 02 módulos de caja para operaciones de interacción con el público para desembolsos, cobros y otras transacciones a brindar con cobro de comisiones

- 01 almacén economato

- 01 bóveda principal

- 02 módulos de atención al público

\subsubsection{Distribución de Equipos y Maquinarias}

\section{Tabla 29}

\begin{tabular}{ll}
\hline Distribución de Equipos y Maquinarias & \multicolumn{1}{c}{ Ambientes } \\
\hline 01 televisor de 50 pulgadas & 5 de cara al Hall \\
05 laptops & $2,4,5$ \\
02 impresora- fotocopiadora Multifuncional & 5 y 7 \\
Aire acondicionado & Hall \\
02 ventiladores & 4 y 11 \\
01 dispensador de agua & 4 \\
01 Deshumedecedor & 6 \\
01 extractor de aire para SSHH & 1 \\
02 cajas pulmón de seguridad de dinero & 5 \\
04 equipos de teléfono con conexión entre si & $2,4,5$ y 6 \\
05 cámaras de seguridad y CPU de almacenamiento & Ingreso, Hall, 4, 5 y 6 \\
06 equipos móviles Smartphone 3G o 4G & Portátil \\
\hline
\end{tabular}

Fuente : Elaboración Propia 
Sobre el local a usar se requiere desarrollar obras civiles con divisiones en drywall y acabados con usos de colores sobrios comerciales, el ambiente debe estar iluminado y ventilado expresando calidez y seguridad a los clientes y usuarios, como se aprecia en

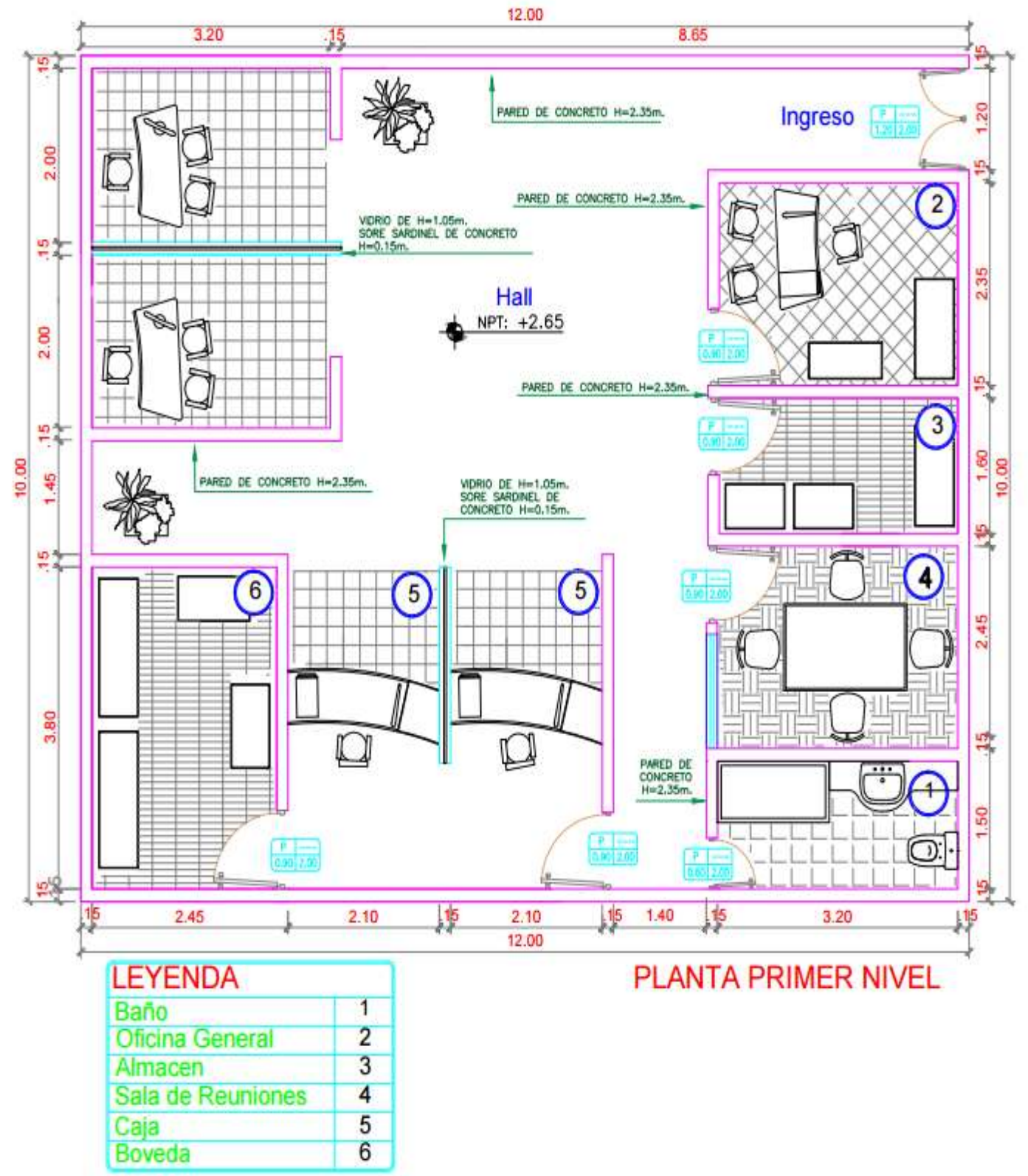

Figura 16 Distribución de la Oficina

Fuente: Elaboración Propia 
La inversión inicial en activos fijos es de 68230 soles, se detalla en la Tabla 30.

\section{Tabla 30}

Inversión inicial en Activos Fijos

\begin{tabular}{|c|c|c|c|}
\hline Descripción & Cantidad & Costo Unitario & Costo Total \\
\hline Acondicionamiento de local & 1 & 16,000 & 16,000 \\
\hline Escritorio & 1 & 850 & 850 \\
\hline Sillas - banquetas & 15 & 100 & 1,500 \\
\hline Módulos de atención & 4 & 782 & 3,128 \\
\hline Computadoras - laptops & 5 & 2,720 & 13,600 \\
\hline Impresora multifuncional & 2 & 1,020 & 2,040 \\
\hline Aire acondicionado & 2 & 2,500 & 5,000 \\
\hline Ventilador & 2 & 100 & 200 \\
\hline Dispensador de agua & 1 & 600 & 600 \\
\hline Deshumecedor & 1 & 700 & 700 \\
\hline Equipos tv monitor & 2 & 3,400 & 6,800 \\
\hline Caja de seguridad - caja buzón & 2 & 1,350 & 2,700 \\
\hline Caja de seguridad - caja pulmón & 1 & 3,000 & 3,000 \\
\hline \multicolumn{4}{|l|}{ Cámaras de seguridad y CPU } \\
\hline almacenamiento & 5 & 400 & 2,000 \\
\hline Equipos móviles Smartphone & 6 & 300 & 1,800 \\
\hline Mesa oval & 1 & 3,000 & 3,000 \\
\hline Modulo portátil mostrador & 1 & 612 & 612 \\
\hline Enseres & 2 & 850 & 1,700 \\
\hline Otros activos & 1 & 3,000 & 3,000 \\
\hline
\end{tabular}

Fuente: Elaboración Propia 


\subsection{Determinación del Tamaño}

Consideramos la necesidad de un establecimiento de 120 mts 2 basada en la elección de dos alternativas finales. En ambas opciones se debe contar con 01 oficina principal, 01 ambiente sala para reuniones, 02 módulos de caja para operaciones, 02 módulos de atención al público, como se indica en la Tabla 31.

\section{Tabla 31}

Alternativas de Local para Agencia

\begin{tabular}{|c|c|c|c|c|c|}
\hline \multirow[t]{2}{*}{ Alternativa } & \multicolumn{2}{|c|}{ Área } & \multicolumn{2}{|c|}{ Costo } & \multirow{2}{*}{$\begin{array}{l}\text { Puntaje } \\
\text { Promedio }\end{array}$} \\
\hline & $\mathrm{M}^{2}$ & Puntaje & Importe & Puntaje & \\
\hline $\begin{array}{l}\text { Próximo a Avenida } 120 \text { mts2 (10 } \\
\text { x } 20 \text { mts. y segundo piso) }\end{array}$ & 120 & 3 & S/1 200 & 4 & 3.5 \\
\hline $\begin{array}{l}\text { Local en 3er Piso Avenida } 200 \\
\text { mts2 ( } 8 \text { x15 mts fondo) }\end{array}$ & 200 & 2 & $S / 2500$ & 3 & 2.5 \\
\hline
\end{tabular}

\subsubsection{Proyección de crecimiento}

El alquiler del local cuenta con un ambiente en el segundo piso el cual inicialmente estará vacío y sin trabajo alguno, en el ambiente se ubicarán módulos de atención exclusivos para Asesores de créditos conforme se incremente el número de colaboradores para la atención de los clientes.

\subsubsection{Recursos}

- Fondeo

La ONG PrestaMas se inicia con un patrimonio de S/. 332910 soles como aportes de sus asociados. Posteriormente un porcentaje de las ganancias no asignadas en el objetivo social de la organización y un fondeo proyectado a través de la captación de inversiones a nuevos 
socios, préstamos a la organización e incluso donaciones permitirá el crecimiento de la ONG PrestaMas.

- Recurso Humano

Tabla 32

Personal, puestos, remuneración y régimen laboral.

\begin{tabular}{|c|c|c|c|}
\hline Personal & Sueldo & Cantidad & Régimen laboral \\
\hline \multicolumn{4}{|l|}{ Administrador $* /$} \\
\hline \multicolumn{4}{|l|}{ Supervisor de } \\
\hline Operaciones & 2040 & 1 & Planilla tiempo completo \\
\hline Supervisor de Créditos & 2380 & 1 & Planilla tiempo completo \\
\hline \multicolumn{4}{|l|}{ Asesor Comercial y } \\
\hline Asesor Créditos & 1700 & 20 & Planilla tiempo completo \\
\hline Operaciones & 1360 & 1 & Planilla tiempo completo \\
\hline Plataforma & 1360 & 1 & Planilla tiempo completo \\
\hline Limpieza & 850 & 1 & Planilla tiempo completo \\
\hline Conserje & 850 & 1 & Planilla tiempo completo \\
\hline Seguridad - Vigilancia & 850 & 2 & Planilla tiempo completo \\
\hline Abogado & 1000 & 1 & Planilla a medio tiempo \\
\hline Contador & 1000 & 1 & Planilla a medio tiempo \\
\hline
\end{tabular}

Fuente: Elaboración Propia

Se requiere contar con conocimiento básico en evaluación de créditos, ventas, cobranzas, desembolsos, cobros y atención al público a fin de brindar excelentes niveles de operación del proceso, incluye los requisitos de calidad y estándares de servicio. Para efectos del funcionamiento al tercer año requerirá del siguiente personal de 20 Asesores colaboradores y el cuadro de personal, como indica la Tabla 32. 
Las Fuentes de abastecimiento de Mano de Obra disponible son hogares con hijos de 18 años a más, con estudios de instituto o universitarios en administración, empresa, marketing, sociología con pro actividad para el trabajo de campo, de buen trato y disfrute de la interacción con el público, provenientes de institutos especializados como IFB, Cepeban, universidades particulares y del estado, como se indica en la Tabla 32.

- Ambiente - Local

Los servicios de alquiler de ambientes de la oficina, suministro de energía eléctrica, suministro de agua potable, suministro de red de teléfono fijo, móvil y de internet, transporte, resguardo de valores, seguridad, mensajería de Courier, call center, son de empresas o del distrito. Dado que las actividades comerciales y operativas se desarrollarán al 95\% en campo o a través de terceros, las necesidades de infraestructura son de una agencia - oficina:

- 01 oficina principal,

- 01 ambiente sala para reuniones, comités de créditos, recuperaciones y clínicas de gestión comercial

- 02 módulos de caja para operaciones de interacción con el público para desembolsos, cobros y otras transacciones a brindar con cobro de comisiones.

- 02 módulos de atención al público para brindar información, recepción documentaria y entrega de órdenes de pagos.

Sobre el local a usar se requiere desarrollar obras civiles con divisiones en drywall y acabados con usos de colores sobrios comerciales, el ambiente debe estar iluminado y ventilado expresando calidez y seguridad a los clientes y usuarios.

- Insumos 
Los insumos de papelería, complemento de impresión y fotocopiado y escaneado también son proporcionados por empresas locales de la ciudad de Lima. Se prevé adquirir cada dos meses un importe de 3000 soles o 18000 soles el primer año, como se indica en la Tabla 33

\section{Tabla 33}

Insumos: Material de Oficina.

\begin{tabular}{|c|c|c|c|}
\hline Cantidad & Ítem o descripción & Costo & Parcial \\
\hline 20 paquetes & Papel Bond & 14 & 280 \\
\hline 4 cajas & Lapiceros & 16 & 64 \\
\hline 50 unidades & Resaltadores & 1.5 & 75 \\
\hline 20 unid & Archivadores & 5 & 100 \\
\hline 20 Cajas & Ligas & 3 & 60 \\
\hline 1000 unid & Folder & 0.65 & 650 \\
\hline 1000 unid & Faster & 0.3 & 300 \\
\hline 6 unid & Antivirus & 20 & 120 \\
\hline 15 unid & Tóner & 30 & 450 \\
\hline 50 unid & Plumón & 3.5 & 175 \\
\hline 3 packs & Artículos de limpieza & 75 & 300 \\
\hline \multirow[t]{3}{*}{20 packs } & Piedras deshumedecedoras & 15 & 300 \\
\hline & Otros & & 126 \\
\hline & Total & & 3000 \\
\hline
\end{tabular}

Fuente: Elaboración Propia

- Capacidad Instalada

Las inversiones iniciales comprenden el uso de la capacidad instalada de la agencia al 100\% que permitirá el desarrollo de actividades sin mayores inversiones en los dos años de existencia por el personal comercial, operaciones, de recuperaciones y administrativo. Adicional a ello el desarrollo de convenios para la tercerización del desembolso y las cobranzas a través de cuentas de ahorros de PrestaMas en entidades financieras permitirá 
mantener holgura respecto a la capacidad instalada, usada sin mayores costos de inversión a la vez que se aprovecha los brazos de colocación y recaudación adicional al de la agencia.

La capacidad a desarrollar es susceptible a ampliarse en el mismo local de primer piso como el segundo piso sin utilizar, cuando se incorpore más personal contratado respecto al del inicio de operaciones. La agencia se proyecta a atender hasta un máximos de 6000 clientes u operaciones de créditos con una media de créditos de S/ 500, un tamaño de cartera de 3000 000 soles en 5 años, para ello se contara inicialmente con los 02 módulos de caja para operaciones de interacción con el público para desembolsos, cobros y otras transacciones a brindar con cobro de comisiones, 02 módulo de atención al público para brindar información, recepción documentaria y entrega de órdenes de pagos, 01 ambiente sala para reuniones, 01 de comités de créditos, recuperaciones y clínicas de gestión comercial.

- Servicio de Terceros para Desembolsos y Cobranza

PrestaMas prevé tercerizar servicios de desembolso y recaudación a través de agentes, cajeros corresponsales, transferencias comerciales a empresas de teléfono o transferencia bancarias sólo con el número de DNI, lo que permite crecer sin recurrir a nuevas inversiones de plataformas operativas, trasladando costos fijos a costos variables por tercerización de servicios.

El servicio de energía telefonía fija, móvil y red de internet, potencialmente se ha identificado tres empresas (Movistar, Claro, Entel) con alquiler una línea adicional de otra empresa a la que se contrate.

Los servicios de energía eléctrica "Edelnor" y potencialmente se ha identificado tres empresas con alquiler de generación eléctrica con motor.

El servicio de seguridad, se ha identificado a diez empresas que brindan el servicio, en cuanto a la custodia de valores y dinerario, se tiene conocimiento de dos empresas que brindan el 
servicio "Prosegur y Hermes" adicionalmente que el uso de cuentas de corrientes permitirá trasladar el costo de custodia de dinero a las empresas financieras con que se tiene las cuentas corrientes.

El servicio de consulta de riesgo interno a la base de datos del software de la ONG, el servicio de consulta de riesgo externo se encargará a Sentinel que brinda paquetes de 2000 consultas a tarifa flat (S/ 2000$)$.

El servicio de Reniec y Sunarp previa inscripción y pago para contar con saldo a favor para hacer consultas (S/ 6.25 por consulta en promedio).

\subsubsection{Tecnología}

La industria de la Microfinanzas ha desarrollado una tecnología de evaluación crediticia que rinde muchos éxitos y anticipa la selección de posibles clientes que no retornarían el crédito, permite determinar el nivel ideal de crédito, plazos, etc. permitiendo el desarrollo de una cartera sana y con el menor nivel de provisiones que afecten el flujo de ingresos y benéficos por posibles perdía de incobrabilidad y demora en el pago de acuerdo al convenio de crédito establecido:

Tecnología Crediticia Tradicional Micro financiera - 5 C del Crédito

- Evaluación in situ, levantamiento de información y elaboración del Estado financiero de Resultado y Flujo de Caja.

- Preguntas del Negocio e Inspección Visual del Asesor con cruce de información para determinar las ventas.

- Visita del domicilio e inspección visual de la vivienda, nivel de vida, acumulación de artefactos, muebles forma de vida, etc.

- Toma de referencias de vecinos en negocio y vivienda. 
Tecnología Crediticia de Vanguardia - Cuestionario Psicométrico

- Diseño de cuestionario de 15 preguntas para determinación de la calidad ética y moral respecto al cumplimiento de compromisos asumidos con PrestaMas.

Soporte Tecnológico para brindar el Servicio Crediticio

El análisis del mercado objetivo del proyecto plantea las siguientes herramientas tecnológicas a requerir:

- Internet y teléfono fijo para la constante comunicación con los Asesores comerciales.

- Cámaras de seguridad que permitirán resguardarnos ante cualquier intento de robo.

- Máquina servidor donde se encontrará instalado el sistema de créditos y cobranzas.

- Equipos móviles Smartphone 3G o 4G que permitirán realizar el ingreso de los datos del cliente para las validaciones de perfiles y créditos.

- Software que permita el pago por el equipo móvil.

\subsubsection{Selección del Tamaño Ideal}

Para el inicio de operaciones se ha considerado el equipamiento del primer piso el cual permitirá usar la capacidad instalada al 100\% en un plazo máximo de dos años, a partir de cual se aprovechará el ambiente en segundo piso, al instalarse módulos de atención con puntos de red para conexión de laptops.

\subsection{Estudio de Localización}

San Juan de Lurigancho por sus características responde al donde realizar la actividad crediticia, por la pirámide poblacional y la predominancia de actividades económicas de la base de la población responde la oportunidad de brindar un producto de cuantía menor o igual a S/ 1 000. Así mismo, dada la eleva oferta de infraestructuras de pagos y cobros responde al 
esarrollo de una nueva modalidad de como brindar créditos, para ello se contará con una oficina - tienda.

\subsubsection{Definición de factores locacionales}

Para la ubicación se han valorado 4 opciones para la mejor oportunidad de atención, se consideró las posibilidades de un establecimiento y se han desarrollado criterios de puntuación para elegir la mejor opción.

1. En la zona comercial de Canto Rey - Av. Próceres de la Independencia.

2. En la zona comercial de Huáscar - Canto Grande - Av. Canto Grande.

3. En la zona comercial de Mariscal Cáceres- Av. Héroes del Cenepa (ex Av. Bayovar este),

4. Montenegro - Av. Fraternidad (al límite con Jicamarca-Huarochirí).

La empresa se ubicará en Calle Francisco B ’O Connor 4355 - Urb. Mariscal Cáceres a media cuadra transversal a la Av. Héroes del Cenepa este, donde se presenta bastante comercio desde las 6:00 a.m. hasta las 12:00 a.m. (media noche), por la característica comercial de la zona existen más de 400 comercios menores entre organizados y ambulantes, además la cercanía al paradero inicial del tren eléctrico, que aglutina a usuarios de la parte alta de SJL, lo cual facilita la accesibilidad, facilidad y disponibilidad de los clientes. Como se aprecia en la Figura 17. 


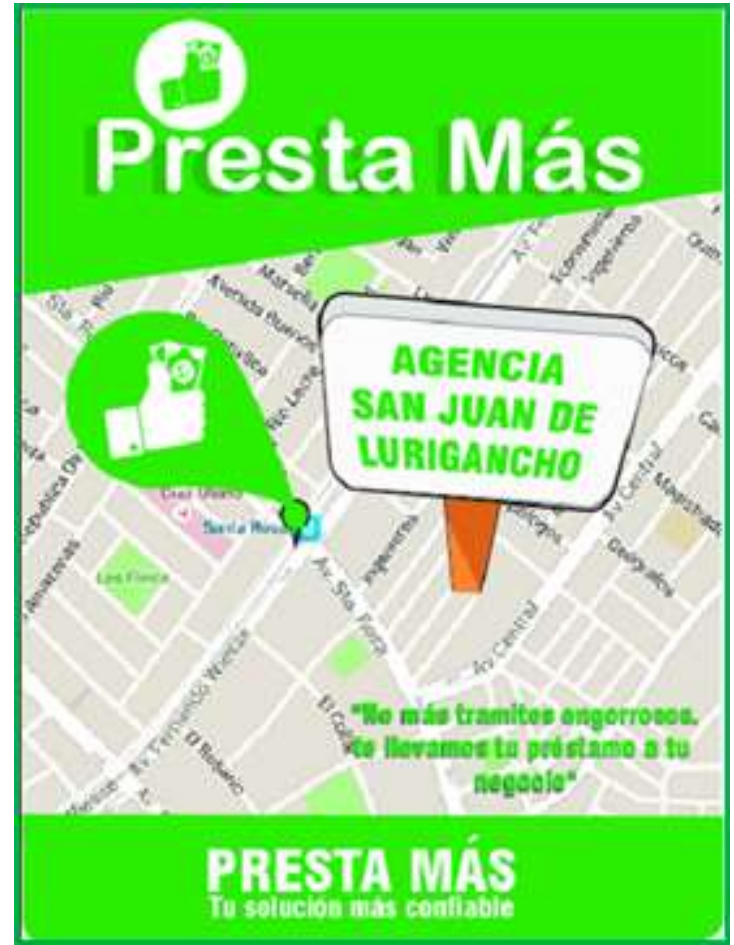

Figura 17 Ubicación de la Agencia

Fuente: Elaboración Propia

\subsubsection{Determinación de la localización optima}

El local del Mariscal Cáceres alcanzó mayor puntuación en la elección entre cuatro opciones pres seleccionados, evaluando la facilidad de acceso de los clientes, el número de comerciantes de la zona, los precios de alquiler y las posibilidades de ampliación como se indica en la Tabla 34

\section{Tabla 34}

Alternativas de elección y ponderación de factores.

\begin{tabular}{lrrrrr}
\hline \multicolumn{1}{c}{ Descripción - Ítem } & Peso & Canto Rey & Huáscar & M Cáceres & Montenegro \\
\hline Facilidad de acceso & $30 \%$ & 2.00 & 2.00 & 3.00 & 3.00 \\
Comerciantes en la zona & $25 \%$ & 2.00 & 4.00 & 4.00 & 3.00 \\
Precio de Alquiler & $35 \%$ & 3.00 & 2.00 & 4.00 & 4.00 \\
Ampliación & $10 \%$ & 4.00 & 3.00 & 4.00 & 4.00 \\
Totales & $100 \%$ & 2.55 & 2.6 & 3.70 & 3.45 \\
\hline
\end{tabular}

Fuente: Elaboración Propia 


\subsection{Consideraciones legales}

\subsubsection{Identificación del marco legal}

PrestaMas se va a desarrollar como ONG de microfinanzas, dada la coincidencia para realizar acciones de desarrollo que involucra la Cooperación Técnica Internacional., la organización a constituirse se determina como una Organización No Gubernamental "ONG”, definidas como aquella:

“organizaciones de carácter social, independientes y autónomas, jurídicamente fundadas y que actúan sin finalidad de lucro. Su acción se orienta hacia la Cooperación al Desarrollo y hacia la búsqueda de acuerdos de ayudas entre Gobiernos con el objetivo de provocar la solidaridad y promover el desarrollo en los pueblos y sociedades del Tercer Mundo". Zabala Matulic I. (1994) en MARTÍNEZ GONZÁLEZ-TABLAS, 1995, pág. 353-54

Aunque en el ordenamiento legal peruano no existe normatividad especial que regule a las organizaciones no gubernamentales de desarrollo (ONGs, o simplemente ONGs), se entiende que su régimen legal se fundamenta a través de la figura de la asociación civil o de la fundación, personas jurídicas que de acuerdo a nuestra legislación vigente actúan sin fines de lucro, siendo el Código Civil la norma regula a la asociación, fundación y al comité como personas jurídicas típicas que si bien carecen de fin de lucro, se encuentran aptas para realizar actividades económicas siempre y cuando a partir de dichas actividades hagan cumplir su objeto social. La distinción de las ONGs respecto de las asociaciones es, su inscripción en la Secretaria Ejecutiva de Cooperación Técnica Internacional del Ministerio de la Presidencia En materia de la Cooperación Técnica Internacional está regulado en el Perú por: 
Decreto Legislativo No. 719 “Ley de Cooperación Internacional” publicada en el Diario Oficial "El Peruano" con fecha 10 de noviembre de 1991.

Establece las normas generales a que se sujeta la cooperación técnica internacional que se gestiona a través de los organismos del Estado y que proviene de fuentes del exterior del carácter público y/o privado.

La Cooperación Técnica Internacional es el medio por el cual el Perú recibe, transfiere y/o intercambia recursos humanos, bienes, servicios, capitales y tecnología de fuentes cooperantes externas cuyo objetivo es complementar y contribuir a los esfuerzos nacionales en materia de desarrollo, destinados a:

- Apoyar la ejecución de actividades y proyectos prioritarios para el desarrollo del país y de sus regiones.

- Adquirir conocimientos científicos y tecnológicos para su adaptación y aplicación en el Perú.

- Brindar preparación técnica, científica y cultural, a peruanos en el país o en el extranjero y a los extranjeros en el Perú.

Decreto Supremo No. 015-92-PCM “Reglamento de la Ley de Cooperación Internacional” publicado con fecha 30 de enero de 1992.

Se denomina "Registro de Organizaciones No Gubernamentales de Desarrollo" (ONGDPERU) constituidas en el Perú, al Registro que para esas personas jurídicas tiene carácter constitutivo y que es conducido por el Ministerio de la Presidencia.

Caracteriza a estas personas jurídicas el carecer de fines de lucro y tener como finalidad la realización de acciones de desarrollo con cooperación técnica internacional. Para la constitución de la ONG PrestaMas se consideran las siguientes características que se indican en la Tabla 35. 


\section{Tabla 35}

\section{Características de la Constitución de una ONG}

Estatuto:

Denominación

Duración

Domicilio.

Objeto y fines.

Bienes que integran al patrimonio.

La constitución y funcionamiento de la asamblea general de asociados, consejo directivo y demás órganos.

Las condiciones para la admisión, renuncia y exclusión de sus miembros.

Los derechos y deberes de los asociados.

Los requisitos para su modificación.

Las normas para la disolución y liquidación de la asociación y las relativas al destino final de los bienes.

Los demás pactos y condiciones que se establezcan.

La elección del primer consejo directivo.

Escritura Pública del Estatuto.

Libro de registro actualizado en que conste el nombre, actividad, domicilio y fecha de admisión de cada uno de sus miembros, con indicación de los que ejerzan cargos de administración o representación.
PrestaMas

Indefinida

Jr. Fco. B O’ Connor 4355 Urb.

Mariscal Cáceres SJL

Brindar educación y servicios

financieros

Aporte de los socios

Anexo

\section{Anexo}

Anexo

Anexo

Anexo

Anexo

Por desarrollar

Legalización de libros sociales: (1)

Libro de Actas, (2) Libro Registro de

Asociados (3) Libro de Actas de

Asamblea General de Asociados, y (4)

Libro de Actas de Consejo Directivo. 


\subsubsection{Ordenamiento Jurídico Tributario de empresa.}

Se rige bajo la modalidad de asociaciones sin fines de lucro, Régimen Impositivo de la ONG. La ONG PrestaMas se procederá a inscribir en el Registro Único de Contribuyentes, a cargo de la Superintendencia Nacional de Administración Tributaria - SUNAT; así mismo, se asentará en el Registro de Entidades Exoneradas del Impuesto a la Renta, respecto de las rentas destinadas a sus fines específicos en el distrito de San Juan de Lurigancho para los fines de: beneficencia, asistencia social, educación, cultural, científica, artística, literaria, deportiva, política, gremial, vivienda.

La ONG PrestaMas se procederá a Legalizar los Libros Contables ante Notario Público precisando el domicilio fiscal “Jr. Fco. B. O’ Connor 4355 Urb. Mariscal Cáceres SJL”. Por contabilidad completa se suele entender los siguientes libros: (1) Caja, (2) Diario, (3) Mayor, (4) Inventarios y (5) Balances. Los libros contables se legalizan

\subsection{Conclusiones}

- La disponibilidad de recursos de materia prima e insumos, humanos, financieros de equipos y de Know How es favorable para brindar el servicio financiero.

- La tecnología crediticia integra la prueba psicométrica de 15 preguntas para agilizar el proceso crediticio al tradicional de evaluación en microfinanzas.

- Se desarrolla una ambiente en el primer piso como inversión inicial que permita soportar el crecimiento de los dos o tres primeros años de existencia de ONG PrestaMas, dado que se podrá incluir, más personal en el periodo en la medida que crezca la cartera y el volumen de operaciones.

- Se elige la ONG por las coincidencias con el espíritu del Proyecto, las ventajas de fondeo con organismos internacionales, por uso de ganancias del periodo, régimen tributario y la posibilidad de operar en el segmento de financiamiento de pequeñas y microempresas. 


\section{CAPITULO VI: ASPECTOS ORGANIZACIONALES}

\subsection{Caracterización de la Cultura Organizacional Deseada}

Asegurar el futuro de la organización, parte de identificar una estructura flexible, abierta al cambio, que permita el logro de los objetivos organizacionales y que sea estable. Para la planeación estratégica del recurso humano, la estructura organizacional, modelos de comunicación formal e informal y la cultura de la organización para el inicio de las operaciones y actividades definidas se analizan los elementos:

1) El trabajo: Administrativos, comercial, operaciones

2) Las personas,

3) El arreglo formal,

4) La organización informal.

\subsubsection{Visión}

"Ser considerado como la más oportuna opción de financiamiento del distrito de San Juan de Lurigancho, con un sistema de evaluación moderno eficiente e innovador que permita generar valor a nuestros clientes y a la sociedad"

\subsubsection{Misión}

“Somos una opción financiera para pequeñas unidades económicas que permite cubrir necesidades financieras, sin mucho trámite documentario y con un asesoramiento permanente"

\subsubsection{Principios}

Humildad

Respeto

Honradez
Trabajo en equipo

Transparencia

Calidez
Tolerancia

Puntualidad

Compromiso 


\subsection{Formulación de Estrategia del Negocio}

ONG PrestaMas tiene por objetivo la oferta de micro créditos brindando educación y más asesoría financiera basado en el equipo humano inducido, con permanente desarrollo y capacitación de conocimientos y habilidades en un área de influencia de fácil y rápido recorrido, lo que lleva a la atención en plazo breve hasta de un día. La sencillez de proceso se basa además en el dominio de la zona de los Asesores. Los clientes se encuentran principalmente en los mercados, paradas y ferias del distrito, ellos cuentan con el negocio muchas veces en su domicilio.

Esto lleva a establecer una estrategia de enfoque por diferenciación dado que la competencia y los posibles sustitutos no tienen el asesoramiento hacia el cliente lo cual significa un valor agrado que valora mucho el cliente y esto se puede corroborar en el estudio cualitativo.

La asignación de trabajo por Asesor serán zonas contiguas entre un área de 50 cuadras por 50 cuadras donde con certeza se encuentran más de 6000 familias y de ellas el 10\% corresponde a actividades micro económico con necesidades de financiamiento que permitirá una eficiencia en tiempos de atención por la reducción de costo de dinero en desplazamiento y en tiempo de traslado. Establecemos una diferencia con la competencia informal de financiamiento crediticio por la vocación de educación financiera y autorregularnos a los estándares de una entidad formal que nos permita mitigar riesgos crediticios, de liquidez y solvencia.

El riesgo crítico de la ONG PrestaMas se enfoca en que la calidad de cartera se deteriore por colocaciones otorgadas que no cumplieron la evaluación crediticia, error humano o dolo del colaborador responsable del otorgamiento del crédito, ya que conlleva a la provisión de pérdidas y reducirá o eliminaría los beneficios proyectados, sustracción y salida de información de la organización, manejo de efectivo en la agencia o en las cobranzas en 


\section{Tabla 36}

Desarrollo de las Estrategias de Negocio

\begin{tabular}{|c|c|c|c|}
\hline Actividades & Desarrollo & Recursos y Ambiente & Políticas y planes diseñados \\
\hline Oferta de créditos en San Juan de & El Asesor atenderá por cuadras & Equipo humano especializado en & Asignación de zonas contiguas de 2500 \\
\hline \multirow[t]{2}{*}{ Lurigancho } & contiguas $(50 \times 50)$ lo cual permite & dominio de zona con soporte de Base de & cuadras $(50 \times 50)$ \\
\hline & mejor control y mayor asesoría. & Datos y mapeo. & \\
\hline \multirow[t]{3}{*}{ Otorgamiento de créditos } & Financiamiento individual de Capital de & Atención hasta 300 créditos por asesor & Desarrollo de crédito promedio de 500 \\
\hline & Trabajo o activo fijo entre 300 y 1000 & en montos créditos de menor cuantía. & soles. Crecimiento de cartera con \\
\hline & nuevos soles. & & reinversión de beneficios y fondeo local. \\
\hline Requisitos y trámites: Copia y & Identificación persona, negocio y & Disponibilidad de tecnología móvil con & Trabajo de campo y de oficina integrada \\
\hline verificación documentaria, visita de & vivienda en tiempo real permitirá a & comunicación y transmisión de datos en & a través de móvil. Permanencia de $90 \%$ \\
\hline \multirow[t]{3}{*}{ campo y vivienda. } & PrestaMas poder tener una respuesta & red. Equipo de almacenamiento con & en trabajo de campo. Asignación de \\
\hline & para aprobación o rechazo oportuna. & backup de seguridad. & equipos móviles o tabletas con red \\
\hline & Evaluación psicométrica. & & inalámbrica. \\
\hline Canales de Distribución y Cobranza. & Atención a través de ventanillas, & Personal de operaciones, cuentas de & Flexibilidad de alternativas de atención \\
\hline Atención de desembolso y cobros a & plataformas de cajeros automáticos, & recaudadoras en cajeros corresponsales y & a elección de solicitantes de créditos con \\
\hline través de ventanillas de agencia & cajeros corresponsales y en el negocio. & agentes bancarios y cobradores de campo. & recargo en operaciones fuera de agencia. \\
\hline
\end{tabular}

Fuente: Elaboración propia 
Tabla $\mathbf{N}^{\circ} 36$

Desarrollo de las Estrategias de Negocio

\begin{tabular}{|c|c|c|c|}
\hline Actividades & Desarrollo & Recursos y Ambiente & Políticas y planes diseñados \\
\hline Proveedor de Fondo para otorgamiento & Aporte de fundadores. & Interesados potenciales para & Apertura de Miembros asociados de la \\
\hline \multirow[t]{4}{*}{ de créditos a nuestros clientes } & Prestamos Locales. & convocatoria e incorporación de socios & ONGs \\
\hline & Reinversión de beneficios. & y/o financistas que buscan mayor & Información Pública de Resultados \\
\hline & Financiamiento y/o donaciones de & retorno de sus inversionistas a los & \\
\hline & Organismos Nacionales. & rendimientos de ahorros del sistema & \\
\hline Equipo Humano calificado con & Plan de convenios por a estudios de & financiero regulado. & \\
\hline asignación de ingresos fijos, variables y & colaboradores, convenios con empresas & Dirección y Gestión Humana de buenas & Desarrollo de una política de \\
\hline beneficios laborales y extra laborales & para acceder a descuentos. & prácticas de buen clima laboral. & capacitación y línea de carrera para los \\
\hline & & & colaboradores. \\
\hline
\end{tabular}

Fuente: Elaboración propia 
campo sujeto a asaltos, las oportunidades desarrollo de cartera de créditos concentrada geográficamente por el dominio de mercado por conocimiento de Asesor.

La estrategia por diferenciación se basa en un servicio a medida y oportuno.

\subsubsection{Análisis FODA}

Del análisis de la información obtenida de la entrevista con los expertos y del estudio de mercado se puede concluir de manera preliminar lo siguiente:

\section{Fortalezas:}

- Asesoría inmediata y personalizada por Asesor en zona en 6 horas máximo.

- Canales de atención adicionales al tradicional por cliente en un radio de kilómetro alrededor de su negocio

- Flexibilidad de la oferta por las múltiples combinaciones en montos de crédito y plazos de pago de cuotas (más de cien).

- Nivel de inversión bajo para la puesta en marcha de 333000 soles, una cuarta parte del capital mínimo que requiere una empresa regulada por la SBS.

- Personal altamente calificado con experiencia en trabajo de campo

- Montos mínimos de financiamiento reducen la exposición crediticia de la cartera

\section{Oportunidades:}

- Masa de micro empresarios sin acceso al crédito o acceso con crédito restringido y en crecimiento

- Gestión de cartera de 300 clientes por Asesor concentrados geográficamente

- Atención de la demanda insatisfecha y desatendida

- Servicio a través de plataformas de terceros en un minuto.

- Incremento del uso de la tecnología a través de los teléfonos celulares

- Concentración de los clientes

- Recortar la brecha del acceso a un financiamiento para el microempresario de SJL

- Mejorar la calidad de vida de los pobladores del distrito 


\section{Debilidades:}

- Mínimo impacto y penetración por ser una empresa nueva y no reconocida

- $\quad$ Alto costo de fondeo sobre promedio para ONG de $12.68 \%$, el doble de las entidades financieras captadoras de depósitos.

- $\quad$ Mínimo impacto por infraestructura moderada de PrestaMas.

- Baja capacidad de respuesta a eventual incremento de demanda.

- $\quad$ Alto costo de sistema de control de clientes.

- $\quad$ Competencia altamente desarrollada en el sector formal e informal

- $\quad$ Dependencia de plataformas externas

\section{Amenazas:}

- Integración de los proveedores.

- $\quad$ Gran disponibilidad de productos sustitutos

- $\quad$ Alto grado de la delincuencia en la zona

- $\quad$ Incremento del nivel de mora en el sector de la microempresa

- Desarrollo de programas de inclusivos de micro bancarización por parte del sector formal de financiamiento

- $\quad$ Bajo costo de cambio

- Reacción por parte del sector formal del financiamiento 
Tabla 37Matriz FODA

\begin{tabular}{|c|c|c|c|c|c|}
\hline & & \multicolumn{3}{|c|}{ Fortalezas } & \multirow{2}{*}{$\begin{array}{l}\text { Debilidades } \\
\text { Competencia altamente desarrollada en el sector formal e informal }\end{array}$} \\
\hline & & 1 & Asesoría inmediata por en zona en 6 horas máximo. & 1 & \\
\hline & & 2 & Mejores canales de atención & 2 & Mínimo impacto y penetración por ser una empresa nueva y no reconocida \\
\hline & & 3 & Atención física personalizada & 3 & Mínimo impacto por infraestructura moderada de PrestaMas. \\
\hline & & 4 & Montos mínimos de financiamiento & 4 & Poco nivel de inversión se refleja en poca infraestructura \\
\hline & & 5 & Flexibilidad de la oferta & 5 & Dependencia de plataformas externas \\
\hline & & 6 & Conocimiento del mercado, por parte de los funcionarios & 6 & Implementación de un sistema de control de clientes que puede generar un alto costc \\
\hline & & 7 & Menor nivel de inversión para la puesta en marcha & 7 & Bajo nivel educativo del sector para el uso de herramientas tecnológicas \\
\hline & Oportunidades & & Estrategia FO & & Estrategia DO \\
\hline 1 & Mercado sin acceso al crédito & 1 & Penetración de mercado de manera concentrada & 1 & Financiamiento de montos menores o iguales a S/. 1000 \\
\hline 2 & Los clientes están concentrados & 2 & Aprovechar las competencias del personal calificado & 2 & Hacer conocida nuestra propuesta/marca \\
\hline 3 & Buena relación valor/precio & 3 & Atender primero la demanda insatisfecha & 3 & Desarrollo de un sistema de recuperaciones más ágil \\
\hline 4 & Existe un demanda insatisfecha & 4 & Otorgar montos menores de mayor precio & 4 & Buscar nuevos socios para la inversión \\
\hline 5 & Alianzas con otras empresas para dar un mejor servicio & 5 & Fomentar el uso del canal de pago externo & 5 & Trabajo de campo permanente para fidelizar al cliente \\
\hline 6 & Bajos costos de implementación & 6 & Uso adecuado de la información en red para una respuesta rápida & 6 & Asesoramiento permanente \\
\hline 7 & Incremento del uso de la tecnología a través de los teléfonos celulares & & & & \\
\hline 8 & Montos mínimos de financiamiento reducen la exposición al riesgo & & & & \\
\hline & Amenazas & & Estrategia FA & & Estrategia DA \\
\hline 1 & Integración delante de los proveedores & 1 & Mejorar la calidad de servicios desarrollando capacitaciones & 1 & Desarrollo de los valores de empresa \\
\hline 2 & Bajo costo de cambio & 2 & Hacer de nuestro servicio un valor agregado que el cliente valore & 2 & Vender más el servicio que la marca \\
\hline 3 & Gran disponibilidad de productos sustitutos & 3 & No hacer mucho ruido publicitario & 3 & Fomentar la cultura del ahorro \\
\hline 4 & Alto grado de la delincuencia en la zona & 4 & Mantener un promedio de crédito máximo por cartera de S/. 500 & 4 & Fomentar un buen clima laboral \\
\hline 5 & Incremento del nivel de mora en el sector de la microempresa & & & & \\
\hline 6 & Reacción por parte del sector formal de financiamiento & & & & \\
\hline
\end{tabular}

Fuente: Elaboración propia 


\subsection{Determinación delas Ventajas Competitivas críticas}

Tomando como base el planteamiento de nuestra estrategia de enfoque por

diferenciación podemos indicar a partir de identificar nuestras principales actividades

cuales resultan ser nuestras ventajas competitivas como se puede apreciar en la tabla 38.

\section{Tabla 38}

\section{Ventajas Competitivas críticas}

\begin{tabular}{|c|c|}
\hline Actividades Críticas & Ventajas Competitivas \\
\hline El Asesor atenderá por cuadras contiguas $(50 \mathrm{x}$ & Contar con un protocolo no sólo en el manejo del territorio \\
\hline 50) lo cual permite mejor control y mayor & delimitado sino además de ello la experiencia del Asesor \\
\hline \multirow[t]{2}{*}{ asesoría. } & que conoce la necesidad de financiamiento y asesoría \\
\hline & permite tener una ventaja frente a la competencia. \\
\hline Financiamiento individual de Capital de Trabajo & $\mathrm{Al}$ mantener un crédito promedio de S/. 500 nuestra \\
\hline \multirow[t]{3}{*}{ o activo fijo entre 300 y 1000 nuevos soles. } & exposición al riesgo por mora se reduce en comparación al \\
\hline & crédito promedio del sector formal que es de S/. 10000 \\
\hline & ello permite un crecimiento sostenido. \\
\hline Identificación persona, negocio y vivienda en & Tener una tecnología crediticia ágil para dar una respuesta \\
\hline tiempo real permitirá a PrestaMas poder tener & a la viabilidad del crédito en tiempo real nos permite tener \\
\hline una respuesta para aprobación o rechazo & un mayor número de prospectos, el tiempo normal de \\
\hline oportuna. & respuesta supera incluso las 48 horas. \\
\hline \multirow[t]{3}{*}{ Evaluación psicométrica. } & Usar plataformas externas con cargo al cliente reduce \\
\hline & significativamente el costo fijo, ello se traduce e \\
\hline & rentabilidad. \\
\hline Atención a través de ventanillas, plataformas de & La mayor parte de los funcionarios no conocen la zona ni \\
\hline cajeros automáticos, cajeros corresponsales y en & la realidad del mercado, desde los fundadores hasta los \\
\hline el puesto de negocio. & colaboradores tiene pleno conocimiento y la experiencia \\
\hline PrestaMas contará con personal altamente & necesaria lo cual es una ventaja distintiva. \\
\hline calificado conocedores del negocio y de la zona & \\
\hline
\end{tabular}

Fuente: Elaboración propia 


\subsection{Diseño de la estructura organizacional deseada}

La estructura formal comprende: 1) El organigrama; 2) La definición de funciones y tareas para el logro de objetivos: 3) La administración y dirección del personal: 4) El sistema de incentivos y remuneraciones para generar motivación y, 5) El sistema de información y de decisión que precisará mucho mejores acciones a seguir.

El esqueleto que permite divisar las áreas, la división del trabajo y cantidad de unidades y cargos, la cobertura de funciones necesidades, el mismo que sintoniza con el mercado y característica de la industria. La organización cuenta con dos niveles en su estructura jerárquica:

\section{Nivel Representativo}

Conformado por los socios de la empresa.

\section{Nivel Ejecutivo}

Constituido por 1 Administrador que tiene nivel de funcionario, 6 de colaboradores operativos y 2 colaboradores contratados a través de servís. Cuyo ejercicio lo establecen los propios reglamentos internos.

- Administrador:

Encargado de la gestión de la agencia que tiene grado de gerencia, operatividad del negocio, supervisión de los créditos y la representación de la empresa.

- Supervisor de Operaciones:

Encargado de monitorea las operaciones de la empresa como desembolsos, cobros, transferencias, emisión de órdenes de pago, etc. Tiene bajo su cargo a 4 personas, dos de manera directa y dos de manera indirecta (operaciones, 
plataforma, personal de limpieza y conserje). También ve los temas de logística, permisos y licencias de la agencia

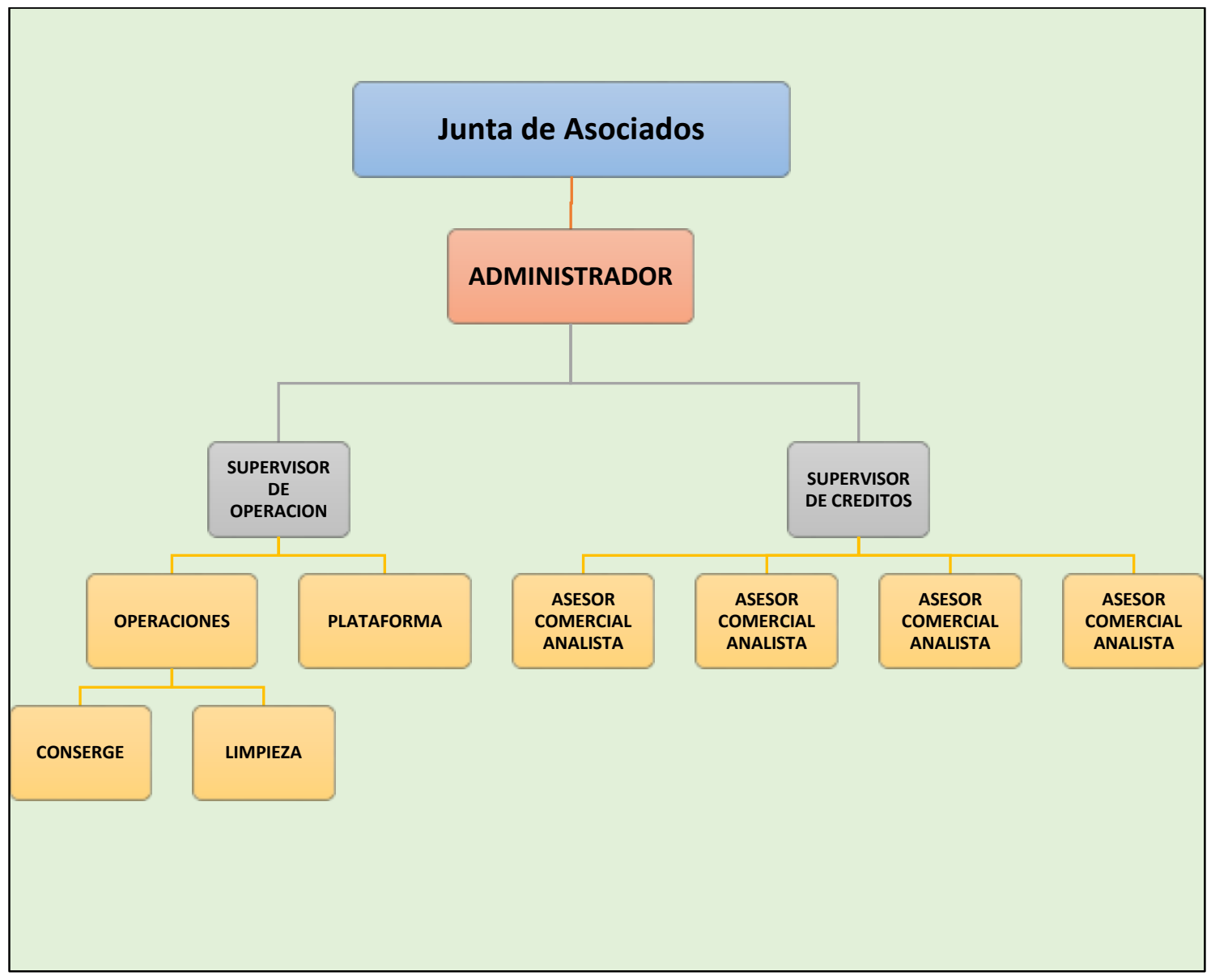

Figura 18 Organigrama de la Agencia

Fuente: Elaboración Propia

- Supervisor de Créditos:

Encargado de monitorear la parte comercial de la empresa, tendrá bajo su cargo a 04 asesores comerciales e inclusive el será un asesor comercial con cartera reducida). Coordinará la formalidad con operaciones

- Operaciones:

Encargado de desembolsos, cobros de cuotas y de servicios de consultas varios por comisión, apoya labores en plataforma (es segundo plataforma). 
- Plataforma:

Encargado de atender al público, velar por la documentación y administración de expedientes, apoya labores en plataforma (es segundo operaciones).

- Asesor de Créditos:

Encargado de generar prospectos de clientes de créditos.

\subsection{Diseño de Perfiles de puesto clave}

El perfil profesional y experiencia laboral requeridos se indica en la Tabal 39

\section{Tabla 39}

\section{Perfiles y Experiencia de Puesto Clave}

\begin{tabular}{|c|c|}
\hline Puesto Clave & Perfiles y Experiencia Laboral \\
\hline Administrador & $\begin{array}{l}\text { Profesional universitario titulado en carreras de empresas, negocios } \\
\text { o sociales. Sin créditos vigentes con atraso, un año de experiencia } \\
\text { en el puesto. }\end{array}$ \\
\hline Supervisor de Créditos & $\begin{array}{l}\text { Titulado de instituto o Bachiller universitario en carreras de } \\
\text { empresas, negocios o sociales. Sin créditos vigentes con atraso, un } \\
\text { año de experiencia en el puesto }\end{array}$ \\
\hline Supervisor de Operaciones & $\begin{array}{l}\text { Titulado de instituto o Bachiller universitario en carreras de } \\
\text { empresas, negocios o sociales. Sin créditos vigentes con atraso, un } \\
\text { año de experiencia en el puesto }\end{array}$ \\
\hline Plataforma & $\begin{array}{l}\text { Titulado de instituto o Bachiller universitario en carreras de } \\
\text { empresas, negocios o sociales. Sin créditos vigentes con atraso, seis } \\
\text { meses de experiencia en el puesto }\end{array}$ \\
\hline Asesor de Crédito & $\begin{array}{l}\text { Titulado de instituto o Bachiller universitario en carreras de } \\
\text { empresas, negocios o sociales. Sin créditos vigentes con atraso, } \\
\text { nueve meses de experiencia en el puesto }\end{array}$ \\
\hline
\end{tabular}




\subsection{Remuneraciones, compensaciones e incentivos}

El primer año se trabajará solo con sueldos fijos, el segundo y tercer año se otorgará un sueldo variable de hasta un $20 \%$ del sueldo fijo, el cuarto año adelante sueldo variable de hasta un $40 \%$ del sueldo fijo en el área comercial si alcanzan las metas propuestas, el desarrollo de una política de pagos variables adicionales al sueldo fijo es apropiada para lograr un óptimo funcionamiento de la empresa. Los supervisores cuentan con un fijo de 2380 y 2040 soles respectivamente, en tanto que los Asesores de créditos son de 1700 soles, personal de operaciones y plataforma es de 1360 soles, conserjería, limpieza, seguridad a través de servis 850 cada uno. Servicios de contador y abogado a tiempo parcial 1000 soles cada uno.

\section{Equipo Inicial Requerido}

\section{Tabla 40}

Cantidad de Personal, Remuneración y Régimen Laboral

\begin{tabular}{lccl}
\hline Personal & Sueldo & Cantidad & Régimen laboral \\
\hline Administrador */ & 2040 & 1 & Tiempo completo \\
Supervisor de Operaciones & 2380 & 0 & Tiempo completo \\
Supervisor de Créditos & 1700 & 4 & Tiempo completo \\
Asesor Comercial - Asesor Créditos & 1360 & 1 & Tiempo completo \\
Operaciones & 1360 & 0 & Tiempo completo \\
Plataforma & 850 & 0.5 & Tiempo completo \\
Limpieza & 850 & 0 & Tiempo completo \\
Conserje & 850 & 2 & Tiempo completo \\
Seguridad - Vigilancia & 2000 & 0.5 & Medio tiempo \\
Abogado & 2000 & 0.5 & Medio tiempo \\
Contador & & & \\
\hline
\end{tabular}

Fuente: Elaboración propia 
El total de empleados requeridos para que este proyecto de nueve personas, se contara con 08 colaboradores y 02 personal externo de apoyo.

La asignación de funcionarios y colaboradores corre por cuenta de los socios empresarios mayoritarios quienes reclutaran personal dada su experiencia en el rubro financiero, comercial y empresarial

Por su parte la estructura informal comprende: 1) las relaciones de poder, 2) las expectativas mutuas de los miembros de la organización y 3) la interacción de sus comportamientos.

Las estructuras se refieren a las relaciones relativamente fijas existentes entre los puestos de una organización, y son el resultado de los procesos de división del trabajo, departamentalización, esferas de control y delegación.

\subsection{Planificación y Política de recursos humanos}

Periodo de prueba y evaluación de desempeño permanente para identificar empleados que no puedan desarrollar sus actividades laborales con satisfacción para su reemplazo. $\underline{\text { Reclutamiento: }}$ Los medios de reclutamiento a usar son la invitación por referencia a posibles colaboradores preseleccionados, estudiantes de instituto y universidades locales, periódico, radio y volantes.

Oportunidad de prácticas laborales que permite suficiencia de candidatos, para depurar entre ellos a los que reúnen los requisitos necesarios para ocupar el puesto vacante. Incorporación de personal con experiencia con aptitudes y actitudes comprobadas para el puesto

Selección de personal: Identificación de actitudes y aptitudes para el puesto, habilidades presentas y potenciales plasmadas en formato de evaluación por puntajes. 
Coherencia de principios y valores personales con los de la organización.

Considerar sus objetivos e intereses del seleccionando con los de la organización Proceso de Selección: (1) Formulación de solicitud de empleo, (2) Entrevista con el encargado, (3) Pruebas psicológicas, físicas y de habilidades, (4) Posible entrevistar con el que sería el jefe inmediato y (5) Contratación.

Capacitación y desarrollo: Con el propósito de mantener o mejorar el desempeño de los trabajadores presentes o nuevos empleados, se prevé inducción y capacitación por parte del administrador de la agencia (práctica usual en sector microfinanzas), para alcanzar y refinar las habilidades específicas para el puesto en: (1) cursos de capacitación, (2) taller de clínica de ventas con simulación, (4) charlas de capacitación.

\section{Aspecto laboral}

Contrato de trabajo el primer año a tiempo completo, la prestación de un trabajo o servicio por necesidades de mercado, la condición de trabajo o servicio es personal o subordinado es a tiempo completo con goce de beneficios de ley y que la ONG considere; y la retribución o pago por concepto de sueldos o salarios por la prestación del servicio con un componente básico y otro variable.

\section{Aspecto extra laboral}

Lograr una mejor integración entre colaboradores y personal de soporte con el desarrollo de actividades extra laborales de esparcimiento de integración de personal y familiar

\section{Reglamento de trabajo:}

Instrumento para lograr la disciplina de los trabajadores y el adecuado cumplimiento de las labores para las cuales fue contratado, dando origen a una disciplina ejemplar y un buen servicio con precisión de: 
- Horas de entrada,

- Horas de salida,

- Lugar de trabajo,

- Días y lugar de pago,

- Permisos y licencias,

- Procedimientos para la aplicación de la disciplina,

- Formas para prevenir el riesgo de trabajo 


\section{CAPITUILO VII. PLAN DE MARKETING}

\subsection{Estrategia de Marketing}

La revisión de las características del mercado de Microfinanzas en San Juan de Lurigancho nos permite determinar que existe una oportunidad para que ONG PrestaMas pueda alcanzar sus objetivos de venta con su estrategia de Diferenciación y consiga liderar la atención de créditos de S/. 300 a S/. 1000 soles entendiendo que la oferta de la competencia descuida y/o abandona al atender operaciones de mayor cuantía s empresas. ONG PrestaMas sigue su estrategia de diferenciación basada en el servicio, aprende de aquellas empresas que ya están en el mercado, mejora la proyección de beneficios al reducir costes totales con la identificación de inversiones que se pueden obviar al trasladarse a gastos de terceros. ONG PrestaMas se esfuerza en desarrollar una comunicación directa con los clientes a fin de posicionarse en la mente del consumidor, aumentar las ventas a la vez que la información del producto, cliente y la competencia es evaluada permanentemente.

El bajo poder adquisitivo de la masa poblacional dedicada a pequeñas actividades económicas producto del desempleo estructural de San Juan de Lurigancho, constituye para PrestaMas un segmento potencial para atender con eficiencia, rapidez, agilidad.

\subsubsection{Estrategia de Producto}

El producto que ofrece PrestaMas es un crédito para Capital de Trabajo y/o Activo Fijo, es un servicio valorado por la comodidad con el cual se brinda basado en la sencillez del proceso, exigencia de mínimos requisitos, agilidad y rapidez de atención de las solicitudes, evaluación, verificación, desembolso y la recuperación del crédito. El proceso de brindar el servicio consiste en: 
- Proceso de evaluación del micro crédito tradicional reforzado con pruebas psicométricas.

- Verificación de negocio inmediata basada el dominio del colaborador de conocimiento de la zona.

- Asesoría permanente por parte del Asesor como parte del valor agregado

- Distintas formas de desembolso, a preferencia del cliente.

Las características del producto se indican en la Tabla 41.

\section{Tabla 41}

Características del Producto

\begin{tabular}{ll}
\hline Criterios & Características \\
\hline Variedad de productos & Para Activo Fijo y Capital de Trabajo \\
Importes de $\mathrm{S} / 300$ a S/ 1,000 \\
Pagos semanales \\
Marca & Prestica \\
Logo & Tu solución más confiable \\
\hline
\end{tabular}

Figura 7. Logo de la ONG PrestaMas

Servicio

Ágil, rápido, sencillo, con plataforma de atención en agencia a través de canales externos y fácil acceso

Fuente: Elaboración Propia

\subsubsection{Estrategia de Precio}

ONG PrestaMas brinda el servicio con precios por encima de la banca tradicional al asegurar rapidez, sencillez y agilidad de atención de los clientes y 
potenciales clientes desatendidos e insatisfechos. ONG PrestaMas además diferencia mayores precios a montos más pequeños y menores precios a montos más grandes. En base a referencias estadísticas de créditos con frecuencia de pagos semanal y visita a la ONG de créditos Crecer se plantea tres escenarios de crédito solicitados, la primera detalla un préstamo promedio de S/. 400 a una TCES de $2.97 \%$ lo cual genera un TCEA de $350 \%$, la segunda simulación muestra un préstamo promedio por S/. 600 a una TCES de $2.88 \%$ que genera una TCEA $330 \%$ y finalmente la tercera es de un préstamo promedio de S/. 750 a una TCES de $2.73 \%$ que genera una TCEA de $300 \%$ todos a un período de 8 semanas, como se indica en la Tabla 42.

\section{Tabla 42}

Tarifas de Crédito por importe otorgado.

\begin{tabular}{lrrr}
\hline \multicolumn{1}{c}{ Características } & \multicolumn{3}{c}{ Crédito a cuatro cuotas fijas semanales } \\
\hline Monto Promedio & S/. 400 & S/ 600 & S/ 850 \\
Interés anual "TCEA" & $350 \%$ & $330 \%$ & $300 \%$ \\
Interés semanal "TCES" & $2.97 \%$ & $2.88 \%$ & $2.73 \%$ \\
Desembolso "SC" & S/. 400 & S/.600 & S/ 850 \\
Pago de Cuota "R" & S/. 56.91 & S/. 85.03 & S/.119.72 \\
Pagos Totales & S/. 455.24 & S/. 680.24 & S/. 957.79 \\
Pagos Totales - Pago de Cuota & S/. 55.24 & S/. 80.24 & S/. 107.79 \\
Gastos de Transporte & S/ $1.20-2.00$ & S/ $1.20-2.00$ & S/ $1.20-2.00$ \\
\hline Fuente: Elaboración propia & & &
\end{tabular}

\subsubsection{Estrategia de Distribución}

PrestaMas cuenta con los canales tradicionales de distribución de la industria que significa una agencia u oficina de atención con un equipo de operaciones para desembolso y cobros. Adicional a ello PrestaMas prevé el uso de intermediarios para 
lograr mayor cobertura que incremente la presencia y puntos de ventas y atención de desembolsos y cobranzas.

- Contaremos con un local ubicado en Calle Francisco B `O Connor 4355 Urb. Mariscal Cáceres a media cuadra transversal a la Av. Héroes del Cenepa Este con fácil acceso.

- Sistema de desembolso en agencia o a través de canales de distribución como depósito a cuenta, transferencia, etc.

- Sistema de cobranza en agencia, de canales de distribución como depósito a cuenta recaudadora a través del uso de plataformas de entidades financieras y/o cobranza in situ con recuperadores de campo.

- El contacto con el cliente se dará a través de nuestros asesores de negocios en el campo en su mayor parte y también en oficina con los funcionarios presentes.

PrestaMas considera establecer alianzas estrategias con organizaciones de comerciantes para colocar módulos portátiles de atención y ofertar productos en ferias, paradas y mercados.

\subsubsection{Estrategia de Promoción y Publicidad}

Una de las principales amenazas de nuestro modelo de negocios es que como sustitutos tenemos a los prestamistas informarles, en la actualidad ellos son la alternativa para estos micros empresarios en la adquisición de préstamos, dichos créditos carecen de sustento técnico que origina una elevada proporción de morosos lo que conlleva a desarrollar operativos de cobranzas; el método de cobranza que aplican es coercitivo, denigra la imagen y ahuyenta potenciales clientes. Nuestra tecnología micro financiera reduce drásticamente malos pagadores de la cartera de clientes desde la evaluación, mantiene una imagen apropiada de la ONG lo cual aumenta nuestras 
posibilidades de uso de micro créditos de PrestaMas, consideramos que nuestra promoción no puede seguir solo los canales tradicionales de publicidad masiva con el objetivo de no generar mucha visibilidad ante los sustitutos.

Además, nuestro enfoque es realizar un proceso comercial en el cual el cliente no tenga que acercarse necesariamente a nuestras oficinas, sino que vamos a realizar una venta más proactiva que se desarrolle en un $95 \%$ en el campo, entendiendo a nuestros potenciales clientes nuestra idea es que nuestros asesores comerciales se acerquen a los mercados y comercios y realicen el contacto con los clientes en sus mismos negocios y puestos de trabajo. Es por eso que buscamos que el servicio personalizado y la practicidad para acceder al crédito sea nuestro sello distintivo, en ese sentido la publicidad estará más enfocada a que sea de boca a boca, es decir que nuestros propios clientes, dada la experiencia vivida en el servicio, puedan transmitir positivamente y recomendar nuestros servicios, entendiendo que este tipo de segmento al cual nos dirigimos es un grupo de comerciantes cerrado y que se conocen entre ellos.

Consideramos que el Asesor Comercial es un factor clave dentro de nuestro proceso comercial, dado esto vamos a orientar a que nuestra promoción se realice a través de ellos mediante Material de Trabajo Promocional como Volantes y Merchandising. 


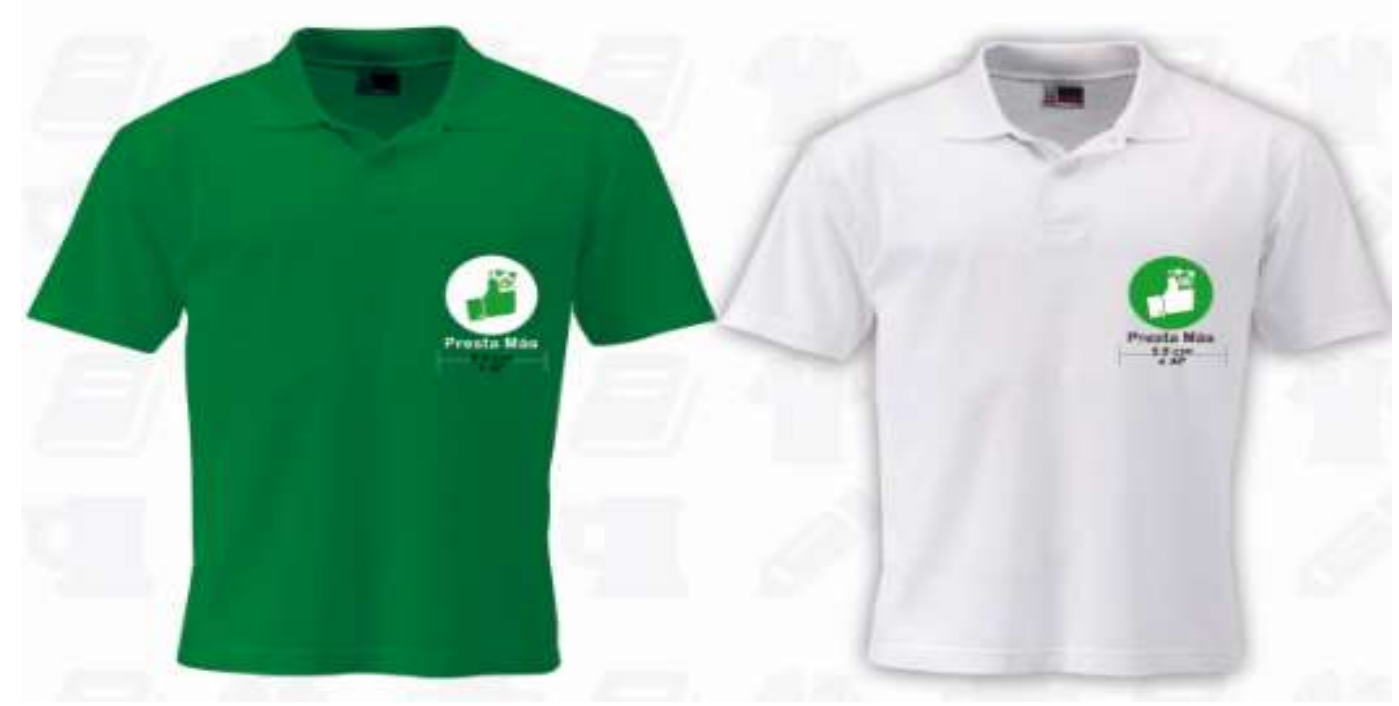

Figura 19 Polo distintivo del colaborador

Fuente: Elaboración Propia

\section{Material de Trabajo Promocional}

Nos referimos con material de trabajo promocional con toda la publicidad que el Asesor Comercial puede realizar al momento de realizar sus labores, es decir uniforme, carpetas de trabajo, tarjetas de presentación y la folletería con el logo de la empresa.

\section{Volantes}

El volante está diseñado en un formato bastante ligero y que sea fácil de lectura, así como en un tamaño adecuado que consideramos puede ser más atractivo para guardar y posteriormente pueda ser pasado de una persona a otra, si fuera en un formato más grande probablemente sería un poco pesado para el cliente llevarlo y lo botaría. En cuanto al mensaje en el volante, buscamos enfocarnos con un slogan corto y directo, el cual es "PrestaMas, tu solución más confiable", queremos diferenciarnos del prestamista informal por eso queremos que el cliente nos asocie con confianza, luego resaltamos otro punto diferenciador con la siguiente frase en el volante "No más trámites engorrosos, te llevamos tu préstamo a tu negocio", con lo cual también nos distanciamos de la banca tradicional y micro financieras. En la cara principal ponemos 
un plano de donde nos ubicamos, lo cual no es una contradicción con nuestro modelo de negocio, ya que no es la finalidad de que el cliente se acerque a nuestras oficinas, sino el objetivo es que sepan que tenemos oficinas y que nos pueden ubicar para cualquier consulta, es decir transmitir confianza. En la cara posterior, tratamos de acercarnos a nuestro público objetivo poniendo la foto de un bodeguero, e indicando cuales son los requisitos mínimos.
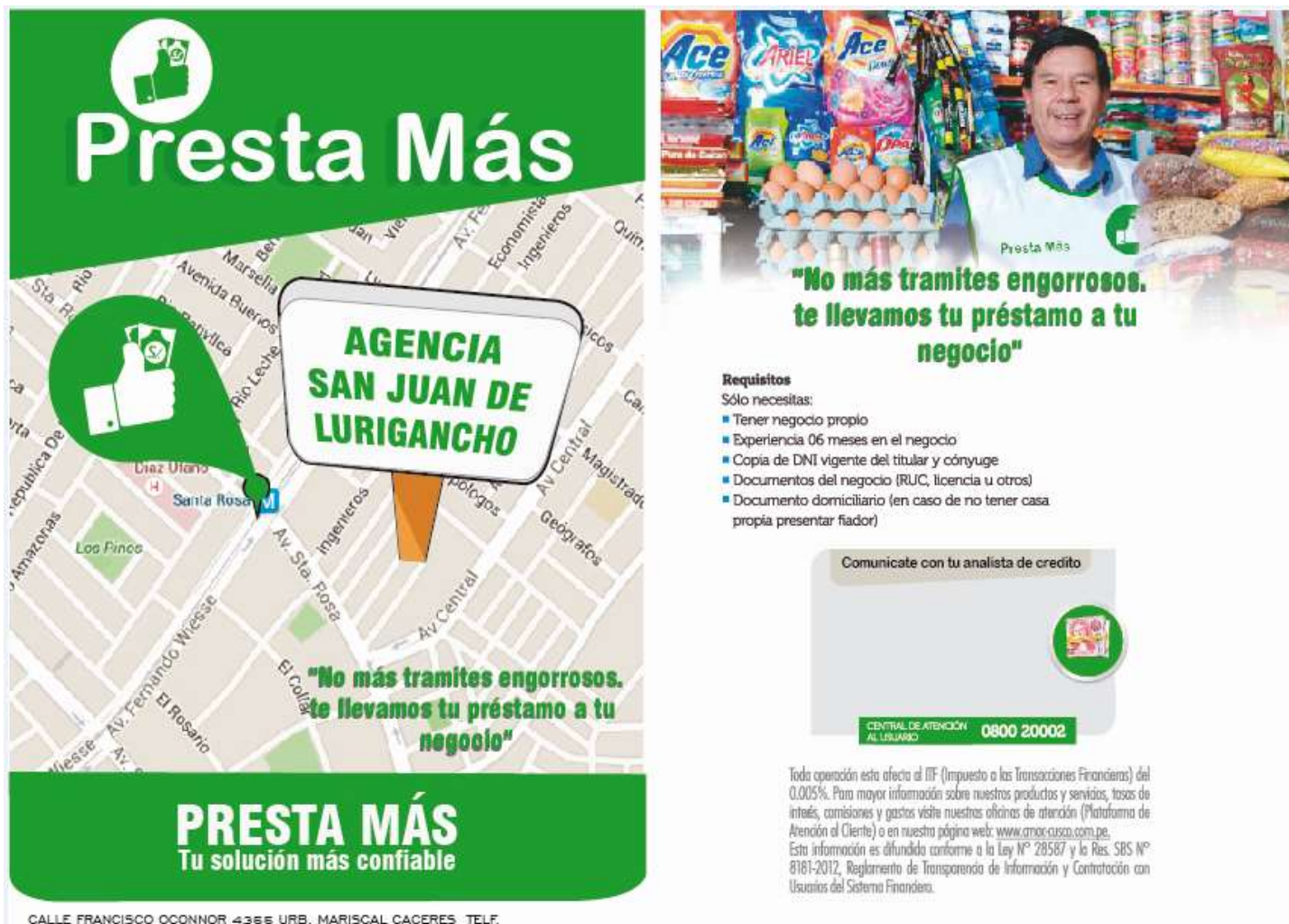

Figura 20 Volante de Promoción.

Fuente: Elaboración Propia

\section{Merchandising}

El merchandising que vamos a ofrecer a nuestros clientes tiene como finalidad (además de ser promocional) ser de utilidad para el que lo recibe, es por eso que en esta primera etapa serian lapiceros, llaveros y destapadores. Hay que tener en cuenta que la persona que va a entregar este material es el Asesor Comercial en su labor diaria, entonces el 
merchandising a considerar tiene que ser ligero para que lo pueda llevar durante sus actividades de campo en los principales mercados de San Juan de Lurigancho.
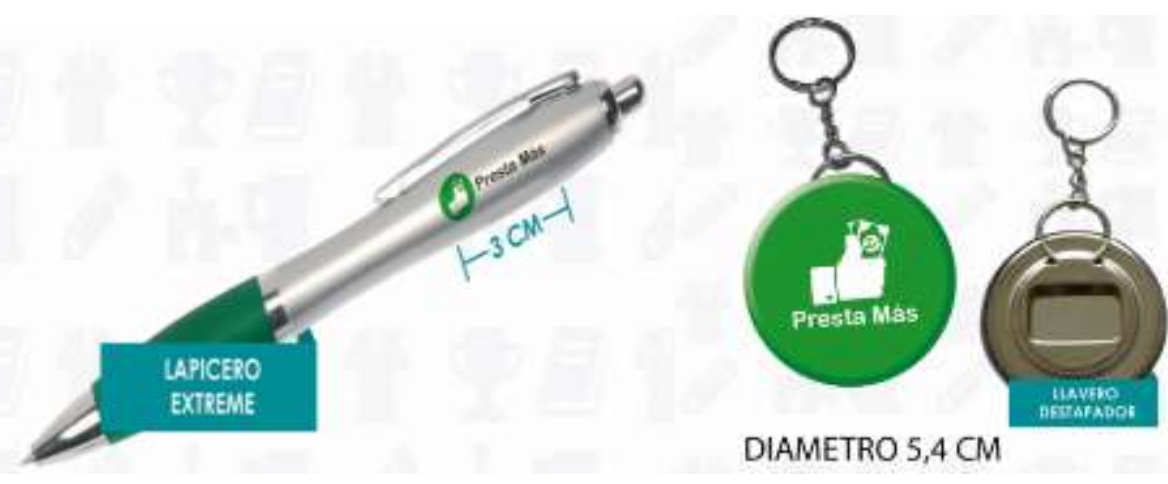

DIAMETRO 5,4 CM

Figura 21Merchandising.

Fuente: Elaboración Propia

PrestaMas desarrolla actividades permanentes de:

- Crear actividades o eventos para promocionar sus servicios.

- Colocar anuncios publicitarios en vehículos de la empresa, o en vehículos de transporte público de la zona.

- Crear carteles, volantes, presentaciones, folletos o calendarios publicitarios.

- Crear una Página Web atractiva y dinámica.

- Usar aplicaciones móviles para promocionarse a través de anuncios.

Si bien es cierto tenemos un local ubicado en Calle Francisco B 'O Connor 4355 - Urb. Mariscal Cáceres, nuestro modelo de negocio tiene como objetivo que las operaciones se generen en el mismo campo, en los mercados a los cuales vamos a atacar. Es importante precisar que dentro de San Juan de Lurigancho estamos enfocándonos en las zonas más profundas del distrito, debido a que al ingreso del distrito encontramos también muchos mercados y zonas con pequeños y micro empresarios, sin embargo, estos si tienen mayor acceso al crédito al ser más formales, como por ejemplo en la zona 
de Zarate. Los principales mercados que van a ser barridos por nuestros Asesores

Comerciales se indican en la tabla 43:

\section{Tabla 43}

Principales Mercados y Ubicación Geográfica en el distrito

\begin{tabular}{|c|c|}
\hline Grupo de Comerciantes & Ubicación \\
\hline Mercado Virgen del Carmen & $\begin{array}{l}\text { Montenegro cerca del paradero } 4 \text { con un aproximado de } 500 \\
\text { comerciantes. }\end{array}$ \\
\hline Mercado Valle Sagrado & $\begin{array}{l}\text { Cerca del paradero } 3 \text { de Huáscar con un aproximado de } 900 \\
\text { comerciantes. }\end{array}$ \\
\hline Mercado 11 de Enero & $\begin{array}{l}\text { Cerca del paradero } 4 \text { de Motupe con un aproximado de } 300 \\
\text { comerciantes. }\end{array}$ \\
\hline Mercado 10 de Octubre & $\begin{array}{l}\text { Cerca del paradero } 5 \text { de Wiesse con un aproximado de } 400 \\
\text { comerciantes. }\end{array}$ \\
\hline Mercado Mayorista & $\begin{array}{l}\text { A una cuadra del paradero Portón cerca del límite de San Juan de } \\
\text { Lurigancho y Lurigancho con un aproximado de } 800 \text { comerciantes. }\end{array}$ \\
\hline Mercado Unión & $\begin{array}{l}\text { Cerca del cruce de la Av. Bayoyar y Héroes del Cenepa con un } \\
\text { aproximado de } 400 \text { comerciantes. }\end{array}$ \\
\hline Mercado 1 de Setiembre & $\begin{array}{l}\text { Cruce de la Av. Central y Héroes de Cenepa, cerca de nuestras } \\
\text { oficinas, con un aproximado de } 1,000 \text { comerciantes. }\end{array}$ \\
\hline Mercado José Carlos Mariátegui & $\begin{array}{l}\text { Ubicado frente al Estadio Mariátegui con un aproximado de } 900 \\
\text { comerciantes. }\end{array}$ \\
\hline Mercado de Motupe & $\begin{array}{l}\text { Paradero } 8 \text { de la Av. Central, con un aproximado de } 300 \\
\text { comerciantes. }\end{array}$ \\
\hline
\end{tabular}

Fuente: Elaboración Propia

Adicional a este trabajo con los mercados, se realizará un trabajo especial con los bodegueros de este distrito ya que existe un interesante potencial en ese segmento de clientes que puedan tener requerimientos de capital de trabajo. 
El presupuesto inicial que estamos considerando para desarrollar el plan de marketing planteado es de S/. 4,478.10 y consiste en lo siguiente:

100 Polos Pique

100 Lapiceros Metálicos

500 Lapiceros de Plástico

100 Llaveros Destapadores

1,000 Volantes

Durante la evaluación del proyecto estimamos que vamos a necesitar 3 veces este requerimiento de material para poder realizar nuestra operación comercial.

\subsection{Estrategia de Ventas}

Adicional a participar permanentemente en ferias, capacitar y motivar el área comercial, usar promociones de ventas y regalar artículos de merchandising consideramos lo siguiente en la Tabla 44:

\subsubsection{Plan de Ventas}

La clave del éxito de todo negocio se inicia en las ventas, para conseguir los objetivos de venta esperada se trabajará principalmente en el:

- Volanteo y desarrollo de base de datos propia con el registro diario de 15 potenciales clientes.

- Prospección de base de datos adquiridos por la jefatura y colaboradores.

- Llamadas telefónicas y envió de cartas mailing a clientes potenciales nuevos e inactivos.

- Barridos promocionales en grupo con polos con colores y logo de la ONG por lapso de tres horas por zona comercial de un mercado y dos cuadras de negocios cercanos los días martes, jueves y sábado de cada semana. 
- Distribución de material poblacional con el logo de PrestaMas

\section{Tabla 44}

\section{Estrategias de Ventas y proceso Táctico de Implementación}

\begin{tabular}{|c|c|}
\hline Cualidades Estratégicas & Proceso Táctico \\
\hline Eficiencia & $\begin{array}{l}\text { Investiga las potenciales persona a contactar aumenta las } \\
\text { probabilidades de éxito. }\end{array}$ \\
\hline Prospección & $\begin{array}{l}\text { Perfilar, conocer más a fondo ser proactivo y definir las } \\
\text { características de los candidatos a convertirse en tus clientes. }\end{array}$ \\
\hline Atención en los detalles & $\begin{array}{l}\text { Escucha activa, ser conciso y no desviarse en los detalles } \\
\text { irrelevantes, enfoque en la necesidad y conocimiento de las } \\
\text { expectativas. }\end{array}$ \\
\hline Cumplimiento de promesas & Proyectar imagen sólida. \\
\hline Trabajo de preguntas inteligentes & $\begin{array}{l}\text { Entrenamiento de los colaboradores del área comercial, escoger } \\
\text { preguntas inteligentes que les ayudarán a constatar, validar, } \\
\text { verificar y aclarar toda la información recibida. }\end{array}$ \\
\hline Cobranza desde las ventas & Confirmar la capacidad y voluntad de pago desde un principio. \\
\hline Brindar servicios adicionales & La asesoría del Asesor \\
\hline Diversificación & $\begin{array}{l}\text { Créditos pequeños en varios clientes es mejor que un cliente con un } \\
\text { crédito grande para asignar un mayor precio (tasa de interés) y } \\
\text { reducir riesgos de perdida por incobrabilidad o pago tardío. }\end{array}$ \\
\hline Diversificar Puntos de venta & $\begin{array}{l}\text { Uso de plataformas de las entidades financieras. } \\
\text { Módulos de atención portátiles mejora la exhibición de los } \\
\text { productos. }\end{array}$ \\
\hline Monitoreo de cliente post - venta & Descubrir oportunidades de mejorar el negocio. \\
\hline Monitorear la competencia & Enfocarnos en sus puntos débiles y reforzar nuestras fortalezas \\
\hline
\end{tabular}

Fuente. Elaboración propia

Para plasmar el Presupuesto consideramos los elementos y las consideraciones

siguientes en la Tabla 45: 


\section{Tabla 45}

Acciones del Plan de Ventas

\begin{tabular}{|c|c|}
\hline Acciones & Consideraciones \\
\hline Supuesto, precio de venta & $\begin{array}{l}\text { TCEA o Tasa mínima anual del } 300 \% \text {, equivale a una tasa del } \\
12.25 \% \text { mensual o una tasa de } 2.76 \% \text { semanal, de acuerdo al monto } \\
\text { de crédito, existen tasas de Mercado que alcanza } 20 \% \text { mensual. } \\
\text { Se espera el contacto diario de } 15 \text { clientes mínimo y una eficiencia } \\
\text { de atención de tres prospectos. }\end{array}$ \\
\hline Proceso de Ventas & $\begin{array}{l}\text { Promoción, Prospección, Contacto con el cliente, Oferta, } \\
\text { Explicación del producto, Escucha y Respuesta a consultas, cierre. }\end{array}$ \\
\hline Canales y mecanismo de llegada & $\begin{array}{l}\text { Crédito inmediato, con requisitos mínimos. } \\
\text { Contacto directo, barrido de Promoción con volantes informativos. } \\
\text { Atención in situ o personal de plataforma para atención de } \\
\text { interesados. La fuerza de ventas son los Asesores con habilidades, } \\
\text { aptitudes y actitudes para transmitir con efectividad todos los } \\
\text { beneficios }\end{array}$ \\
\hline Presupuesto Ventas Total & $\begin{array}{l}\text { Año } 1 \text { y 2: } 8 \% \text { de los Ingresos Anuales, el mismo que se prorratea } \\
\text { por zonas asignadas (número de Asesores). Siguientes años 3\%. }\end{array}$ \\
\hline Costo de Fondeo & $1 \%$ Mensual. \\
\hline
\end{tabular}

Fuente: Elaboración Propia. 
Tabla 46

Colocaciones, Número de Asesor, Número de Clientes y Estado de Resultado Año 1 y Año 2

\begin{tabular}{ccccrrrr}
\hline Mes & $\begin{array}{c}\text { Saldo } \\
\text { Cartera }\end{array}$ & Colocación/Ventas & $\begin{array}{c}\text { Colocación } \\
\text { Promedio }\end{array}$ & Analista & $\begin{array}{c}\text { Días } \\
\text { Mes }\end{array}$ & $\begin{array}{c}\text { Crédito } \\
\text { Promedio }\end{array}$ & $\begin{array}{r}\mathbf{N}^{\circ} \\
\text { Créditos }\end{array}$ \\
\hline 1 & 75805 & 108,000 & 27,000 & 4 & 24 & 375 & 3 \\
2 & 115,748 & 108,000 & 27,000 & 4 & 24 & 375 & 3 \\
3 & 115,748 & 108,000 & 27,000 & 4 & 24 & 375 & 3 \\
4 & 115,748 & 108,000 & 27,000 & 4 & 24 & 375 & 3 \\
5 & 115,748 & 108,000 & 27,000 & 4 & 24 & 375 & 3 \\
6 & 115,748 & 108,000 & 27,000 & 4 & 24 & 375 & 3 \\
7 & 141,016 & 144,000 & 36,000 & 4 & 24 & 400 & 4 \\
8 & 161,069 & 153,600 & 38,400 & 4 & 24 & 400 & 4 \\
9 & 164,620 & 153,600 & 38,400 & 4 & 24 & 400 & 4 \\
10 & 164,620 & 153,600 & 38,400 & 4 & 24 & 400 & 4 \\
11 & 164,620 & 153,600 & 38,400 & 4 & 24 & 400 & 4 \\
12 & 164,620 & 153,600 & 38,400 & 4 & 24 & 400 & 4 \\
Año 1 & 164,620 & $1,560,000$ & 38,400 & 4 & 288 & 400 & 412 \\
\hline
\end{tabular}

\begin{tabular}{rcr}
\hline Ingresos & $\begin{array}{c}\text { Costo } \\
(12.25 \%\end{array}$ & $\begin{array}{c}\text { Morosidad- } \\
\text { Dinero }\end{array}$ \\
$\begin{array}{r}\text { Incobrables } \\
(0.30 \%)\end{array}$ \\
\hline 9,283 & - & 227 \\
14,175 & - & 347 \\
14,175 & - & 347 \\
14,175 & - & 347 \\
14,175 & - & 347 \\
14,175 & - & 347 \\
17,269 & - & 423 \\
19,725 & - & 483 \\
20,160 & - & 494 \\
20,160 & - & 494 \\
20,160 & - & 494 \\
20,160 & - & 494 \\
197,790 & - & 4845
\end{tabular}




\begin{tabular}{ccccrrrr}
\hline Mes & $\begin{array}{c}\text { Saldo } \\
\text { Cartera }\end{array}$ & Colocación/Ventas & $\begin{array}{c}\text { Colocación } \\
\text { Promedio }\end{array}$ & Analista & $\begin{array}{c}\text { Días } \\
\text { Mes }\end{array}$ & $\begin{array}{c}\text { Crédito } \\
\text { Promedio }\end{array}$ & $\begin{array}{r}\text { N }^{\circ} \\
\text { Créditos }\end{array}$ \\
\hline 13 & 225,263 & 240,000 & 48,000 & 5 & 24 & 400 & 5 \\
14 & 267,747 & 255,000 & 51,000 & 5 & 24 & 425 & 5 \\
15 & 273,294 & 255,000 & 51,000 & 5 & 24 & 425 & 5 \\
16 & 273,294 & 255,000 & 51,000 & 5 & 24 & 425 & 5 \\
17 & 273,294 & 255,000 & 51,000 & 5 & 24 & 425 & 5 \\
18 & 273,294 & 255,000 & 51,000 & 5 & 24 & 425 & 5 \\
19 & 395,003 & 428,400 & 61,200 & 7 & 24 & 450 & 6 \\
20 & 476,822 & 453,600 & 64,800 & 7 & 24 & 450 & 6 \\
21 & 486,143 & 453,600 & 64,800 & 7 & 24 & 450 & 6 \\
22 & 486,143 & 453,600 & 64,800 & 7 & 24 & 450 & 6 \\
23 & 486,143 & 453,600 & 64,800 & 7 & 24 & 450 & 6 \\
24 & 486,143 & 453,600 & 64,800 & 7 & 24 & 450 & 6 \\
Año 2 & 486,143 & $4,211,400$ & 64,800 & 7 & 288 & 450 & 1,080 \\
\hline
\end{tabular}

\begin{tabular}{rcr}
\hline $\begin{array}{r}\text { Ingresos } \\
(12.25 \%\end{array}$ & $\begin{array}{c}\text { Costo } \\
\text { Dinero }\end{array}$ & $\begin{array}{r}\text { Morosidad- } \\
\text { Incobrables } \\
\text { Mensual })\end{array}$ \\
\hline $2 \%)$ & $(0.30 \%)$ \\
\hline 27,586 & 4,269 & 1,126 \\
32,789 & 4,269 & 1,339 \\
33,468 & 4,269 & 1,366 \\
33,468 & 4,269 & 1,366 \\
33,468 & 4,269 & 1,366 \\
33,468 & 4,269 & 1,366 \\
48,373 & 4,269 & 1,975 \\
58,393 & 4,269 & 2,384 \\
59,534 & 4,269 & 2,431 \\
59,534 & 4,269 & 2,431 \\
59,534 & 4,269 & 2,431 \\
59,534 & 4,269 & 2,431 \\
539,149 & 51,230 & 22,013 \\
\hline
\end{tabular}


Para el segundo año se prevé fondear el incremento en saldo de cartera al mes 24 menos el efectivo de caja disponible al cierre del mes 12.

\section{Tabla 47}

Evolución del Saldo de Cartera, Colocaciones, Número de Asesor, Número de Clientes y Estado de Resultado Año 3 y Año 4

\begin{tabular}{cccccccr}
\hline Mes & $\begin{array}{c}\text { Saldo } \\
\text { Cartera }\end{array}$ & Colocación/Ventas & $\begin{array}{c}\text { Colocación } \\
\text { Promedio }\end{array}$ & Analista & $\begin{array}{c}\text { Días } \\
\text { Mes }\end{array}$ & $\begin{array}{c}\text { Crédito } \\
\text { Promedio }\end{array}$ & Créditos \\
\hline 25 & 645,332 & 680,400 & 75,600 & 9 & 24 & 450 & 7 \\
26 & 755,746 & 718,200 & 79,800 & 9 & 24 & 475 & 7 \\
27 & 769,726 & 718,200 & 79,800 & 9 & 24 & 475 & 7 \\
28 & 769,726 & 718,200 & 79,800 & 9 & 24 & 475 & 7 \\
29 & 769,726 & 718,200 & 79,800 & 9 & 24 & 475 & 7 \\
30 & 769,726 & 718,200 & 79,800 & 9 & 24 & 475 & 7 \\
31 & 969,766 & $1,003,200$ & 91,200 & 11 & 24 & 475 & 8 \\
32 & $1,112,233$ & $1,056,000$ & 96,000 & 11 & 24 & 500 & 8 \\
33 & $1,311,761$ & $1,056,000$ & 96,000 & 11 & 24 & 500 & 8 \\
34 & $1,311,761$ & $1,056,000$ & 96,000 & 11 & 24 & 500 & 8 \\
35 & $1,311,761$ & $1,056,000$ & 96,000 & 11 & 24 & 500 & 8 \\
36 & $1,311,761$ & $1,056,000$ & 96,000 & 11 & 24 & 500 & 8 \\
Año 3 & $1,311,761$ & $10,554,600$ & 96,000 & 11 & 288 & 500 & 2,264 \\
\hline
\end{tabular}

\begin{tabular}{rcr}
\hline $\begin{array}{r}\text { Ingresos } \\
(12.25 \% \\
\text { Mensual })\end{array}$ & $\begin{array}{c}\text { Costo } \\
\text { Dinero } \\
(1 \%)\end{array}$ & $\begin{array}{r}\text { Morosidad- } \\
\text { Incobrables } \\
(0.30 \%)\end{array}$ \\
\hline 79,029 & 11,855 & 3,227 \\
92,550 & 11,855 & 3,779 \\
94,262 & 11,855 & 3,849 \\
94,262 & 11,855 & 3,849 \\
94,262 & 11,855 & 3,849 \\
94,262 & 11,855 & 3,849 \\
118,759 & 11,855 & 4,849 \\
136,206 & 11,855 & 5,561 \\
138,598 & 11,855 & 5,659 \\
138,598 & 11,855 & 5,659 \\
138,598 & 11,855 & 5,659 \\
138,598 & 11,855 & 5,659 \\
$1,357,984$ & 11,855 & 55,445 \\
\hline
\end{tabular}




\begin{tabular}{cccccccr}
\hline Mes & $\begin{array}{c}\text { Saldo } \\
\text { Cartera }\end{array}$ & Colocación/Ventas & $\begin{array}{c}\text { Colocación } \\
\text { Promedio }\end{array}$ & Analista & $\begin{array}{c}\text { Días } \\
\text { Mes }\end{array}$ & $\begin{array}{c}\text { Crédito } \\
\text { Promedio }\end{array}$ & Créditos \\
\hline 37 & $1,376,020$ & $1,404,000$ & 108,000 & 13 & 24 & 500 & 9 \\
38 & $1,554,000$ & $1,474,200$ & 113,400 & 13 & 24 & 525 & 9 \\
39 & $1,579,964$ & $1,474,200$ & 113,400 & 13 & 24 & 525 & 9 \\
40 & $1,579,964$ & $1,474,200$ & 113,400 & 13 & 24 & 525 & 9 \\
41 & $1,579,964$ & $1,474,200$ & 113,400 & 13 & 24 & 525 & 9 \\
42 & $1,579,964$ & $1,474,200$ & 113,400 & 13 & 24 & 525 & 9 \\
43 & $1,871,811$ & $1,890,000$ & 126,000 & 15 & 24 & 525 & 10 \\
44 & $2,088,765$ & $1,980,000$ & 132,000 & 15 & 24 & 550 & 10 \\
45 & $2,122,051$ & $1,980,000$ & 132,000 & 15 & 24 & 550 & 10 \\
46 & $2,122,051$ & $1,980,000$ & 132,000 & 15 & 24 & 550 & 10 \\
47 & $2,122,051$ & $1,980,000$ & 132,000 & 15 & 24 & 550 & 10 \\
48 & $2,122,051$ & $1,980,000$ & 132,000 & 15 & 24 & 550 & 10 \\
Año 4 & $2,122,051$ & $20,565,000$ & 132,000 & 15 & 288 & 550 & 3,858 \\
\hline
\end{tabular}

\begin{tabular}{rcr}
\hline $\begin{array}{c}\text { Ingresos } \\
(12.25 \% \\
\text { Mensual })\end{array}$ & $\begin{array}{c}\text { Costo } \\
\text { Dinero } \\
(1 \%)\end{array}$ & $\begin{array}{r}\text { Morosidad- } \\
\text { Incobrables } \\
(0.30 \%)\end{array}$ \\
\hline 168,510 & 17,512 & 6,880 \\
190,306 & 17,512 & 7,770 \\
193,486 & 17,512 & 7,900 \\
193,486 & 17,512 & 7,900 \\
193,486 & 17,512 & 7,900 \\
193,486 & 17,512 & 7,900 \\
229,226 & 17,512 & 9,359 \\
255,794 & 17,512 & 10,444 \\
259,871 & 17,512 & 10,610 \\
259,871 & 17,512 & 10,610 \\
259,871 & 17,512 & 10,610 \\
259,871 & 17,512 & 10,610 \\
$2,657,262$ & 210,143 & 108,493 \\
\hline
\end{tabular}


Para el tercer año se prevé fondear el incremento en saldo de cartera al mes 36 menos el efectivo de caja disponible al cierre del mes 24.Para el cuarto año se prevé fondear el incremento en saldo de cartera al mes 48 menos el efectivo de caja disponible al cierre del mes 36.

\section{Tabla 48}

Evolución del Saldo de Cartera, Colocaciones, Número de Asesor, Número de Clientes y Estado de Resultado Año 5.

\begin{tabular}{cccccccc}
\hline Mes & $\begin{array}{c}\text { Saldo } \\
\text { Cartera }\end{array}$ & $\begin{array}{c}\text { Colocación } \\
\text { /Ventas }\end{array}$ & $\begin{array}{c}\text { Colocación } \\
\text { Promedio }\end{array}$ & Analista & $\begin{array}{c}\text { Días } \\
\text { Mes }\end{array}$ & $\begin{array}{c}\text { Crédito } \\
\text { Promedio }\end{array}$ & $\begin{array}{c}\mathrm{N}^{\circ} \\
\text { Créditos }\end{array}$ \\
\hline 49 & $2,566,771$ & $2,613,600$ & 145,200 & 18 & 24 & 550 & 11 \\
50 & $2,884,493$ & $2,732,400$ & 151,800 & 18 & 24 & 575 & 11 \\
51 & $2,928,431$ & $2,732,400$ & 151,800 & 18 & 24 & 575 & 11 \\
52 & $2,928,431$ & $2,732,400$ & 151,800 & 18 & 24 & 575 & 11 \\
53 & $2,928,431$ & $2,732,400$ & 151,800 & 18 & 24 & 575 & 11 \\
54 & $2,928,431$ & $2,732,400$ & 151,800 & 18 & 24 & 575 & 11 \\
55 & $3,335,248$ & $3,312,000$ & 165,600 & 20 & 24 & 575 & 12 \\
56 & $3,650,686$ & $3,456,000$ & 172,800 & 20 & 24 & 600 & 12 \\
57 & $3,703,944$ & $3,456,000$ & 172,800 & 20 & 24 & 600 & 12 \\
58 & $3,703,944$ & $3,456,000$ & 172,800 & 20 & 24 & 600 & 12 \\
59 & $3,703,944$ & $3,456,000$ & 172,800 & 20 & 24 & 600 & 12 \\
60 & $3,703,944$ & $3,456,000$ & 172,800 & 20 & 24 & 600 & 12 \\
Año & & & & & & & \\
5 & $3,703,944$ & $36,867,600$ & 172,800 & 20 & 288 & 600 & 6,173 \\
\hline
\end{tabular}

\begin{tabular}{rcccccr}
\hline $\begin{array}{c}\text { Ingresos } \\
(12.25 \%\end{array}$ & $\begin{array}{c}\text { Costo } \\
\text { Dinero } \\
(1 \%)\end{array}$ & $\begin{array}{c}\text { Gastos } \\
\text { Administrativos } \\
(65 \%)\end{array}$ & $\begin{array}{c}\text { Morosidad- } \\
\text { Incobrables } \\
(0.30 \%)\end{array}$ & $\begin{array}{c}\text { Utilidad } \\
\text { Líquida } \\
\text { antes de } \\
\text { Impuestos }\end{array}$ & $\begin{array}{c}\text { Impuesto } \\
\text { a la } \\
\text { Renta } \\
(0 \%)\end{array}$ & $\begin{array}{c}\text { Utilidad } \\
\text { Líquida } \\
\text { después de } \\
\text { Impuestos }\end{array}$ \\
\hline 256,677 & 29,171 & 166,840 & 12,834 & 47,832 & - & 47,832 \\
288,449 & 29,171 & 187,492 & 14,422 & 57,364 & - & 57,364 \\
292,843 & 29,171 & 190,348 & 14,642 & 58,682 & - & 58,682 \\
292,843 & 29,171 & 190,348 & 14,642 & 58,682 & - & 58,682 \\
292,843 & 29,171 & 190,348 & 14,642 & 58,682 & - & 58,682 \\
292,843 & 29,171 & 190,348 & 14,642 & 58,682 & - & 58,682 \\
333,525 & 29,171 & 216,791 & 16,676 & 70,887 & - & 70,887 \\
365,069 & 29,171 & 237,295 & 18,253 & 80,350 & - & 80,350 \\
370,394 & 29,171 & 240,756 & 18,520 & 81,947 & - & 81,947 \\
370,394 & 29,171 & 240,756 & 18,520 & 81,947 & - & 81,947 \\
370,394 & 29,171 & 240,756 & 18,520 & 81,947 & - & 81,947 \\
370,394 & 29,171 & 240,756 & 18,520 & 81,947 & - & 81,947 \\
$3,896,670$ & 350,051 & $2,532,835$ & 194,833 & 818,950 & - & 818,950 \\
\hline
\end{tabular}

Fuente: Elaboración propia 
Para el quinto año se prevé fondear el incremento en saldo de cartera al mes 60 menos el efectivo de caja disponible al cierre del mes 48.

La tabla 46 contiene información sobre la evolución de la cartera de créditos, es importante señalar que en éste tipo de negocios las ventas/colocaciones no son equivalentes a los saldo debido a que éstos últimos tienen amortizaciones que son el producto del pago de las cuotas por parte de los clientes, para poder crecer y lograr los objetivos PrestaMas debe asignar mayor número de Asesores por año e incrementar el crédito promedio, la alta rotación de los créditos permite generar una alta rentabilidad, luego debemos evaluar los diferentes escenarios con el principal indicador que reduce la utilidad, la mora que no es otra cosa que los créditos que no pagan o presentan atrasos. 


\section{Tabla 49}

Presupuesto de Gastos de Ventas primer año

\section{PRESUPUESTO DE GASTOS DE VENTA MENSUAL -1ER AÑO}

\begin{tabular}{|c|c|c|c|c|c|c|c|c|c|c|c|c|c|}
\hline \multicolumn{14}{|c|}{ (Expresado Soles) } \\
\hline CONCEPTO & 1 & 2 & 3 & 4 & 5 & 6 & 7 & 8 & 9 & 10 & 11 & 12 & TOTAL \\
\hline Comisiones Vtas/ Cobranzas & 0 & 0 & 0 & 0 & 0 & 0 & 0 & 0 & 0 & 0 & 0 & 0 & 0 \\
\hline Publicidad & 0 & 0 & 0 & 0 & 0 & 0 & 0 & 0 & 0 & 0 & 0 & 0 & 0 \\
\hline Marketing & 4478 & & & & 4478 & & & & 4478 & & & & 13434 \\
\hline Eventualidad y Patrocinio & 120 & 120 & 120 & 120 & 120 & 120 & 120 & 120 & 120 & 120 & 120 & 120 & 1440 \\
\hline Gastos Diversos de gestión & 0 & 0 & 0 & 0 & 0 & 0 & 0 & 0 & 0 & 0 & 0 & 0 & 0 \\
\hline Gastos de Venta & 4598 & 120 & 120 & 120 & 4598 & 120 & 120 & 120 & 4598 & 120 & 120 & 120 & 14874 \\
\hline Ingresos & 9,283 & 14,175 & 14,175 & 14,175 & 14,175 & 14,175 & 17,269 & 19,275 & 20,160 & 20,160 & 20,160 & 20,160 & 197,790 \\
\hline Gasto Ventas Presupuestado $(=<8 \%)$ & 706 & 1,077 & 1,077 & 1,077 & 1,077 & 1,077 & 1,312 & 1,499 & 1,532 & 1,532 & 1,532 & 1,532 & 15032 \\
\hline
\end{tabular}

Fuente: Elaboración propia 
Se espera un crecimiento del Presupuesto de marketing, eventualidad y patrocinio de $15 \%$ del año anterior y en publicidad de $3 \%$ a partir del tercer año.

\section{Tabla 50}

Presupuesto de Gastos de Ventas de cinco años

\begin{tabular}{|c|c|c|c|c|c|c|}
\hline \multicolumn{7}{|c|}{$\begin{array}{l}\text { PRESUPUESTO DE GASTOS DE VENTA ANUAL - } 5 \text { AÑOS } \\
\text { (Expresado en Soles) }\end{array}$} \\
\hline CONCEPTO & 1 & 2 & 3 & 4 & 5 & TOTALES \\
\hline Publicidad & & 3,000 & 3,090 & 3,183 & 3,278 & 12,551 \\
\hline Marketing & 13,434 & 13,434 & 15,449 & 17,767 & 20,432 & 80,517 \\
\hline Gastos de Venta & 14,874 & 17874 & 40,740 & 79,718 & 143,158 & 296364 \\
\hline Ingresos & 197,790 & 539,149 & $1,357,984$ & $2,657,262$ & $4,771,941$ & \\
\hline Gasto Ventas Presupuestado $(=<8 \%)$ & 15,823 & 43,132 & & & & \\
\hline Gasto Ventas Presupuestado $(=<3 \%)$ & & & 40,740 & 79,718 & 143,158 & \\
\hline
\end{tabular}

Fuente: Elaboración Propia 


\section{Publicidad}

Estará a cargo de terceros con la finalidad de posicionar la marca, se estima una publicidad de casi 3000 soles anuales a partir del segundo año.

\section{Marketing}

Se plantea hacer 3 requerimientos de S/ 4 478.10, que asciende al año por un total de S/.

13434 de acuerdo a la figura 11:

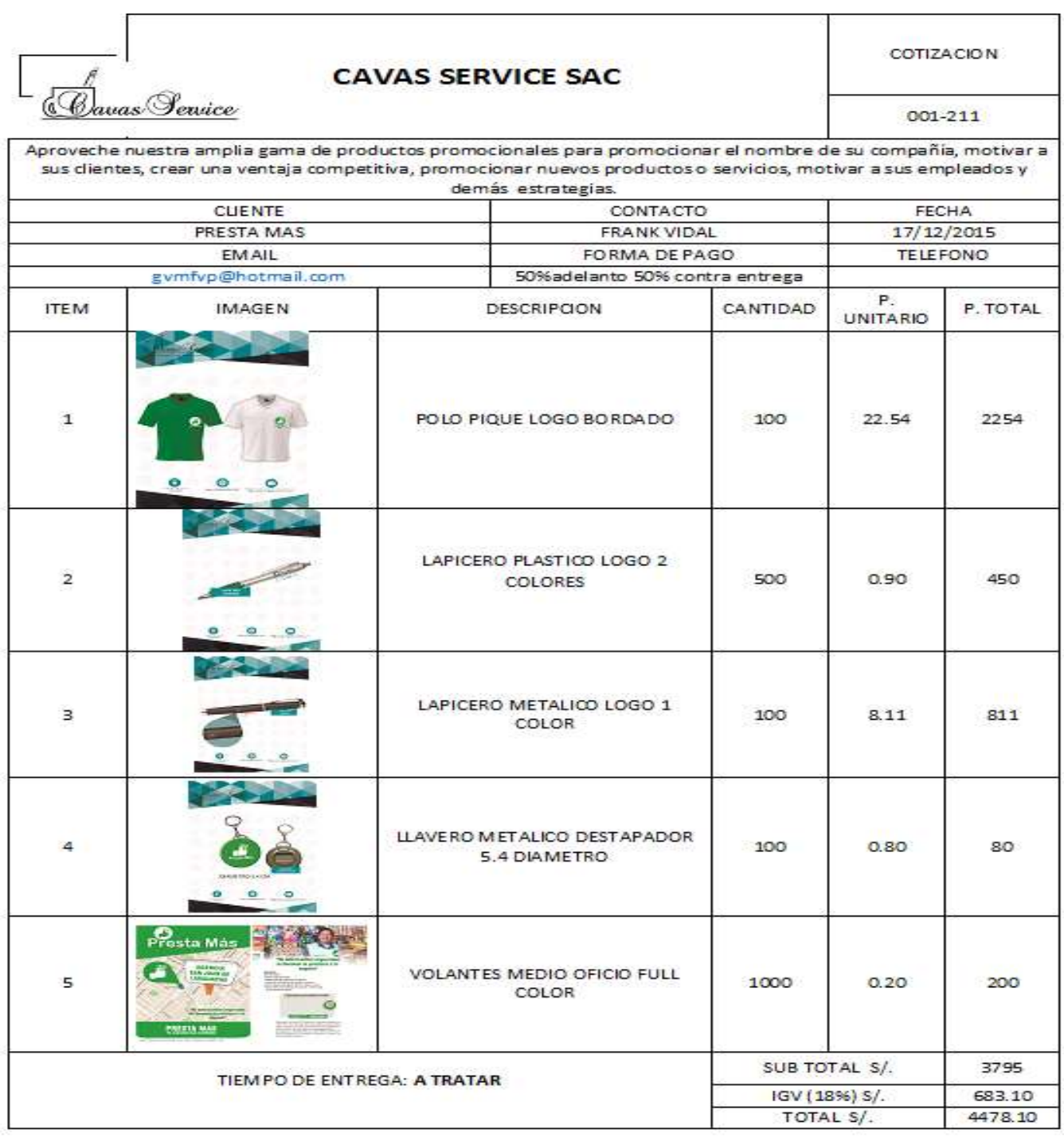

Figura 22 Marketing

Fuente: Elaboración Propia 
También se dispone de S/. 1566 soles en efectivo para eventualidades sumando en total

S/. 15000 para el primer año. Los años siguientes se estima un incremento de 3\% sobre el gasto anterior.

\subsubsection{Política de Servicios y garantías}

- PrestaMas desarrolla políticas sobre el servicio al cliente basado en la calidad y la asesoría permanente por parte del asesor comercial.

- Asegurarnos de que todas las personas en contacto directo con el cliente tengan el perfil de servicio necesario.

- Capacitar al personal sobre la atención al cliente de manera constante.

- Orientar los procesos de tu negocio a las necesidades el cliente, no a las nuestras.

- Realizar encuestas periódicas para medir el nivel de satisfacción del cliente.

- Se trata de un intangible por tanto la garantía está dada en el contrato que establece las condiciones del crédito y en la promesa realizada que incluye la asesoría, esto se garantiza con un seguimiento adecuado al trabajo que realizan en el día a día los asesores comerciales por parte del Supervisor de manera inopinada. 


\section{CAPITULO VIII. PLANIFICACION FINANCIERA}

Con el fin de desarrollar y analizar la viabilidad financiera del Proyecto de Inversión de una ONG de créditos en San Juan de Lurigancho, se elaboran los estados financieros de la implementación de la propuesta. La fuente interna de fondos financieros de la empresa será de accionistas, en tanto la externa de préstamos de particulares, dada la restricción legal de captar fondos del público en tanto no se constituya como una empresa del sistema financiero de acuerdo a la normativa de la Ley general de Bancos 266702.

\subsection{La Inversión}

La inversión tangible en Activos Fijos y Capital de Trabajo asciende a 332,910 soles, la misma que se compone de Activos Fijos por 68,230 soles, Intangibles y Pre Operativos a 16,180 soles y de Capital de Trabajo por 248,500 soles, como se indica en la Tabla 49.

\subsubsection{Inversión Pre operativa}

La inversión en activos intangible y pre - operativos asciende a 16180.00 soles, como se indica en la Tabla 51.

\subsubsection{Inversión de Capital de Trabajo}

Para el inicio de las operaciones es necesario contar con un capital de trabajo para la operación normal de 248,500 soles, debido a la propia naturaleza del negocio de la empresa, siendo el importe de capital de trabajo superior a la inversión en tangibles e intangibles. 


\section{Tabla 51}

Inversión Inicial de Activos Fijos

\begin{tabular}{|c|c|c|c|}
\hline Descripción & Cantidad & Costo Unitario & Costo Total \\
\hline Acondicionamiento de local & 1 & $16,000.00$ & $16,000.00$ \\
\hline Escritorio & 1 & 850.00 & 850.00 \\
\hline Sillas - banquetas & 15 & 100.00 & $1,500.00$ \\
\hline Módulos de atención & 4 & 782.00 & $3,128.00$ \\
\hline Computadoras - laptops & 5 & $2,720.00$ & $13,600.00$ \\
\hline Impresora multifuncional & 2 & $1,020.00$ & $2,040.00$ \\
\hline Aire acondicionado & 2 & $2,500.00$ & $5,000.00$ \\
\hline Ventilador & 2 & 100.00 & 200.00 \\
\hline Dispensador de agua & 1 & 600.00 & 600.00 \\
\hline Deshumedecedor & 1 & 700.00 & 700.00 \\
\hline Monitor TV & 2 & $3,400.00$ & $6,800.00$ \\
\hline Caja de seguridad - caja buzón & 2 & $1,350.00$ & $2,700.00$ \\
\hline Caja de seguridad - caja & 1 & $3,000.00$ & $3,000.00$ \\
\hline \multicolumn{4}{|l|}{ pulmón } \\
\hline Cámaras de seguridad y CPU & 5 & 400.00 & $2,000.00$ \\
\hline \multicolumn{4}{|l|}{ almacenamiento } \\
\hline Equipos móviles Smartphone & 6 & 300.00 & $1,800.00$ \\
\hline Mesa oval & 1 & $3,000.00$ & $3,000.00$ \\
\hline Módulo portátil mostrador & 1 & 612.00 & 612.00 \\
\hline Enseres & 2 & 850.00 & $1,700.00$ \\
\hline Otros activos & 1 & $3,000.00$ & $3,000.00$ \\
\hline Total Activos Fijos & & & $68,230.00$ \\
\hline
\end{tabular}

Fuente: Elaboración Propia 


\section{Tabla 52}

Inversión en Intangibles y Pre operativa

\begin{tabular}{lrr}
\hline Descripción & Precio Unitario & Monto \\
\hline Instalación de línea telefónica & 100.00 & 100.00 \\
Instalación de software & $1,700.00$ & $1,700.00$ \\
Costos municipales & - & - \\
$\quad$ - licencia de funcionamiento & $1,530.00$ & $1,530.00$ \\
$\quad$ - administrativos & 850.00 & 850.00 \\
Planilla pre operativa & - & - \\
Costo de marketing & - & - \\
$\quad$ - letrero & 900.00 & 900.00 \\
$\quad$ - volantes & 600.00 & 600.00 \\
$\quad$ - autorizaciones municipales para afiches & 300.00 & 300.00 \\
Estudio de factibilidad & $10,200.00$ & $10,200.00$ \\
Total Intangibles y pre Operativos & & $16,180.00$
\end{tabular}

Fuente: Elaboración Propia

\section{Tabla 53}

Inversión en Capital de Trabajo

Descripción Monto

Servicios

Sueldos

Gastos operativos

Alquiler de local

Alquiler de vehículo

Cuenta de ahorro

Efectivo mínimo / caja chica

Total 


\subsubsection{Costo de Proyecto}

Asciende a 332910 soles como se indica en la Tabla 54.

\section{Tabla 54}

Cuadro resumen de Inversión

\begin{tabular}{lr}
\hline \multicolumn{1}{c}{ Descripción } & Importe \\
\hline Activos Fijos & 68,230 \\
Intangibles y Pre- Operativos & 16,180 \\
Capital de Trabajo & 248,500 \\
Inversión Total & 332,910
\end{tabular}

Fuente: Elaboración Propia

\subsection{Financiamiento}

Para el inicio de operaciones se requiere 332,910 soles, de los cuales el $100 \%$ corresponden al aporte propio.

\section{Tabla 55}

Estructura Financiera Inicial

\begin{tabular}{lrr}
\multicolumn{1}{c}{ Descripción } & \multicolumn{1}{l}{ Monto } & \multicolumn{1}{c}{ Porcentaje } \\
\hline Aporte propio & 332,910 & $100,00 \%$ \\
Socios ONG y/o convenios particulares & 0,00 & $0,00 \%$ \\
Total Inversión & 332,910 & $100,00 \%$ \\
\hline
\end{tabular}

Fuente: Elaboración Propia

El primer periodo no requiere de aportes financieros externos, para garantizar el crecimiento de los siguientes periodos se prevé financiamientos cuyos montos se detallan en la tabla 56. 
Tabla 56

Evolución de Deuda en cinco años.

\begin{tabular}{|c|c|c|c|c|c|}
\hline Mes & Préstamo Total & $\begin{array}{c}\text { Amortización } \\
\text { Mensual }\end{array}$ & $\begin{array}{c}\text { Intereses } \\
1.00 \% \\
\end{array}$ & $\begin{array}{c}\text { Cuota } \\
\text { Mensual } \\
\end{array}$ & $\begin{array}{c}\text { Saldo Deuda } \\
\text { (Financiamiento) }\end{array}$ \\
\hline 1 & - & - & - & - & - \\
\hline 2 & - & - & - & - & - \\
\hline 3 & - & - & - & - & - \\
\hline 4 & - & - & - & - & - \\
\hline 5 & - & - & - & - & - \\
\hline 6 & - & - & - & - & - \\
\hline 7 & - & - & - & - & - \\
\hline 8 & - & - & - & - & - \\
\hline 9 & - & - & - & - & - \\
\hline 10 & - & - & - & - & - \\
\hline 11 & - & - & - & - & - \\
\hline 12 & - & - & - & - & - \\
\hline 13 & 437,382 & $-437,382$ & 4,374 & 4,374 & 437,382 \\
\hline 14 & 437,382 & - & 4,374 & 4,374 & 437,382 \\
\hline 15 & 437,382 & - & 4,374 & 4,374 & 437,382 \\
\hline 16 & 437,382 & - & 4,374 & 4,374 & 437,382 \\
\hline 17 & 437,382 & - & 4,374 & 4,374 & 437,382 \\
\hline 18 & 437,382 & - & 4,374 & 4,374 & 437,382 \\
\hline 19 & 437,382 & - & 4,374 & 4,374 & 437,382 \\
\hline 20 & 437,382 & - & 4,374 & 4,374 & 437,382 \\
\hline 21 & 437,382 & - & 4,374 & 4,374 & 437,382 \\
\hline 22 & 437,382 & - & 4,374 & 4,374 & 437,382 \\
\hline 23 & 437,382 & - & 4,374 & 4,374 & 437,382 \\
\hline 24 & 437,382 & - & 4,374 & 4,374 & 437,382 \\
\hline 25 & $1,185,467$ & $-748,085$ & 11,855 & 11,855 & $1,185,467$ \\
\hline 26 & $1,185,467$ & - & 11,855 & 11,855 & $1,185,467$ \\
\hline 27 & $1,185,467$ & - & 11,855 & 11,855 & $1,185,467$ \\
\hline 28 & $1,185,467$ & - & 11,855 & 11,855 & $1,185,467$ \\
\hline 29 & $1,185,467$ & - & 11,855 & 11,855 & $1,185,467$ \\
\hline 30 & $1,185,467$ & - & 11,855 & 11,855 & $1,185,467$ \\
\hline 31 & $1,185,467$ & - & 11,855 & 11,855 & $1,185,467$ \\
\hline 32 & $1,185,467$ & - & 11,855 & 11,855 & $1,185,467$ \\
\hline 33 & $1,185,467$ & - & 11,855 & 11,855 & $1,185,467$ \\
\hline 34 & $1,185,467$ & - & 11,855 & 11,855 & $1,185,467$ \\
\hline 35 & $1,185,467$ & - & 11,855 & 11,855 & $1,185,467$ \\
\hline 36 & $1,185,467$ & - & 11,855 & 11,855 & $1,185,467$ \\
\hline 37 & $1,739,812$ & $-554,345$ & 17,398 & 17,398 & $1,739,812$ \\
\hline 38 & $1,739,812$ & - & 17,398 & 17,398 & $1,739,812$ \\
\hline 39 & $1,739,812$ & - & 17,398 & 17,398 & $1,739,812$ \\
\hline 40 & $1,739,812$ & - & 17,398 & 17,398 & $1,739,812$ \\
\hline 41 & $1,739,812$ & - & 17,398 & 17,398 & $1,739,812$ \\
\hline 42 & $1,739,812$ & - & 17,398 & 17,398 & $1,739,812$ \\
\hline 43 & $1,739,812$ & - & 17,398 & 17,398 & $1,739,812$ \\
\hline 44 & $1,739,812$ & - & 17,398 & 17,398 & $1,739,812$ \\
\hline 45 & $1,739,812$ & - & 17,398 & 17,398 & $1,739,812$ \\
\hline 46 & $1,739,812$ & - & 17,398 & 17,398 & $1,739,812$ \\
\hline 47 & $1,739,812$ & - & 17,398 & 17,398 & $1,739,812$ \\
\hline 48 & $1,739,812$ & - & 17,398 & 17,398 & $1,739,812$ \\
\hline 49 & $1,853,281$ & $-113,469$ & 18,533 & 18,533 & $1,853,281$ \\
\hline 50 & $1,853,281$ & - & 18,533 & 18,533 & $1,853,281$ \\
\hline 51 & $1,853,281$ & - & 18,533 & 18,533 & $1,853,281$ \\
\hline 52 & $1,853,281$ & - & 18,533 & 18,533 & $1,853,281$ \\
\hline 53 & $1,853,281$ & - & 18,533 & 18,533 & $1,853,281$ \\
\hline
\end{tabular}


Fuente: Elaboración propia

\begin{tabular}{lllll}
$1,853,281$ & - & 18,533 & 18,533 & $1,853,281$ \\
$1,853,281$ & - & 18,533 & 18,533 & $1,853,281$ \\
$1,853,281$ & - & 18,533 & 18,533 & $1,853,281$ \\
$1,853,281$ & - & 18,533 & 18,533 & $1,853,281$ \\
$1,853,281$ & - & 18,533 & 18,533 & $1,853,281$ \\
$1,853,281$ & - & 18,533 & 18,533 & $1,853,281$ \\
$1,853,281$ & - & 18,533 & 18,533 & $1,853,281$ \\
\hline
\end{tabular}

\subsubsection{Endeudamiento y condiciones}

Se captará préstamos que competirán principalmente como oferta con la tasa de interés que ofrecen las entidades financieras por depósitos a plazo fijo.

\section{Tabla 57}

\section{Condiciones de fondeo}

\begin{tabular}{lr}
\hline \multicolumn{1}{c}{ Descripción } & Modalidad \\
\hline Tasa de interés efectiva & $12.68 \%$ anual \\
Periodo de gracia & 0 meses \\
Plazo de amortización & $\infty$ \\
Tipo de amortización -Pago de Intereses, devolución capital al final & Americano
\end{tabular}

Fuente: Elaboración Propia

\subsubsection{Capital y Costo de Oportunidad}

El aporte propio es de 332,910 soles y corresponde al 100\% de la inversión total. El Costo de capital esperado es del $18.33 \%$ el mismo que se ha tomado del trabajo de investigación sobre el cálculo del COK para entidades Microfinancieras en el Perú. “Determinación del Costo de Oportunidad de Capital en las Entidades Microfinancieras del Perú" de la UPC presentada en mayo del 2015 y que se muestra en la tabla 58. 


\section{Tabla 58}

COK del Sistema Microfinanciero en el Perú

\begin{tabular}{lrrrrrrr}
\hline \multicolumn{1}{c}{ Empresa } & D/E & $\begin{array}{c}\text { Beta } \\
\text { Apalancado }\end{array}$ & Omega $(\Omega)$ & $\begin{array}{c}\text { Riesgo } \\
\text { País }\end{array}$ & $\begin{array}{c}\text { Prima por } \\
\text { Riesgo }\end{array}$ & $\begin{array}{c}\text { Tasa Libre } \\
\text { de Riesgo }\end{array}$ & $\mathrm{K}_{\mathrm{IMF}}$ \\
\hline MiBanco & 8.1 & 3 & 3.66 & $1.71 \%$ & $4.41 \%$ & $3.95 \%$ & $23.45 \%$ \\
Financieras & 5.09 & 1.73 & 3.26 & $1.71 \%$ & $4.41 \%$ & $3.95 \%$ & $17.18 \%$ \\
CMAC & 6.66 & 2.21 & 2.65 & $1.71 \%$ & $4.41 \%$ & $3.95 \%$ & $18.22 \%$ \\
CRAC & 8.75 & 2.78 & 2.95 & $1.71 \%$ & $4.41 \%$ & $3.95 \%$ & $21.24 \%$ \\
EDPYMES & 3.28 & 1.29 & 2.37 & $1.71 \%$ & $4.41 \%$ & $3.95 \%$ & $13.68 \%$ \\
TOTAL & $\mathbf{6 . 1 6}$ & $\mathbf{2 . 2}$ & $\mathbf{3 . 0 2}$ & $\mathbf{1 . 7 1 \%}$ & $\mathbf{4 . 4 1 \%}$ & $\mathbf{3 . 9 5 \%}$ & $\mathbf{1 8 . 8 3 \%}$ \\
\hline
\end{tabular}

Fuente: Tesis "Determinación del costo de oportunidad de capital en las entidades microfinancieras del Perú" Pág. 178

http://repositorioacademico.upc.edu.pe/upc/bitstream/10757/576910/1/DETERMINACI\%C3\%93N+DEL+COSTO.pdf

\subsection{Presupuesto Base}

\subsubsection{Presupuesto de Ventas}

Se colocará a una TCEA mínima del 300\%, lo que equivale a una tasa del $12,25 \%$ mensual o una tasa de $2.73 \%$ semanal, para créditos menores o igual a S/ 1000 con plazos de hasta 24 semanas para montos mayores, se explica a detalle en la tabla 60. Se ha establecido el precio o tasa de interés observando que en el mercado informal existen tasas de hasta $20 \%$ mensual con pagos diarios en créditos atomizados, en tanto que en el mercado formal cobra una tasa hasta $250 \%$.

\section{Tabla 59}

Estructura de colocación por montos, tasa y número de créditos

\begin{tabular}{lrrrrrr}
\hline $\begin{array}{c}\text { Rango de } \\
\text { Crédito }\end{array}$ & $\begin{array}{c}\text { Promedio } \\
\text { de Crédito }\end{array}$ & $\begin{array}{c}\text { Tasa } \\
\text { Efectiva } \\
\text { Semanal }\end{array}$ & TCEA & $\begin{array}{c}\text { Número de } \\
\text { Créditos }\end{array}$ & Saldo & Interés \\
\hline 300 a 500 & 400 & $2.97 \%$ & $350 \%$ & 402 & 160,800 & 4,772 \\
501 a 700 & 600 & $2.88 \%$ & $330 \%$ & 10 & 6,000 & 173 \\
701 a 1000 & 850 & $2.73 \%$ & $300 \%$ & 0 & - & - \\
Promedio & $2.96 \%$ & $349 \%$ & 412 & 166,800 & 4,945 \\
& & & & & & \\
Evolución Primer Año & $2.73 \%$ & $300 \%$ & 412 & 164,620 & 197,790 \\
\hline
\end{tabular}

Fuente: Elaboración Propia 
La propuesta de PrestaMas se basa en principio en la oferta real que actualmente existe en el mercado teniendo como referencia a la ONG Crecer que cobra una TCEA de $643 \%$, los prestamistas informales que cobran una TCEA de $7724 \%$ comprobada en el trabajo de campo y por la parte de la oferta regulada tenemos al Banco Azteca que ofrece una TCEA de $180 \%$ sin embargo el acceso a éste último resulta complicado dado que ofrecen sólo créditos grupales, finalmente el testeo en la investigación cuantitativa nos lleva a determinar que es la tasa más conveniente.

Correspondiente a incobrabilidad o cuentas de difícil recuperación se considera un índice de morosidad respecto al ingreso del 2,4\% para el primer año; $4,1 \%$ para el segundo año; 5,0\% para el tercer año; 5,0\% para el cuarto año y 5,0\% para el quinto año; o un índice de morosidad respecto del Saldo de Cartera del 2,9\% para el primer año; 4,5\% para el segundo año; 4,9\% para el tercer año; 5,1\% para el cuarto año y 5,3\% para el quinto año.

\section{Tabla 60}

Saldo de Cartera, Ingresos Financieros Brutos y Netos ajustados por incobrabilidad

\begin{tabular}{lcrrrr}
\hline & Año 1 & \multicolumn{1}{c}{ Año 2 } & \multicolumn{1}{c}{ Año 3 } & \multicolumn{1}{c}{ Año 4 } & \multicolumn{1}{c}{ Año 5 } \\
\hline Saldo de Cartera & 164,620 & 486,143 & $1,131,761$ & $2,122,051$ & $3,703,944$ \\
Ingresos Financieros & 197,790 & 539,149 & $1,357,984$ & $2,657,262$ & $4,771,941$ \\
Incobrabilidad & 4,845 & 22,013 & 55,445 & 108,493 & 194,833 \\
Ingreso Neto Financiero & 192,944 & 517,137 & $1,302,539$ & $2,548,768$ & $4,577,108$ \\
$\begin{array}{l}\text { Morosidad } \\
\text { (\% Ingresos Financieros) }\end{array}$ & $2.51 \%$ & $4.26 \%$ & $4.26 \%$ & $4.26 \%$ & $4.26 \%$ \\
$\begin{array}{l}\text { Morosidad } \\
\text { (\% Saldo de Cartera) }\end{array}$ & $2.94 \%$ & $4.53 \%$ & $4.90 \%$ & $5.11 \%$ & $5.26 \%$ \\
\hline
\end{tabular}

Fuente: Elaboración Propia

Los saldos de colocación para los primeros cinco años son de S/. 164620 el primer año, S/. 486143 soles el segundo año, S/. 1131791 el tercer año, S/. 2122051 soles el cuarto año y S/. 3703944 el quinto año. Los ingresos financieros estimados para los siguientes cinco años son de S/. 197790 el primer año, S/. 539149 el segundo año, S/. 1357984 el tercer año, S/. 2657262 soles el cuarto año y S/. 4771941 el quinto 
año. Ajuste en cada periodo por concepto de incobrabilidad, considerando una tolerancia de mora al 5\% respecto del saldo de la cartera de la industria financiera peruana basado en las ratios del sistema financiero como se indica en la Tabla 61 .

\section{Tabla 61}

Ratio de Cartera Microempresa Morosa

\begin{tabular}{ccccc}
\hline & $\begin{array}{c}\text { Sistema } \\
\text { Marzo 2015 }\end{array}$ & $\begin{array}{c}\text { Financiera } \\
\text { Marzo 2015 }\end{array}$ & $\begin{array}{c}\text { CMAC } \\
\text { Marzo 2015 }\end{array}$ & $\begin{array}{c}\text { CRAC } \\
\text { Marzo 2015 }\end{array}$ \\
\hline $\begin{array}{c}\text { Micro } \\
\text { Empresa }\end{array}$ & $6,7 \%$ & $6,7 \%$ & $7,6 \%$ & $14,5 \%$ \\
\hline Elaboracion: Propia & & & & \\
\hline
\end{tabular}

Elaboracion: Propia.

Extraido de http://www.bcrp.gob.pe/docs/Publicaciones/Reporte-Estabilidad-Financiera/ref-mayo-2015.pdf

El crecimiento de los Ingresos Financieros en los cinco primeros años se estima sea una tasa promedio del $125 \%$ y el crecimiento de los Ingresos Netos Financieros se estima sea una tasa promedio del $124 \%$ por año, como se indica en la Tabla 62.

\section{Tabla 62}

Ingresos Financieros

\begin{tabular}{lrrrrr}
\hline & Año 1 & Año 2 & Año 3 & Año 4 & Año 5 \\
\hline & 197,790 & 539,149 & $1,357,984$ & $2,657,262$ & $4,771,941$ \\
$\begin{array}{l}\text { Ingresos Financieros } \\
\text { Variación de }\end{array}$ & & $173 \%$ & $152 \%$ & $96 \%$ & $80 \%$ \\
$\begin{array}{l}\text { Ingresos Financieros } \\
\text { Ingresos Neto Financiero }\end{array}$ & 192,944 & 517,137 & $1,302,539$ & $2,548,768$ & $4,577,108$ \\
$\begin{array}{l}\text { Variación de } \\
\text { Ingresos Netos Financieros }\end{array}$ & & $168 \%$ & $152 \%$ & $96 \%$ & $80 \%$ \\
\hline
\end{tabular}

Fuente: Elaboración Propia

El crecimiento de la cartera se estima sea una tasa promedio del $123 \%$ por año, como se indica en la Tabla 63

\section{Tabla 63}

\section{Saldos de Cartera}

\begin{tabular}{lrrrrr}
\hline & Año 1 & Año 2 & Año 3 & Año 4 & Año 5 \\
\hline $\begin{array}{l}\text { Saldo de Cartera } \\
\begin{array}{l}\text { Variación de } \\
\text { Saldo de Cartera }\end{array}\end{array}$ & 164,620 & 486,143 & $1,131,761$ & $2,122,051$ & $3,703,944$ \\
\hline
\end{tabular}

Fuente: Elaboración Propia 


\subsubsection{Presupuesto de Costos}

El crecimiento del Gasto Financiero (costo de fondeo) respecto al incremento del Financiamiento se estima sea una tasa promedio del $75 \%$ por cada año, como se indica en la Tabla 64.

\section{Tabla 64}

Montos de Gasto Financiero (Costo de Fondeo de Dinero)

\begin{tabular}{lrrrrr}
\hline & Año 1 & Año 2 & Año 3 & Año 4 & Año 5 \\
\hline $\begin{array}{l}\text { Gasto Financiero } \\
\text { Variación de }\end{array}$ & - & 51,230 & 142,256 & 210,143 & 225,591 \\
Gasto Financiero (Costo Fondeo) & & & $178 \%$ & $48 \%$ & $7 \%$ \\
\hline
\end{tabular}

Fuente: Elaboración Propia

El gasto financiero o costo de fondeo para PrestaMas por unidad monetaria es del $1 \%$ mensual o del $12.68 \%$ anual, en tanto que para las organizaciones dedicadas a la actividad micro financiera y financiera el costo del dinero de fuentes externas oscila entre el $4.44 \%$ al $7.44 \%$ en soles, considerando que a la fecha del presente proyecto los Depósito a Plazo Fijo “DPF” a 360 para las Cajas Municipales, Financieras, Cajas Rurales sin considerar a los Bancos que pagan menos del $2 \%$ en las mismas condiciones cuyos fondos deberían ser más conveniente obtener para el proyecto, ONG PrestaMas ofrece un adicional sobre el límite superior de $7.44 \%$, la diferencia sobre dichas tasas es el plus a los potenciales acreedores interesados en financiar recursos para ampliar nuestras operaciones de créditos, estando entre los inmediatos interesados funcionarios de créditos con excedentes que conocen muy de cerca dicha actividad. 


\section{Tabla 65}

Tasas de Ahorros por Grupo de Entidades Financieras

\begin{tabular}{|c|c|c|c|c|c|c|c|}
\hline \multicolumn{4}{|c|}{$\begin{array}{l}\text { Tasa de Interés Pasiva Promedio por Tipo de } \\
\text { Depósito }\end{array}$} & \multicolumn{4}{|c|}{$\begin{array}{l}\text { Tasa de Interés Pasiva Promedio por Tipo de } \\
\text { Depósito }\end{array}$} \\
\hline \multicolumn{4}{|c|}{ Cajas Rurales } & \multicolumn{4}{|c|}{ Financieras } \\
\hline & Ahorro & Plazo & CTS & & Ahorro & Plazo & CTS \\
\hline Jun. 2010 & $1.12 \%$ & $6.04 \%$ & $13.84 \%$ & Jun. 2010 & $2.89 \%$ & $2.34 \%$ & $7.22 \%$ \\
\hline Dic. 2010 & $0.9 \%$ & $6.82 \%$ & $13.74 \%$ & Dic. 2010 & $2.65 \%$ & $2.52 \%$ & $8.55 \%$ \\
\hline Jun. 2011 & $1.02 \%$ & $7.18 \%$ & $13.69 \%$ & Jun. 2011 & $1.35 \%$ & $4.53 \%$ & $9.05 \%$ \\
\hline Dic. 2011 & $0.76 \%$ & $6.88 \%$ & $12.03 \%$ & Dic. 2011 & $1.81 \%$ & $3.96 \%$ & $10.85 \%$ \\
\hline Jun. 2012 & $1.02 \%$ & $7.18 \%$ & $13.68 \%$ & Jun. 2012 & $1.59 \%$ & $3.92 \%$ & $7.55 \%$ \\
\hline Dic. 2012 & $1.42 \%$ & $6.41 \%$ & $12.03 \%$ & Dic. 2012 & $1.69 \%$ & $3.77 \%$ & $7.26 \%$ \\
\hline Jun. 2013 & $1.37 \%$ & $5.76 \%$ & $9.96 \%$ & Jun. 2013 & $1.47 \%$ & $3.72 \%$ & $8.47 \%$ \\
\hline Dic. 2013 & $1.28 \%$ & $5.24 \%$ & $7.82 \%$ & Dic. 2013 & $0.79 \%$ & $4.24 \%$ & $8.49 \%$ \\
\hline Jun. 2014 & $1.07 \%$ & $5.33 \%$ & $7.61 \%$ & Jun. 2014 & $0.84 \%$ & $3.96 \%$ & $8.23 \%$ \\
\hline Dic. 2014 & $0.86 \%$ & $5.02 \%$ & $6.64 \%$ & Dic. 2014 & $0.96 \%$ & $4.17 \%$ & $7.30 \%$ \\
\hline Mar. 2015 & $0.92 \%$ & $5.21 \%$ & $7.11 \%$ & Mar. 2015 & $0.90 \%$ & $4.44 \%$ & $7.44 \%$ \\
\hline
\end{tabular}

Fuente: http://www.equilibrium.com.pe/sectorialmfidic14.pdf

\subsubsection{Presupuesto de Gastos Administrativos}

PrestaMas, para el primer año considera unos gastos que ascienden a 366721

soles que representan un $190 \%$ respecto a los ingresos Netos Financieros para el primer año; sin embargo, de año en año se reducirán hasta alcanzar menos del 50\% que permitirá establecer planes de crecimiento, ello significará haber alcanzado una eficiencia de gastos administrativos. El promedio para los cinco años es de $83 \%$.

\section{Tabla 66}

Evolución de Gastos Administrativos

\begin{tabular}{lrrrrr}
\hline & Año 1 & \multicolumn{1}{c}{ Año 2 } & \multicolumn{1}{c}{ Año 3 } & \multicolumn{1}{c}{ Año 4 } & \multicolumn{1}{c}{ Año 5 } \\
\hline Ingresos Financieros & 197,790 & 539,149 & $1,357,984$ & $2,657,262$ & $4,771,941$ \\
Ingreso Neto Financiero & 192,944 & 517,137 & $1,302,539$ & $2,548,768$ & $4,577,108$ \\
Gastos Administrativos & 235,076 & 429,308 & 574,247 & 690,254 & 806,526 \\
Gastos de Ventas & 125,645 & 152,265 & 161,469 & 195,216 & 212,362 \\
Total Gastos & 360,721 & 581,574 & 735,716 & 885,469 & $1,018,888$ \\
Total Gastos/Ingresos Financieros & $182 \%$ & $108 \%$ & $54 \%$ & $33 \%$ & $21 \%$ \\
$\begin{array}{l}\text { Total Gastos/Ingresos Netos } \\
\text { Financieros }\end{array}$ & $187 \%$ & $112 \%$ & $56 \%$ & $35 \%$ & $22 \%$ \\
\hline
\end{tabular}

Fuente: Elaboración Propia 
Presupuesto de Requerimiento de Insumos y compras de insumos

\section{Tabla 67}

\section{Evolución de Gastos de Servicios}

\begin{tabular}{|c|c|c|c|c|c|}
\hline & Año 1 & Año 2 & Año 3 & Año 4 & Año 5 \\
\hline Servicios & 18,600 & 18,918 & 19,243 & 19,576 & 19,917 \\
\hline $\begin{array}{l}\text { Variación Gasto en } \\
\text { Servicios (Agua, Energía eléctrica y Teléfono) }\end{array}$ & & $1.71 \%$ & $1.72 \%$ & $1.73 \%$ & $1.74 \%$ \\
\hline $\begin{array}{l}\text { Servicios de Consultoría y Representación } \\
\text { Variación Gasto en }\end{array}$ & 2,400 & 4,800 & 24,000 & 26,400 & 29,040 \\
\hline Servicios de Consultoría y representación & & $100.00 \%$ & $400.00 \%$ & $10.00 \%$ & $10.00 \%$ \\
\hline $\begin{array}{l}\text { Útiles Oficina } \\
\text { Variación Gasto en Útiles } \\
\text { de Oficina }\end{array}$ & 18,000 & 18,540 & 19,096 & 19,669 & 20,259 \\
\hline
\end{tabular}

Fuente: Elaboración Propia

\section{Servicios}

Se prevé un requerimiento el primero año, dos el segundo año y diez el tercer año.

A partir del cuarto año se incrementará en $10 \%$ respecto al año anterior, se detalla en la Tabla 68.

\section{Tabla 68}

Estructura de costos de Servicios (Servicios de Consultoría y Representación)

\begin{tabular}{|c|c|c|c|}
\hline Cantidad & Ítem o descripción & Costo & Parcial \\
\hline 6000 & Consultas de Riesgos Sentinel & 0.17 & 1000 \\
\hline 50 & Reniec & 2.50 & 100 \\
\hline 15 & Sunarp & 10.00 & 150 \\
\hline 10 & Movilidad & 35.00 & 350 \\
\hline 10 & Almuerzo o cena de Esparcimiento e Integración & 30.00 & 300 \\
\hline & Otros & 100 & 100 \\
\hline Total & & & 2000 \\
\hline
\end{tabular}

Fuente: Elaboración Propia

\section{Útiles de Oficina}

Se prevé adquirir cada dos meses importes de 3000 soles (18 000 al primer año), como se indica en la Tabla 69. 
Tabla 69

Útiles de Oficina

\begin{tabular}{llrr}
\hline \multicolumn{1}{c}{ Cantidad } & \multicolumn{1}{c}{ Ítem o descripción } & 14 & Parcial \\
\hline 20 paquetes. & Papel Bond & 16 & 640 \\
4 cajas & Lapiceros & 1.5 & 75 \\
50 unidades & Resaltadores & 5 & 100 \\
20 unid & Archivadores & 3 & 60 \\
20 Cajas & Ligas & 0.65 & 650 \\
1000 unid & Folder & 0.3 & 300 \\
1000 unid & Faster & 20 & 120 \\
6 unid & Antivirus & 30 & 450 \\
15 unid & Tóner & 3.5 & 175 \\
50 unid & Plumón & 75 & 300 \\
3 packs & Artículos de limpieza & 15 & 300 \\
20 packs & Piedras deshumecedoras & & 126 \\
& Otros & Total & 3000 \\
\hline
\end{tabular}

Fuente: Elaboración Propia

\subsubsection{Presupuesto de Marketing y Ventas}

Ascenderá a 125645 soles el primer año y se incrementará 14\% anual

Tabla 70

Evolución de Gastos de Marketing y Ventas

\begin{tabular}{lrrrrr}
\hline & Año 1 & Año 2 & Año 3 & Año 4 & Año 5 \\
\hline Gastos de Ventas & 125,645 & 152,265 & 161,469 & 195,216 & 212,362 \\
Sueldo Ventas & 99,874 & 102,870 & 105,956 & 109,135 & 112,409 \\
Alquileres vehiculares & 6,300 & 6,489 & 6,684 & 6,884 & 7,091 \\
Deprec. - Amortización & 3,236 & 3,236 & 3,236 & 3,236 & 3,236 \\
Seguros & 412 & 1,215 & 2,829 & 5,305 & 9,260 \\
Publicidad & 823 & 2,431 & 5,659 & 10,610 & 18,520 \\
Variable Sueldos Ventas & - & 20,574 & 21,191 & 43,654 & 44,964 \\
MKT & & 15,450 & 15,914 & 16,391 & 16,883 \\
Variación Gastos de Ventas & 15,000 & $21.19 \%$ & $6.04 \%$ & $20.90 \%$ & $8.78 \%$ \\
\hline
\end{tabular}

Fuente: Elaboración Propia 


\section{Seguros}

Al inicio de las operaciones se contratarán sólo el seguro contra robos sobre los activos del local que se estima en unos S/. 411.55 al primer año, 1215.36 el segundo año, 2 829.40 el tercer año, 5305.13 el cuarto año y 9259.86 el quinto año, en el mercado no existe un seguro para resguardar el dinero que existiera dentro del local, para ello se tendrá que aplicar las mejores prácticas para mantener los menores niveles de efectivo. Conforme el proyecto se consolide se podrá evaluar la contratación de otro tipo de seguros.

\section{Publicidad}

Estará a cargo de los mismos asesores de créditos y de nuestros mismos clientes como se planteó en la Estrategia de Marketing pues tenemos el valor agregado de la asesoría, se estima un gasto publicidad de apoyo de 823 soles para el primer año que básicamente es el gasto que realiza por pasar menciones en la radio local del Marcado más cercano a nuestro local, éste mismo presupuesto se incrementará sin embargo no requiere de mucha inversión por la naturaleza del negocio y por un tema de seguridad.

\section{Marketing}

Se plantea hacer 3 requerimientos de S/ 4 478.10, que asciende al año por un total de S/. 13434 de acuerdo a la Figura 11.

También se dispone de S/. 1566 soles en efectivo para eventualidades sumando en total S/. 15000 para el primer año. Los años siguientes se estima un incremento de 3\% sobre el gasto anterior.

\section{Presupuesto de Gasto}

Respecto a los gastos administrativos de la industria micro financiera oscilan entre un $40 \%$ y $66 \%$ de los ingresos. 


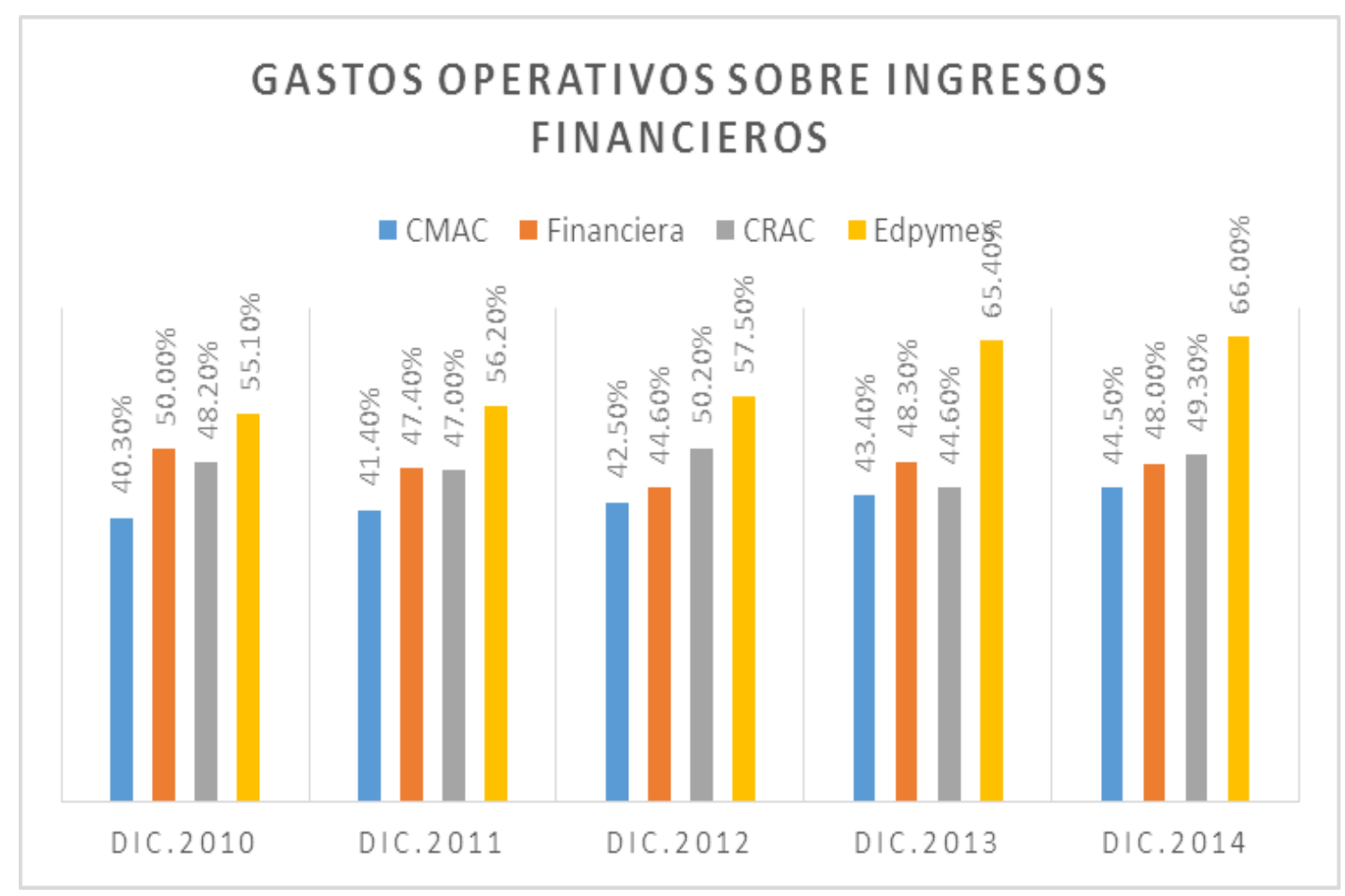

Figura 23. Gastos Administrativos del Sistema Financiero

Fuente: SBS http://www.equilibrium.com.pe/sectorialmfidic14.pdf

\section{Aporte de Inversionistas}

El aporte de los inversionistas es de 332910 soles, representa un $100.00 \%$ del total de la inversión. La composición de los 332910 soles se observa en el capital social del Balance General de inicio de operaciones, los asociados de la organización de inicio son:

1. Guillermo Mallma Mauricio, con aporte de 120000 soles

2. José Luis Pérez Valencia, con aporte de 100000 soles

3. Frank Vidal Mostacero, con aporte de 62910 soles

4. Nadia Abarca Lino, con aporte de 50000 soles 
Tabla 71

Aporte de Inversionistas

\section{PATRIMONIO}

CAPITAL SOCIAL

TOTAL DEL PATRIMONIO

Fuente: Elaboración Propia

En base a las ventas y el saldo de cartera estimada se proyectan los Estados Financieros.

\begin{tabular}{|l|c|c|c|c|c|}
\cline { 2 - 6 } \multicolumn{1}{c|}{} & \multicolumn{1}{c|}{ Año 1 } & \multicolumn{1}{c|}{ Año 2 } & \multicolumn{1}{c|}{ Año 3 } & \multicolumn{1}{c|}{ Año 4 } & \multicolumn{1}{c|}{ Año 5 } \\
\hline Ventas & $1,560,000$ & $4,211,400$ & $10,554,600$ & $20,565,000$ & $36,867,600$ \\
\hline Saldo de Cartera & 164,620 & 486,143 & $1,131,761$ & $2,122,051$ & $3,703,944$ \\
\hline
\end{tabular}

Fuente: Elaboración Propia

\subsection{Presupuesto de Resultados}

\subsubsection{Estado de Ganancias y Pérdidas proyectado}


Tabla 72

Estado de Ganancias y Pérdidas Proyectado en soles

\begin{tabular}{|c|c|c|c|c|c|}
\hline Días del Año & $\begin{array}{c}\text { Año 1 } \\
360 \\
\end{array}$ & $\begin{array}{c}\text { Año 2 } \\
360 \\
\end{array}$ & $\begin{array}{c}\text { Año } 3 \\
360\end{array}$ & $\begin{array}{c}\text { Año } 4 \\
360 \\
\end{array}$ & $\begin{array}{c}\text { Año } 5 \\
360\end{array}$ \\
\hline Prodi 1: Ingresos Financieros & 197,790 & 539,149 & $1,357,984$ & $2,657,262$ & $4,771,941$ \\
\hline Incobrables & 4,845 & 22,013 & 55,445 & 108,493 & 194,833 \\
\hline Ingresos Financieros Neto & 192,944 & 517,137 & $1,302,539$ & $2,548,768$ & $4,577,108$ \\
\hline Costo de Ventas: & - & 51,230 & 142,256 & 210,143 & 225,591 \\
\hline Utilidad Bruta & 192,944 & 465,906 & $1,160,283$ & $2,338,626$ & $4,351,517$ \\
\hline Gastos Administrativos: & 235,076 & 429,308 & 574,247 & 690,254 & 806,526 \\
\hline Sueldos Administración & 171,412 & 361,387 & 485,244 & 596,945 & 708,646 \\
\hline Alquileres & 14,400 & 14,400 & 14,400 & 14,400 & 14,400 \\
\hline Servicios & 18,600 & 18,918 & 19,243 & 19,576 & 19,917 \\
\hline $\begin{array}{l}\text { Servicios de Consultoría y } \\
\text { Representación }\end{array}$ & 2,400 & 4,800 & 24,000 & 26,400 & 29,040 \\
\hline Ut. Oficina & 18,000 & 18,540 & 19,096 & 19,669 & 20,259 \\
\hline Depreciación & 9,264 & 9,264 & 9,264 & 9,264 & 9,264 \\
\hline Variable Sueldos Administrativos & - & - & - & - & - \\
\hline Otros & 1,000 & 2,000 & 3,000 & 4,000 & 5,000 \\
\hline Gastos de Ventas & 125,645 & 152,265 & 161,469 & 195,216 & 212,362 \\
\hline Sueldo Vas. & 99,874 & 102,870 & 105,956 & 109,135 & 112,409 \\
\hline Alquileres vehiculares & 6,300 & 6,489 & 6,684 & 6,884 & 7,091 \\
\hline Depreca. - Amortización & 3,236 & 3,236 & 3,236 & 3,236 & 3,236 \\
\hline Seguros & 412 & 1,215 & 2,829 & 5,305 & 9,260 \\
\hline Publicidad & 823 & 2,431 & 5,659 & 10,610 & 18,520 \\
\hline Variable Sueldos Ventas & - & 20,574 & 21,191 & 43,654 & 44,964 \\
\hline MKT & 15,000 & 15,450 & 15,914 & 16,391 & 16,883 \\
\hline Utilidad Operativa & $-167,776$ & $-115,668$ & 424,567 & $1,453,156$ & $3,332,629$ \\
\hline Impuesto & - & - & - & - & - \\
\hline Utilidad Neta & $-167,776$ & $-115,668$ & 424,567 & $1,453,156$ & $3,332,629$ \\
\hline
\end{tabular}

Fuente: Elaboración Propia 


\subsubsection{Balance General proyectado}

Tabla 73 Balance General Proyectado en soles

BALANCE GENERAL ONG "Prestamos" (en Soles)

Inicio

Año 1

\begin{tabular}{rr}
$\mathbf{2 2 7 , 0 0 0}$ & $\mathbf{3 2 1 , 5 2 3}$ \\
27,000 & 32,15 \\
200,000 & 289,37 \\
- & $\mathbf{1 6 4 , 6 2 0}$ \\
$\mathbf{6 8 , 2 3 0}$ & $\mathbf{6 8 , 2 3 0}$ \\
- & $-9,264$ \\
- & \\
$\mathbf{1 6 , 1 8 0}$ & $\mathbf{1 6 , 1 8}$ \\
- & $-3,236$ \\
$\mathbf{3 1 1 , 4 1 0}$ & $\mathbf{5 7 0 , 5 5 3}$ \\
- & \\
- & \\
\hline &
\end{tabular}

\section{$\underline{\text { ACTIVO }}$}

DISPONIBLE Y REND. DEVENGADOS

CAJA

DEL PAIS

CARTERA DE CREDITOS NETOS Y REND.

DEVENGADOS

INMUEBLES, MOBILIARIO Y EQUIPO

- DEPRECIACION ACUMULADA

IMPUESTO A LA RENTA Y PARTICIPACIONES

DIFERIDAS

OTROS ACTIVOS

AMORTIZACION ACUMULADA POR GASTOS

AMORTIZABLES

TOTAL ACTIVO

CONTINGENTES DEUDORAS

CUENTAS DE ORDEN DEUDORAS

CONTRACUENTA DE CUENTAS DE ORDEN

ACREEDORAS

Añ 2

Año 3

Año 4

Año 5

Variación (\%)

\section{PASIVO}

PALIGACIONES CON LOS ASOCIADOS Y GTOS. POR

PAGAR

FONDOS, FONDOS INTERBANCARIOS Y GTOS. POR

PAGAR

TOTAL DEL PASIVO

PATRIMONIO

CAPITAL SOCIAL

TOTAL DEL PATRIMONIO

TOTAL DEL PASIVO Y PATRIMONIO

Fuente: Elaboración Propia

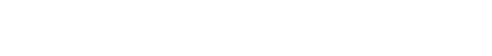

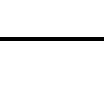


PrestaMas inicia operaciones con 331715 soles, para mantener la proyección de crecer $74 \%$ promedio anual, superior al $40 \%$ anual respecto a la industria, ONG PrestaMas reinvertirá los beneficios, tiene abierta la posibilidad de captar asociados; sin embargo, de acuerdo a la proyección no se precisa. Para el primer periodo PrestaMas debe comprometer todas sus utilidades e inclusive requiere créditos. Del segundo al cuarto periodo, PrestaMas sostiene su crecimiento con recursos propios.

\subsubsection{Flujo de Caja proyectado}

\section{Tabla 74}

Flujo de Caja Proyectado en soles

\begin{tabular}{|c|c|c|c|c|c|c|}
\hline $\begin{array}{r}\text { CONCEPTOS } \\
\text { 1)Ingresos }\end{array}$ & AÑ̃O 0 & AÑ̃ 1 & AÑO 2 & AÑ̃ 3 & AÑ̃ 4 & AÑ̃ 5 \\
\hline Cobranza Netas a Clientes & & & $\mathbf{5 1 7 , 1 3 7}$ & $1,302,539$ & $2,548,768$ & $4,577,108$ \\
\hline \multicolumn{7}{|l|}{ 2)Egresos } \\
\hline a) Inversión & $-332,910$ & - & - & - & - & - \\
\hline b) Operación & - & $-349,310$ & $-600,195$ & $-843,315$ & $-1,036,202$ & $-1,179,993$ \\
\hline Pago a Proveedores & & - & $-51,230$ & $-142,256$ & $-210,143$ & $-225,591$ \\
\hline Sueldos & & $-271,286$ & $-464,257$ & $-591,200$ & $-706,080$ & $-821,056$ \\
\hline Compras Varias & & $-14,000$ & $-14,180$ & $-14,363$ & $-14,548$ & $-14,736$ \\
\hline Alquileres & & $-20,700$ & $-20,889$ & $-21,084$ & $-21,284$ & $-21,491$ \\
\hline Servicios & & $-18,600$ & $-18,918$ & $-19,243$ & $-19,576$ & $-19,917$ \\
\hline $\begin{array}{l}\text { Servicios de Consultoría y } \\
\text { Representación }\end{array}$ & & $-2,400$ & $-4,800$ & $-24,000$ & $-26,400$ & $-29,040$ \\
\hline Ut. Oficina & & $-18,000$ & $-18,540$ & $-19,096$ & $-19,669$ & $-20,259$ \\
\hline Otros & & $-1,000$ & $-2,000$ & $-3,000$ & $-4,000$ & $-5,000$ \\
\hline Publicidad & & -823 & $-2,431$ & $-5,659$ & $-10,610$ & $-18,520$ \\
\hline Ppto. Mkt. & & $-15,000$ & $-15,450$ & $-15,914$ & $-16,391$ & $-16,883$ \\
\hline Depreciación y Amortización & & 12,500 & 12,500 & 12,500 & 12,500 & 12,500 \\
\hline Impuesto a la renta & & - & - & - & - & - \\
\hline Crédito Fiscal del Impto. Rpta. & & - & - & - & - & - \\
\hline FLUJO CAJA ECONOMICO & $-332,910$ & $-349,310$ & $-83,059$ & 459,225 & $1,512,566$ & $3,397,115$ \\
\hline
\end{tabular}

Fuente: Elaboración Propia 


\section{CAPITULO IX. EVALUACION ECONOMICO FINANCIERA}

\subsection{Evaluación Financiera}

\subsubsection{Tasa Interna de Retorno}

La TIR económica para el proyecto es de $65.67 \%$, una tasa superior a la del COK del $18.27 \%$ y del costo de fondeo esperado expresado en el Kd del $12.68 \%$; es factible y muy atractivo el desarrollo del presente proyecto de inversión.

\subsubsection{Valor Actual Neto (VAN)}

La empresa registra un VAN positivo de 1,831 052 soles que hace viable al proyecto, dado que se genera valor a la empresa. Para el cálculo del VAN económico se han trabajado los flujos de efectivo a una tasa de descuento del $18.27 \%$ denominado COK o costo Oportunidad de Capital.

\subsubsection{ROE}

PrestaMas considera obtener un ROE mayor a 18.27\%. Al quinto año el ROE es de 63.59\% resultado de 3, 332,629 soles de utilidad y de un Patrimonio de 5, 241,055 soles.

\begin{tabular}{|l|c|r|r|r|r|r|}
\cline { 2 - 7 } \multicolumn{1}{c|}{} & \multicolumn{1}{c|}{$\mathbf{0}$} & \multicolumn{1}{c|}{$\mathbf{1}$} & \multicolumn{1}{c|}{$\mathbf{2}$} & \multicolumn{1}{c|}{$\mathbf{3}$} & \multicolumn{1}{c|}{$\mathbf{4}$} & \multicolumn{1}{c|}{$\mathbf{5}$} \\
\hline Utilidad/Pérdida & & $-167,776$ & $-115,668$ & 424,567 & $1,453,156$ & $3,332,629$ \\
\hline Patrimonio & 311,410 & 143,634 & 30,704 & 455,271 & $1,908,427$ & $5,241,056$ \\
\hline ROE & & $-116.81 \%$ & $-376.72 \%$ & $93.26 \%$ & $76.14 \%$ & $63.59 \%$ \\
\hline
\end{tabular}

\subsection{Análisis de Sensibilidad}

Se han desarrollado los escenarios de sensibilidad del proyecto con tres proyecciones de índice de morosidad sobre los ingresos:

Escenario 1: Escenario Optimista con Índice de Mora del 3\%. 
Escenario 2: Escenario Normal con Índice de Mora del 5\%.

Escenario 3: Escenario Pesimista con Índice de Mora del 10\%

Escenario 4: Escenario que Índice de Mora hace que VAN =0

\section{Tabla 75}

Escenarios de morosidad en el VAN y el TIR

\begin{tabular}{cccc}
\hline Mora & & VAN & TIR \\
\hline $3.00 \%$ & 1881153 & $67 \%$ \\
$5.00 \%$ & 1788621 & $65 \%$ \\
$10.00 \%$ & 1557292 & $60 \%$ \\
$43.66 \%$ & 0 & $18.27 \%$ \\
\hline
\end{tabular}

Fuente: Elaboración Propia

Este cuadro se explica en detalle en las siguientes tablas 77, 78, 79 y 80. 


\section{Tabla 76}

Escenario 1: Escenario Optimista con Índice de Mora del $3 \%$.

Escenario: (Índice de Mora 3,00\% de Ingresos o 3,63\% de Cartera)

\section{ESTADO DE GANANCIAS Y PERDIDAS PROYECTADO}

\begin{tabular}{|c|c|c|c|c|c|}
\hline & Año 1 & Año 2 & Año 3 & Año 4 & Año 5 \\
\hline Días del Año & 312 & 312 & 312 & 312 & 312 \\
\hline Cartera & 164,620 & 486,143 & $1,131,761$ & $2,122,051$ & $3,703,944$ \\
\hline Incobrable/ Cartera & $3.60 \%$ & $3.33 \%$ & $3.60 \%$ & $3.76 \%$ & $3.87 \%$ \\
\hline \multicolumn{6}{|l|}{ INGRESOS EN S/. } \\
\hline \multicolumn{6}{|l|}{ CONCEPTO } \\
\hline Prod 1: & $\begin{array}{c}197,789.72 \\
-\end{array}$ & $\begin{array}{l}539,149.43 \\
-\end{array}$ & $\begin{array}{c}1,357,984.31 \\
-\end{array}$ & $2,657,261.67$ & $4,771,941.32$ \\
\hline Incobrables & $5,933.69$ & $16,174.48$ & $40,739.53$ & $-79,717.85$ & $-143,158.24$ \\
\hline \multicolumn{6}{|l|}{ Prod 2} \\
\hline SubTotal & $191,856.02$ & $522,974.95$ & $1,317,244.78$ & 2,577,543.82 & $4,628,783.08$ \\
\hline Costo de Ventas: & - & 51,230 & 142,256 & 210,143 & $225,591.19$ \\
\hline Utilidad Bruta & 191,856.02 & $471,744.68$ & $1,174,988.74$ & 2,367,401.02 & $4,403,191.90$ \\
\hline Gastos Operativos & $360,720.65$ & $581,573.77$ & $735,715.67$ & $885,469.45$ & $1,018,887.98$ \\
\hline Utilidad Operativa & $\begin{array}{l}- \\
168,864.62\end{array}$ & $\begin{array}{l}- \\
109,829.08\end{array}$ & 439,273.07 & $1,481,931.57$ & 3,384,303.92 \\
\hline UTILIDAD NETA & $\begin{array}{l}- \\
168,864.62\end{array}$ & $\begin{array}{l}- \\
109,829.08\end{array}$ & 439,273.07 & $1,481,931.57$ & 3,384,303.92 \\
\hline
\end{tabular}

\section{FLUJO DE CAJA PROYECTADO}

$\begin{array}{lllll}\text { Año } 0 & \text { Año } 1 & \text { Año } 2 & \text { Año } 3 & \text { Año } 4\end{array}$

FLUJO CAJA

ECONOMICO

\begin{tabular}{llllll}
$-332,910.67$ & $-349,309.90$ & $-77,220.45$ & $473,930.27$ & $1,541,341.82$ & $3,448,790.30$ \\
\hline
\end{tabular}

Fuente: Elaboración Propia 


\section{Tabla 77}

Escenario 2: Escenario con Índice de Mora del $5 \%$.

\begin{tabular}{|c|c|c|c|c|c|}
\hline \multicolumn{6}{|c|}{ ESTADO DE GANANCIAS Y PERDIDAS PROYECTADO } \\
\hline & Año 1 & Año 2 & Año 3 & Año 4 & Año 5 \\
\hline Días del Año & 312 & 312 & 312 & 312 & 312 \\
\hline Cartera & 164,620 & 486,143 & $1,131,761$ & $2,122,051$ & $3,703,944$ \\
\hline Incobrable/ Cartera & $6.01 \%$ & $5.55 \%$ & $6.00 \%$ & $6.26 \%$ & $6.44 \%$ \\
\hline \multicolumn{6}{|l|}{ INGRESOS EN S/. } \\
\hline Prod 1: & $\begin{array}{c}197,789.72 \\
-\end{array}$ & $\begin{array}{c}539,149.43 \\
-\end{array}$ & $\begin{array}{l}1,357,984.31 \\
-\end{array}$ & $\begin{array}{l}2,657,261.67 \\
\quad-\end{array}$ & $\begin{array}{l}4,771,941.32 \\
-\end{array}$ \\
\hline Incobrables & $9,889.49$ & $26,957.47$ & $67,899.22$ & $132,863.08$ & $238,597.07$ \\
\hline \multicolumn{6}{|l|}{ Prod 2} \\
\hline SubTotal & $187,900.23$ & $512,191.96$ & $1,290,085.09$ & $2,524,398.59$ & $4,533,344.26$ \\
\hline Costo de Ventas: & - & $51,230.27$ & $142,256.04$ & $210,142.80$ & $225,591.19$ \\
\hline Utilidad Bruta & $187,900.23$ & $460,961.69$ & $1,147,829.05$ & $2,314,255.79$ & 4,307,753.07 \\
\hline Gastos Operativos & $\begin{array}{l}360,720.65 \\
-\end{array}$ & $\begin{array}{l}581,573.77 \\
-\end{array}$ & $735,715.67$ & $885,469.45$ & $1,018,887.98$ \\
\hline Utilidad Operativa & $\begin{array}{l}172,820.42 \\
-\end{array}$ & $\begin{array}{l}120,612.07 \\
-\end{array}$ & $412,113.39$ & $1,428,786.33$ & $3,288,856.09$ \\
\hline UTILIDAD NETA & $172,820.42$ & $120,612.07$ & 412,113.39 & $1,428,786.33$ & $3,288,856.09$ \\
\hline
\end{tabular}

FLUJO DE CAJA PROYECTADO

\begin{tabular}{lcccccc} 
& Año 0 & Año 1 & Año 2 & Año 3 & Año 4 & Año 5 \\
FLUJO CAJA & & & & & & \\
ECONOMICO & $-332,910.67$ & $-349,309.90$ & $-88,003.44$ & $446,770.58$ & $1,458,196.59$ & $3,353,351.48$ \\
\hline
\end{tabular}

Fuente: Elaboración Propia 


\section{Tabla 78}

Escenario 3: Escenario con Índice de Mora del 10\%.

Escenario: (Índice de Mora 10,00\% de Ingreso o 12,10\% de Cartera)

\section{ESTADO DE GANANCIAS Y PERDIDAS PROYECTADO}

\begin{tabular}{lccccc} 
& Año 1 & Año 2 & Año 3 & Año 4 & Año 5 \\
\hline Días del Año & 312 & 312 & 312 & 312 & 312 \\
Cartera & 164,620 & 486,143 & $1,131,761$ & $2,122,051$ & $3,703,944$ \\
Incobrable/ Cartera & $12.01 \%$ & $11.09 \%$ & $12.00 \%$ & $12.52 \%$ & $12.88 \%$
\end{tabular}

INGRESOS EN S/.

\section{CONCEPTO}

\begin{tabular}{lccccc} 
Prod 1: & $197,789.72$ & $539,149.43$ & $1,357,984.31$ & $2,657,261.67$ & $4,771,941.32$ \\
& - & - & - & - & - \\
Incobrables & $19,778.97$ & $53,914.94$ & $135,798.43$ & $265,726.17$ & $477,194.13$ \\
Prod 2 & & & & & \\
\multicolumn{1}{c}{ SubTotal } & $\mathbf{1 7 8 , 0 1 0 . 7 4}$ & $\mathbf{4 8 5 , 2 3 4 . 4 9}$ & $\mathbf{1 , 2 2 2 , 1 8 5 . 8 8}$ & $\mathbf{2 , 3 9 1 , 5 3 5 . 5 0}$ & $\mathbf{4 , 2 9 4 , 7 4 7 . 1 9}$ \\
& & & & & \\
Costo de Ventas: & - & $51,230.27$ & $142,256.04$ & $210,142.80$ & $225,591.19$ \\
& & & & & \\
Utilidad Bruta & $\mathbf{1 7 8 , 0 1 0 . 7 4}$ & $\mathbf{4 3 4 , 0 0 4 . 2 2}$ & $\mathbf{1 , 0 7 9 , 9 2 9 . 8 4}$ & $\mathbf{2 , 1 8 1 , 3 9 2 . 7 0}$ & $\mathbf{4 , 6 0 9 , 1 5 6 . 0 0}$ \\
& & & & & \\
Gastos Operativos & $360,720.65$ & $581,573.77$ & $735,715.67$ & $885,469.45$ & $1,018,887.98$ \\
Utilidad Operativa & $\mathbf{1 8 2 , 7 0 9 . 9 0}$ & $\mathbf{1 4 7 , 5 6 9 . 5 4}$ & $\mathbf{3 4 4 , 2 1 4 . 1 7}$ & $\mathbf{1 , 2 9 5 , 9 2 3 . 2 5}$ & $\mathbf{3 , 0 5 0 , 2 6 8 . 0 3}$ \\
& - & - & & & \\
UTILIDAD NETA & $\mathbf{1 8 2 , 7 0 9 . 9 0}$ & $\mathbf{1 4 7 , 5 6 9 . 5 4}$ & $\mathbf{3 4 4 , 2 1 4 . 1 7}$ & $\mathbf{1 , 2 9 5 , 9 2 3 . 2 5}$ & $\mathbf{3 , 0 5 0 , 2 6 8 . 0 3}$ \\
\hline
\end{tabular}

\section{FLUJO DE CAJA PROYECTADO}

$\begin{array}{llllll}\text { Año } 0 & \text { Año } 1 & \text { Año } 2 & \text { Año } 3 & \text { Año } 4 & \text { Año } 5\end{array}$

FLUJO CAJA

ECONOMICO

\begin{tabular}{llllll}
$-332,910.67$ & $-349,309.90$ & $-114,960.91$ & $378,871.37$ & $1,355,333.50$ & $3,114,754.41$ \\
\hline
\end{tabular}

Fuente: Elaboración Propia 


\section{Tabla 79}

Escenario 4: Escenario con Índice de Mora de 43.66\% con VAN $=0$

Escenario: (Índice de Mora 43,66\% de Ingreso o 52,84\% de Cartera)

\begin{tabular}{|c|c|c|c|c|c|}
\hline \multicolumn{6}{|c|}{ ESTADO DE GANANCIAS Y PERDIDAS PROYECTADO } \\
\hline & Año 1 & Año 2 & Año 3 & Año 4 & Año 5 \\
\hline Días del Año & 312 & 312 & 312 & 312 & 312 \\
\hline Cartera & 164,620 & 486,143 & $1,131,761$ & $2,122,051$ & $3,703,944$ \\
\hline Incobrable/ Cartera & $52,46 \%$ & $48,42 \%$ & $52,39 \%$ & $54,67 \%$ & $56,25 \%$ \\
\hline \multicolumn{6}{|l|}{ INGRESOS EN S/. } \\
\hline \multicolumn{6}{|l|}{ CONCEPTO } \\
\hline Prod 1: & $\begin{array}{c}197,789.72 \\
-\end{array}$ & $\begin{array}{l}539,149.43 \\
-\end{array}$ & $\begin{array}{l}\text { 1,357,984.31 } \\
\text { - }\end{array}$ & $\begin{array}{l}2,657,261.67 \\
-\end{array}$ & $\begin{array}{l}4,771,941.32 \\
-\end{array}$ \\
\hline Incobrables & $86,354.40$ & $235,391.02$ & $592,891.88$ & $1,160,152.47$ & $2,083,415.27$ \\
\hline \multicolumn{6}{|l|}{ Prod 2} \\
\hline SubTotal & $111,435.32$ & $303,758.41$ & $765,092.44$ & $1,497,109.20$ & $2,688,526.06$ \\
\hline Costo de Ventas: & - & $51,230.27$ & $142,256.04$ & $210,142.80$ & $225,591.19$ \\
\hline Utilidad Bruta & $111,435.32$ & $252,528.14$ & $622,836.40$ & $1,286,966.39$ & $2,462,934.87$ \\
\hline Gastos Operativos & $\begin{array}{c}360,720.65 \\
-\end{array}$ & $\begin{array}{l}581,573.77 \\
-\end{array}$ & $\begin{array}{l}735,715.67 \\
-\end{array}$ & $885,469.45$ & $1,018,887.98$ \\
\hline Utilidad Operativa & $\begin{array}{c}249,285.33 \\
-\end{array}$ & $\begin{array}{l}329,045.62 \\
-\end{array}$ & $\begin{array}{c}112,879.27 \\
-\end{array}$ & $401,496.94$ & $1,444,046.89$ \\
\hline UTILIDAD NETA & $249,285.33$ & $329,045.62$ & $112,879.27$ & $401,496.94$ & $1,444,046.89$ \\
\hline
\end{tabular}

\section{FLUJO DE CAJA PROYECTADO}

$\begin{array}{llllll}\text { Año } 0 & \text { Año } 1 & \text { Año } 2 & \text { Año } 3 & \text { Año } 4 & \end{array}$

FLUJO CAJA

ECONOMICO

Fuente: Elaboración Propia 


\subsection{Conclusiones}

$\checkmark$ El costo de fondeo de $1 \%$ mensual o $13 \%$ anual, supera a los pagos en DPF, fondos mutuos o inversión, hace atractivo a funcionarios de créditos que desean lograra retornos superiores al $8 \%$ anual.

$\checkmark$ PrestaMas, al ejercer búsqueda de fondeo, podrá sustituir financiamientos logrando un sistema de pago americano sobre los financiamientos progresivos.

$\checkmark$ El Costo de Oportunidad calculado es congruente con la industria sobre el $18 \%$ anual. El pago de $13 \%$ anual por fondeo permite alcanzar un ROE de $65 \%$.

$\checkmark$ Con estimaciones de incobrabilidad de un $3 \%, 5 \%$ y $10 \%$, de mora por incobrabilidad respecto al Saldo de Cartera colocada genera un VAN positivo, siendo el VAN igual a 0 cuando la mora supera el $43 \%$.

$\checkmark$ Los gastos administrativos estimados se han calculado sobre el porcentaje máximo de las empresas financieras menos eficientes de $63 \%$ al quinto año, permite alcanzar beneficios esperados. 


\section{CONCLUSIONES}

$\checkmark$ Existe una demanda de micro créditos insatisfecha en el mercado de San Juan de Lurigancho que requiere un financiamiento para necesidades de caja.

$\checkmark$ Las restricciones regulatorias no permiten a la banca tradicional atender a los microempresarios y que está siendo aprovechada por los prestamistas informales.

$\checkmark$ El tiempo de respuesta es más valorado que la tasa de interés, máximo 24 horas

$\checkmark$ Establecer alianzas estratégicas para la recaudación será vital para la operatividad, para cobros o recaudaciones.

$\checkmark$ Contar con personal calificado se convierte en nuestra ventaja competitiva, al ser especialistas pueden brindar el asesoramiento que el cliente requiere.

$\checkmark$ El cliente del segmento meta necesita una correcta orientación financiera

$\checkmark$ El plan de Marketing no requiere de mucha inversión, sin embargo, requiere de mucho trabajo de campo que es un elemento diferenciador

$\checkmark$ El valor agregado está enfocado en el servicio por parte del asesor y el conocimiento de su territorio

$\checkmark$ El ideal es un promedio de crédito ideal para nuestra cartera es de S/. 500 y 300 clientes máximo por asesor.

$\checkmark$ Incluso trabajando con una TEA mínima de $300 \%$ el proyecto resulta rentable llegando al punto de equilibrio en 3 años

$\checkmark$ Con análisis de sensibilidad considerando una mora muy por encima del reporte más alto del sistema el proyecto es rentable.

$\checkmark$ La tasa de interés no representa un determinante en la toma de decisiones para acceder a un crédito en nuestro segmento 


\section{RECOMENDACIONES}

$\checkmark$ El proceso adecuado en la colocación de los créditos siguiendo los lineamientos establecidos garantizará el éxito del proyecto.

$\checkmark$ Controlar adecuadamente las cobranzas y orientar a los clientes sobre la importancia de los pagos puntuales les garantiza la oportunidad de seguir contando con el financiamiento por tanto la continuidad del negocio.

$\checkmark$ Trabajar en zonas consideradas de alto riesgo por alto índice de la delincuencia podría afectar de manera negativa los resultados por ello se debe hacer un mapeo para descartar o tener mayores consideraciones de seguridad.

$\checkmark$ Se debe revisar la reglamentación vigente para el correcto funcionamiento de la ONG en el distrito de San Juan de Lurigancho

$\checkmark$ Establecer un correcto plan de reclutamiento y la adecuada asignación de los puesto de trabajo puede garantizar el éxito del proyecto

$\checkmark$ El uso adecuado de los recursos permitirá la sostenibilidad del negocio dado su alto grado de sensibilidad

$\checkmark$ Invertir en publicidad con fuerza a partir de la consolidación y no de la mano con la creación sería lo más adecuado para el proyecto

$\checkmark$ Puede tomarse como referencia el modelo exitoso de la ONG Acción Comunitaria que bajo el sistema de pagos semanales y créditos de bajo monto, ésta empresa se convirtió en MiBanco y fue vendida en 180 Millones de soles. 


\section{REFERENCIAS}

Baca G., 2014. Evaluación de Proyectos

BCRP (Año 2002). Estudios Económicos BRCP: "El Costo del Crédito en el Perú", estudio publicado por el Banco Central de Reserva del Perú en noviembre de 2002. (pp.1)

Centro de Innovación del BBVA (2015) La bancarización de África: repitiendo el éxito de M-Pesa en Kenya

Chunga, P. (Noviembre 2014). El Microfinanciero - Año $V N^{\circ} 24$ : Editorial (p. 4)

Economist IntelligenceUnit UK (2014). Microscopio global sobre el entorno de negocios para las microfinanzas 2010. (p. 61)

Equilibrium Clasificadora de Riesgo S.A. (2015), Análisis del Sistema Microfinanciero Peruano (p. 7)

http://www.bcrp.gob.pe/docs/Publicaciones/Revista-Estudios-Economicos/11/EstudiosEconomicos-11-4.pdf

http://www.deguate.com/artman/publish/gestion_merca/La_matriz_Atractivo_del_merc ado_-_Posici_n_del_Neg_459.shtml\#.V3GVU9J97cs

https://dineroenmovimiento.wordpress.com/tag/inclusion-financiera/page/2/

http://emprendedor.pe/finanzas/878-tipos-de-creditos-en-peru.html/

http://www.esan.edu.pe/conexion/actualidad/2012/05/15/industria-microfinanzas-peru/

http://www.fenacrep.org/web/st_center.php?id_subtitulo=9

http://gestion.pe/economia/adquisicion-microfinancieras-bancos-grandes-redujocreditos-pyme-y-subio-morosidad-2102727 
https://intranet1.sbs.gob.pe/estadistica/financiera/2015/Setiembre/SF-0003-se2015.PDF

http://larepublica.pe/17-01-2015/inei-lima-tiene-9-millones-752-mil-habitantes

http://proyectos.inei.gob.pe/web/biblioineipub/bancopub/Est/Lib0843/index.htm

http://repositorioacademico.upc.edu.pe/upc/bitstream/10757/576910/1/DETERMINACI \%C3\%93N+DEL+COSTO.pdf

http://www.sbs.gob.pe/principal/categoria/sistema-financiero/148/c-148

Iguíñiz y León, (2011) Desigualdad Distributiva en el Perú PUCP (p 307)

Municipalidad de San Juan de Lurigancho (2014) Plan de Desarrollo Concertado 20152021 (p. 181)

Quispe, Z \&León (Año 2002). Moneda BRCP - $N^{\circ}$ 151: El exitoso desarrollo de las microfinanzas en el Perú, (pp.14-15)

Resolución S.B.S Nº14353-2009. Diario Oficial El Peruano, Lima, Perú, 04 de Noviembre 2009.

SBS (2013). Documentos de Trabajo (p. 2) 